UNIVERSIDADE DE SÃO PAULO

ESCOLA DE ENGENHARIA DE LORENA

LUIZ EDUARDO THANS GOMES

Desenvolvimento analítico e quantificação de fármacos e defensivos agrícolas no rio Paraíba do Sul

LORENA 



\section{Desenvolvimento analítico e quantificação de fármacos e defensivos agrícolas no rio Paraíba do Sul}

Tese apresentada à escola de engenharia de Lorena da Universidade De São Paulo para obtenção do título de doutor em Ciências do Programa de Pós-Graduação em Biotecnologia Industrial na área de concentração de conversão de biomassa.

Orientador: Prof. Dr. Flávio Teixeira da Silva Co-Orientadora: Prof. ${ }^{a}$ Dr. ${ }^{a}$ Cassiana Carolina Montagner

VERSÃO ORIGINAL 
AUTORIZO A REPRODUÇÃO E DIVULGAÇÃO TOTAL OU PARCIAL DESTE TRABALHO, POR QUALQUER MEIO CONVENCIONAL OU ELETRÔNICO, PARA FINS DE ESTUDO E PESQUISA, DESDE QUE CITADA A FONTE

Ficha catalográfica elaborada pelo Sistema Automatizado da Escola de Engenharia de Lorena, com os dados fornecidos pelo(a) autor(a)

Gomes, Luiz Eduardo Thans

Desenvolvimento analítico e quantificação de

fármacos e defensivos agrícolas no rio paraíba do sul / Luiz Eduardo Thans Gomes; orientador Flávio

Teixeira da Silva; co-orientadora Cassiana Carolina Montagner - Versão Original. - Lorena, 2019.

$89 \mathrm{p}$.

Tese (Doutorado em Ciências - Programa de Pós Graduação em Biotecnologia Industrial na Área de Conversão de Biomassa) - Escola de Engenharia de Lorena da Universidade de São Paulo. 2019

1. Rio paraíba do sul. 2. Fármacos. 3. Defensivos agrícolas. 4. Contaminantes emergentes. I. Título. II. Silva, Flávio Teixeira da, orient. III. Montagner, Cassiana Carolina, co-orient. 


\section{AGRADECIMENTOS}

Ao Prof. Dr. Flávio Teixeira da Silva pela pela oportunidade e pela orientação.

A Prof. ${ }^{a}$ Dr $^{\mathrm{a}}$. Teresa Cristina Brazil de Paiva por me ter recebido tão bem.

A Lucinha e ao Cleber pela valiosa ajuda sempre que necessitada.

A todo o pessoal do laboratório, em especial Juliana, Gabriela, Lucas e Rodrigo, pelas discussões proveitosas e o bom ambiente de trabalho.

A Prof. ${ }^{a}$ Dr $^{\mathrm{a}}$ Cassiana Carolina Montagner, por ter aberto as portas do LQA da Unicamp sem o qual não seria possível a realização deste trabalho.

A todo o pessoal do LQA/GIA da Unicamp, em especial ao Raphael Acayaba e a Cristhiane Vidal, pelo auxilio, dicas e todo o conhecimento técnico

A minha esposa Heloisa, pela paciência, compreensão e por muitas palavras sábias.

Aos amigos que fiz na EEL/Lorena: Angela, Zé Moreira, Otto, Uira, Fernanda, Morun e Ana Maria.

A todos os funcionários da Biblioteca da EEL (Campus I e Campus II) pelo auxilio prestado. Ao $\mathrm{CNPq}$ pela bolsa concedida.

Para a Agevap, pelo auxílio financeiro concedido. 



\section{RESUMO}

GOMES, L. E.T. Desenvolvimento analítico e quantificação de fármacos e defensivos agrícolas no Rio Paraíba do Sul. 2019. 89p. Tese (Doutorado em Ciências) - Escola de Engenharia de Lorena, Universidade de São Paulo, Lorena-SP, 2019.

A Bacia do Rio Paraíba do Sul engloba uma das regiões mais industrializadas do país. Paralelamente a este desenvolvimento, danos ao meio ambiente estão em condições bem plausíveis de ocorrer, principalmente em relação a questão dos micropoluentes. Quatro métodos analitos, utilizando-se cromatografia liquida acoplada a um espectrômetro de massas, para a quantificação de fármacos e defensivos agrícolas foram validados para a avaliação, através de monitoramento da concentração dos referidos analitos, do panorama da qualidade das águas na região de maior densidade demográfica da bacia, que compreende o Vale do Paraíba paulista e o sul-fluminense. Os analitos contemplados foram fármacos da classe dos analgésicos - cafeína, diclofenaco, ibuprofeno, naproxeno e paracetamol- e defensivos agrícolas utilizados nas culturas mais abundantes da região (arroz, eucalipto e pastagens) que foram: ácido diclorofenoxiacético (2,4-D), atrazina, bentazona, fipronil, imidacloprida e simazina. O monitoramento da concentração foi realizado em onze (11) cidades- Jacareí, São José dos Campos, Caçapava, Taubaté, Pindamonhangaba, Guaratinguetá, Lorena e Lavrinhas - pertencentes ao Estado de São Paulo, e Resende, Volta Redonda e Barra Mansa. A cafeína foi o analito mais detectado (100\% das amostras) e que apresentou as maiores concentrações (389 ng.L $\left.\mathrm{L}^{-1}\right)$, enquanto para os defensivos agrícolas, o 2,4-D foi o que apresentou maior frequência de detecção (90\%) e a bentazona a maior concentração $\left(75,8 \mathrm{ng} . \mathrm{L}^{-1}\right)$

Palavras-chave: Rio Paraíba do Sul, Fármacos, Defensivos Agrícolas, Contaminantes Emergentes. 


\begin{abstract}
GOMES, L. E.T. Analytical Development and quantification of pharmaceutical compounds and agricultural pesticides from Paraiba do Sul River. 2019. 89p. Thesis (Doctor in Science) - Escola de Engenharia de Lorena, Universidade de São Paulo, LorenaSP, 2019.
\end{abstract}

The Paraíba do Sul River Basin encompasses one of the most industrialized regions of the country. Together with this development, damages to the environment are in very plausible conditions to occur, especially regarding the issue of micropollutants. Four analytical methods, using liquid chromatography coupled to a mass spectrometer, for the quantification of drugs and agricultural pesticides were validated for the evaluation, by monitoring the concentration of chosen analytes, of the panorama of water quality in the region of higher density demography of the basin, which comprises the Vale do Paraiba from São Paulo State and the south of the Rio de Janeiro State. The analyzed analytes were drugs of the analgesic class - caffeine, diclofenac, ibuprofen, naproxen and paracetamol - and agricultural pesticides used in the most abundant crops of the region (rice, eucalyptus and pastures), which were: dichlorophenoxyacetic acid (2,4-D), atrazine, bentazone, fipronil, imidacloprid and simazine. The concentration monitoring was carried out in eleven (11) cities - Jacareí, São José dos Campos, Caçapava, Taubaté, Pindamonhangaba, Guaratinguetá, Lorena and Lavrinhas - belonging to the State of São Paulo, and Resende, Volta Redonda and Barra Mansa. The caffeine was the most detected analyte (was indentified in $100 \%$ of the samples) and show the highest concentrations (389 ng.L-1), while for the agricultural pesticides 2,4D was the one with the highest detection frequency (90\%) and the bentazone with the highest concentration (75.8 ng.L-1).

Keywords: Paraíba do Sul River, Pharmaceutical Compounds, Agriculture Pesticides, Emmergent Pollutants. 


\section{LISTA DE FIGURAS}

Figura 1- Representação do Mapa da bacia do Rio Paraíba do Sul.

Figura 2- Representação do Mapa da Bacia Hidrográfica da bacia do Paraíba do Sul no Estado de São Paulo

Figura 3- Representação do Mapa da Bacia Hidrográfica do Médio Paraíba do Sul. ......... 19

Figura 4- Rotas dos fármacos até o meio ambiente........................................................... 22

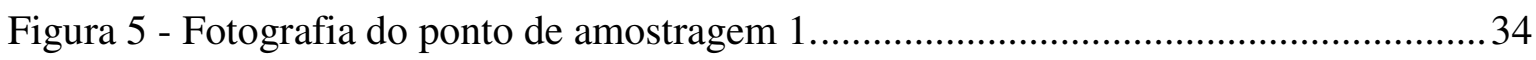

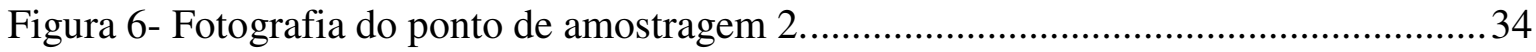

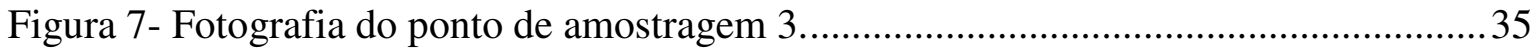

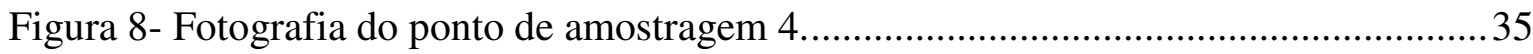

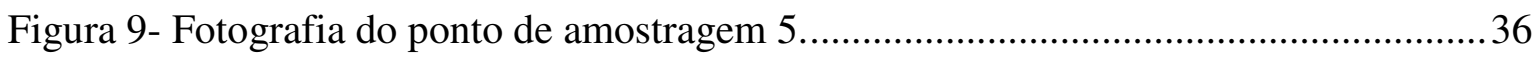

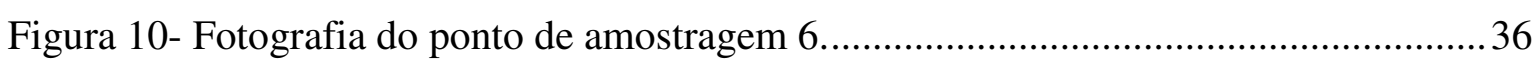

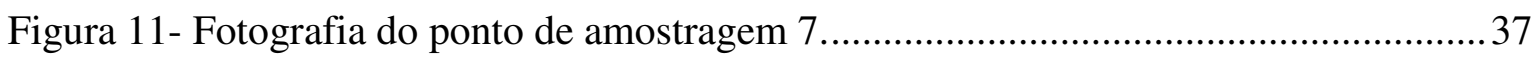

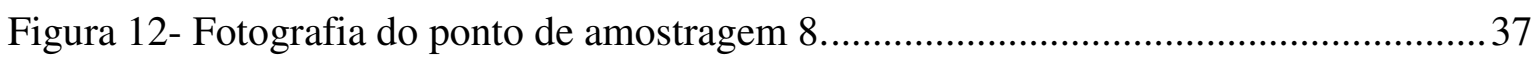

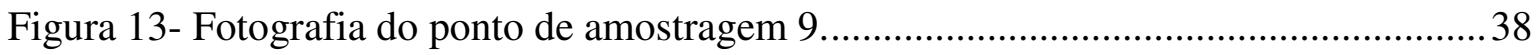

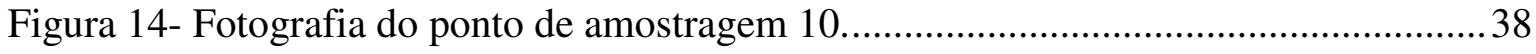

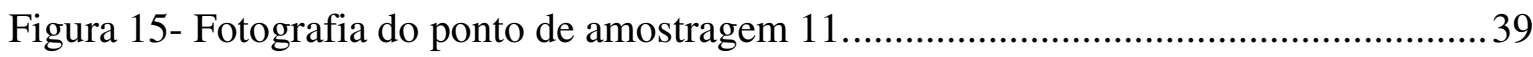

Figura 16- Sistema de Extração em Fase sólida para concentração das amostras................44

Figura 17- Representação gráfica dos valores das áreas em função das condições da fonte.

Figura 18- Cromatogramas de corrente iônica total (TIC) da separação de ibuprofeno, diclofenaco e naproxeno eluídos na condição 5 (ver tabela 3) do teste de otimização das condições da fonte de ionização utilizando ácido acético 0,04\%: acetonitrila como fase móvel.

Figura 19- Cromatogramas de cada fragmento (MRM) da separação de ibuprofeno, diclofenaco e naproxeno eluídos na condição 5 (ver tabela 3) do teste de otimização das condições da fonte de ionização utilizando ácido acético 0,04\%: acetonitrila como fase móvel

Figura 20- Representação gráfica dos valores das áreas em função das condições da fonte. 
Figura 21- Cromatogramas de corrente iônica total (TIC) da separação de cafeína e paracetamol eluídos na condição 4 (ver tabela 3) do teste de otimização das condições da fonte de ionização utilizando metanol: hidróxido de amônio 0,01\% como fase móvel. .....51 Figura 22- Cromatogramas de cada fragmento (MRM) da separação de cafeína , e paracetamol eluídos na condição 4 (ver tabela 3) do teste de otimização das condições da fonte de ionização utilizando hidróxido de amônio $0,01 \%$ : metanol como fase móvel. .....52 Figura 23- Gráfico da variação das áreas em função concentração de paracetamol.............53 Figura 24- Gráfico da variação das áreas em função concentração de cafeína.....................53 Figura 25- Gráfico da variação da área em função concentração de diclofenaco.................53 Figura 26- Gráfico da variação da área em função concentração de Naproxeno. ................54

Figura 27- Gráfico da variação da área em função concentração de Ibuprofeno. ................54

Figura 28 - Curvas analíticas obtidas no solvente e na matriz para Naproxeno. ..................58

Figura 29- Curvas analíticas obtidas no solvente e na matriz para diclofenaco. .................58

Figura 30- Curvas analíticas obtidas no solvente e na matriz para Ibuprofeno. ...................58

Figura 31- Curvas analíticas obtidas no solvente e na matriz para paracetamol. ................59

Figura 32- Curvas analíticas obtidas no solvente e na matriz para cafeína. .59

Figura 33- Representação gráfica dos valores das áreas dos picos do 2,4 D, bentazona, e fipronil em função das condições da fonte.

Figura 34 - Cromatogramas de corrente iônica total (TIC) da separação de 2,4-D, bentazona e fipronil eluídos na condição 3 (ver tabela 3 ) do teste de otimização das condições da fonte de ionização utilizando ácido fórmico 0,1\%: metanol como fase móvel..... .67 Figura 35- Cromatogramas de cada fragmento (MRM) da separação de 2,4-D, bentazona e fipronil eluídos na condição 3 (ver tabela 3 ) do teste de otimização das condições da fonte de ionização utilizando ácido fórmico $0,1 \%$ : metanol como fase móvel. .68 Figura 36- Representação gráfica dos valores das áreas de atrazina, imidacloprida e simazinaem função das condições da fonte.

Figura 37- Cromatogramas de corrente iônica total (TIC) da separação de atrazina, imidacloprida e simazina, eluídos na condição 3 (ver tabela 3) do teste de otimização das condições da fonte de ionização utilizando metanol: ácido fórmico $0,1 \%$ como fase móvel.

Figura 38- Cromatogramas de cada fragmento (MRM) da separação de atrazina, imidacloprida e simazina eluídos na condição 3 (ver tabela 3) do teste de otimização das condições da fonte de ionização utilizando ácido fórmico 0,01\%: metanol como fase móvel. 
Figura 39- Gráfico da variação da área em função da concentração do 2,4-D.................... 71

Figura 40- Gráfico da variação da área em função da concentração de atrazina..................72

Figura 41- Gráfico da variação da área em função concentração de Bentazona. .................72

Figura 42- Gráfico da variação da área em função concentração de fipronil. ...................... 72

Figura 43- Gráfico da variação da área em função concentração de imidacloprida.............73

Figura 44- Gráfico da variação da área em função concentração de simazina.....................73

Figura 45- Curvas analíticas obtidas no solvente e na matriz para 2,4-D. .......................... 76

Figura 46 - Curvas analíticas obtidas no solvente e na matriz para atrazina. .......................76

Figura 47 - Curvas analíticas obtidas no solvente e na matriz para Bentazona....................77

Figura 48 - Curvas analíticas obtidas no solvente e na matriz para Fipronil........................77

Figura 49- Curvas analíticas obtidas no solvente e na matriz para imidacloprida. ..............77

Figura 50 - Curvas analíticas obtidas no solvente e na matriz para simazina. .....................78 


\section{LISTA DE TABELAS}

Tabela 1- Os dez municípios do Estado de SP com maior área ocupada (hectares) pelo cultivo

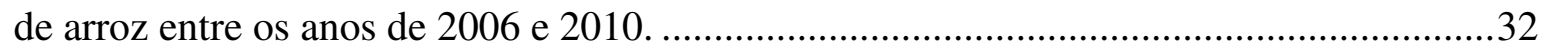

Tabela 2- Pontos de amostragem, suas coordenadas geográficas e sua localização.............33

Tabela 3 - Valores dos parâmetros em cada condição testada da fonte................................41

Tabela 4- Os fármacos estudados e algumas de suas propriedades físico químicas.............45

Tabela 5- Íons precursores, Íons produtos de quantificação (Íon Quant.) e Íons produto de confirmação (Íon Conf.) e a energia de colisão de cada analito. .......................................46

Tabela 6- Gradiente utilizado para a eluição de ibuprofeno, naproxeno e diclofenaco tendo Ácido Acético 0,04\%: Acetonitrila como fase móvel.........................................................47

Tabela 7- Área do pico de cada composto em função das condições da fonte de ionização .47

Tabela 8- Área de cada composto em função das condições da fonte de ionização............50

Tabela 9- Cálculo dos limites de quantificação do método (LQm), instrumental (LQi) e limites de detecção do método (LDm) e instrumental (LDi) ............................................54

Tabela 10- Taxa de recuperação $(\%)$ dos analitos em $500 \mathrm{~mL}$ de água ultrapura fortificada

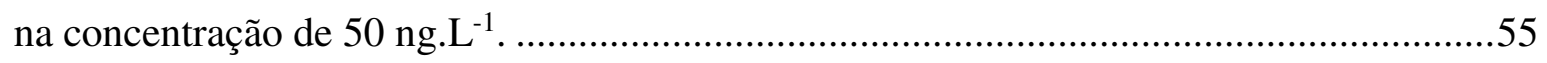

Tabela 11- Recuperação dos analitos quando se utiliza cartucho de troca aniônica Strata XA. .56

Tabela 12- Recuperações médias (\%) para cada nível de concentração e a recuperação média (\%) e o desvio padrão relativo entre as 9 recuperações. Entre parênteses o desvio padrão

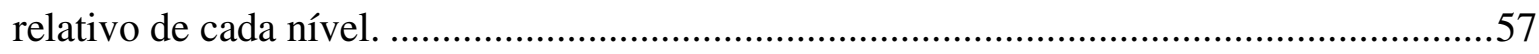

Tabela 13- Valores de $\alpha$ s, $\alpha \mathrm{m}$ e do efeito matriz calculado para cada analito ......................59

Tabela 14 - Concentração em ng. $\mathrm{mL}^{-1}$ dos fármacos estudados neste trabalho para cada amostra analisada. LQ: limite de quantificação, LD: limite de detecção .62 Tabela 15- Os defensivos agrícolas estudados e algumas de suas propriedades físicoquímicas.

Tabela 16- Íons Precursores, Íons Produtos de Quantificação (Íon Quant.), Íons Produtos de Confirmação (Íon Conf.) e Energia de colisão de cada defensivo agrícola. .65

Tabela 17- Gradiente utilizado para a eluição de 2,4-D, bentazona e fipronil tendo ácido Fórmico 0,1\%: metanol como fase móvel. .66

Tabela 18- Gradiente utilizado para a eluição de atrazina, imidacloprida e simazina, tendo ácido Fórmico $0,1 \%$ e metanol como fase móvel. .66 
Tabela 19- Área de cada composto em função das condições da fonte de ionização...........66

Tabela 20- Área de cada composto em função das condições da fonte de ionização..........69

Tabela 21- Erro padrão da intersecção da reta, coeficiente angular da reta, limites de quantificação e detecção instrumentais e limites de quantificação e detecção do método. 74 Tabela 22- Recuperações médias (\%) para cada nível de concentração e a recuperação média (\%) e o desvio padrão relativo entre as 9 recuperações. Entre parênteses o desvio padrão

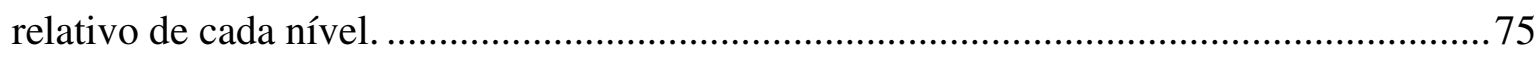

Tabela 23- Valores de $\alpha$ s, $\alpha \mathrm{m}$ e do efeito matriz calculado para cada analito......................78 Tabela 24- Concentração em ng. $\mathrm{mL}^{-1}$ dos defensivos agrícolas estudados neste trabalho para

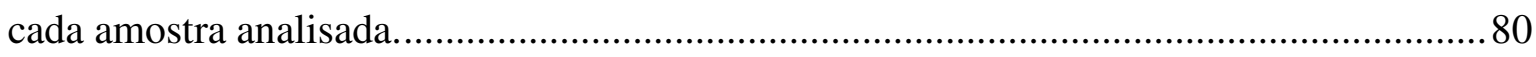





\section{INTRODUÇÃO}

\section{SUMÁRIO}

1.1 A Bacia do Rio Paraíba do Sul................................................................... 17

1.2 Bacia Hidrográfica do Paraíba do Sul no Estado de São Paulo. ...................... 18

1.3 Bacia Hidrográfica do Médio Paraíba do Sul. ................................................ 19

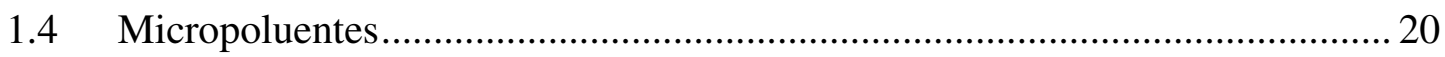

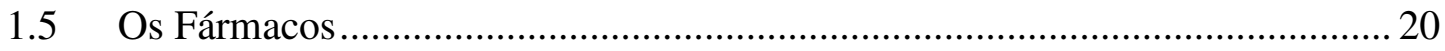

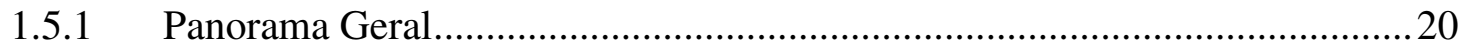

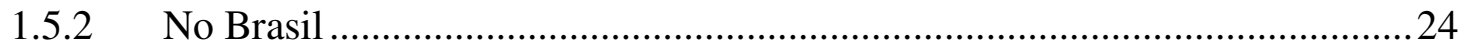

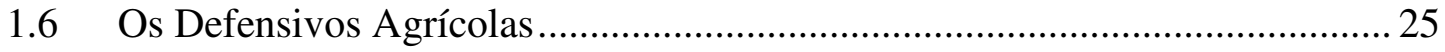

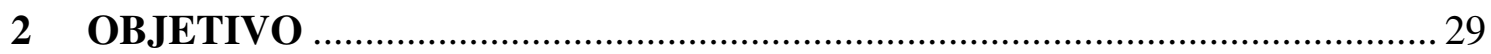

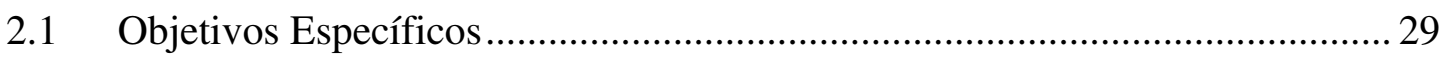

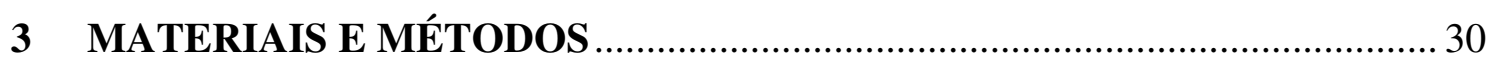

3.1 Equipamentos, materiais e reagentes utilizados ........................................... 30

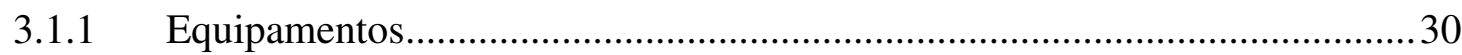

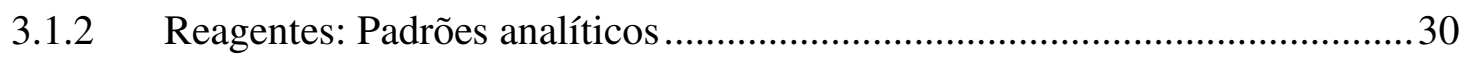

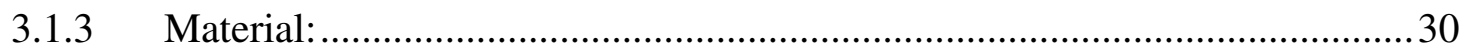

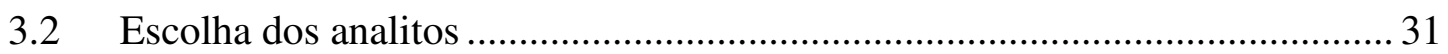

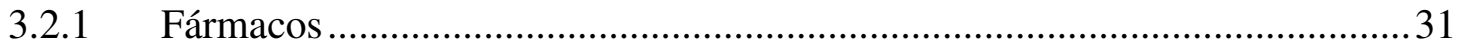

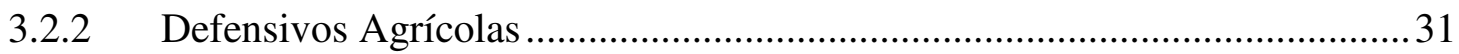

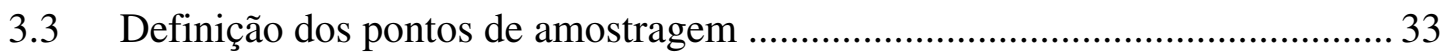

3.4 Desenvolvimento de metodologia analítica.................................................. 39

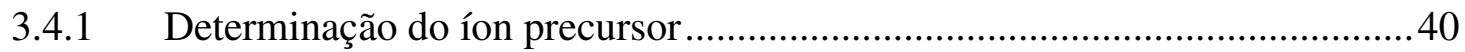

3.4.2 Determinação das energias de colisão e dos íons produto.............................40

3.4.3 Escolha da fase móvel e do melhor aditivo. ................................................40

3.4.4 Otimização dos parâmetros da fonte de ionização (ESI) ..............................40

3.5 Validação de metodologia analítica ............................................................... 41

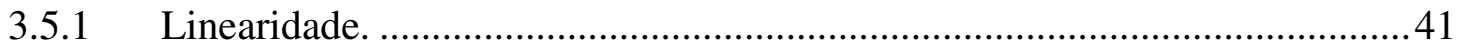

3.5.2 Limite de Quantificação e Limite de Detecção (LQ e LD). ...........................42

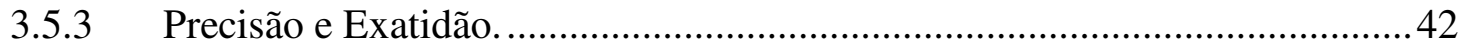

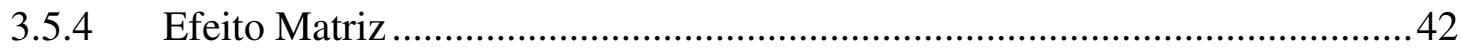

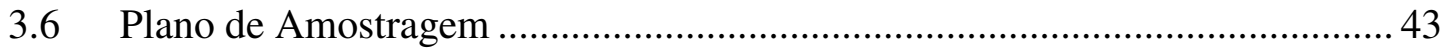

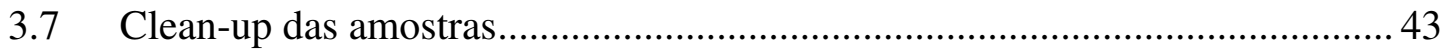

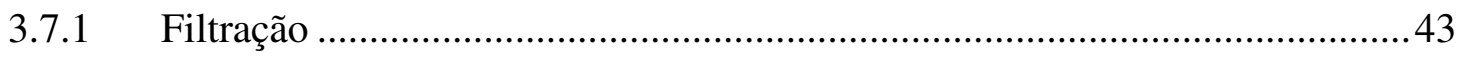

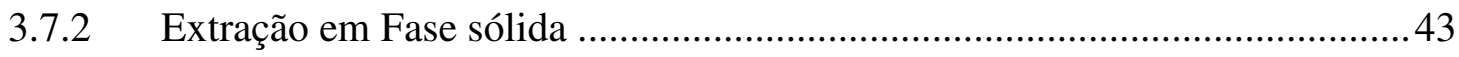

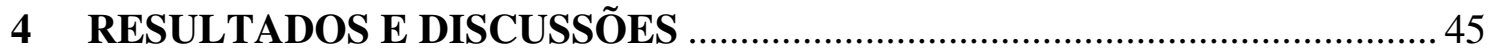


4.1.1 Desenvolvimento de metodologia analítica .45

4.1.1.1 Determinação dos íons precursores, das energias de colisão e dos íons produto 45

4.1.1.2 Otimização dos parâmetros da fonte de ionização (ESI). .47

4.1.1.3 Composição da fase móvel para os compostos analisados no modo positivo 50

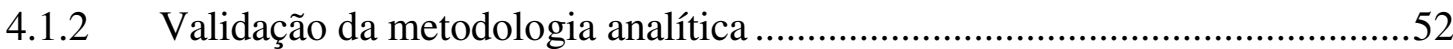

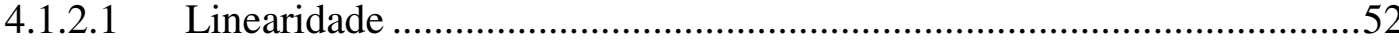

4.1.2.2 Limite de detecção (LD) e Limite de quantificação (LQ) .......................54

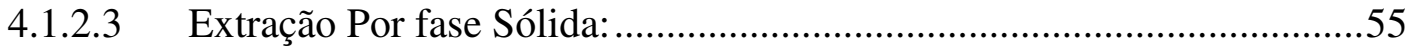

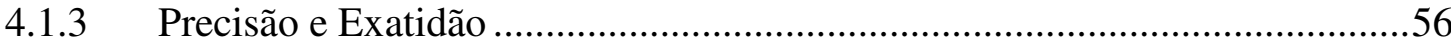

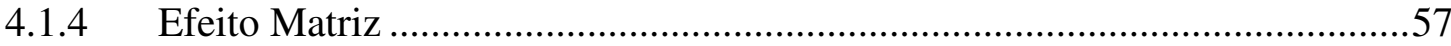

4.1.5 Ocorrência de fármacos em águas superficiais do rio Paraíba do Sul ...........60

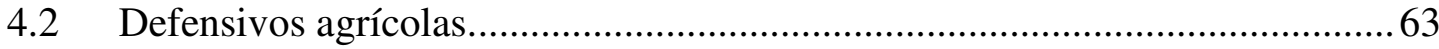

4.2.1 Desenvolvimento de metodologia analítica. ..............................................63

4.2.1.1 Determinação dos íons precursores, das energias de colisão e dos íons produto. 63

4.2.1.2 Otimização dos parâmetros da fonte de ionização (ESI) para defensivos

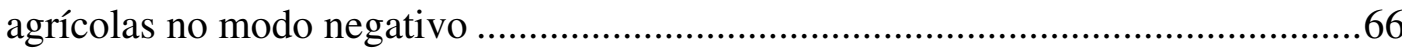

4.2.2 Validação da metodologia analítica ............................................................71

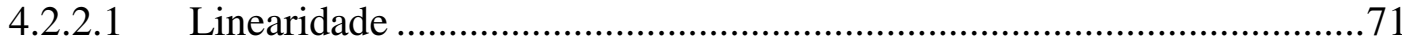

4.2.2.2 Limite de detecção (LD) e Limite de quantificação (LQ) ......................73

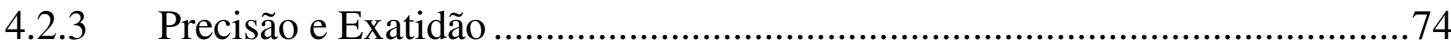

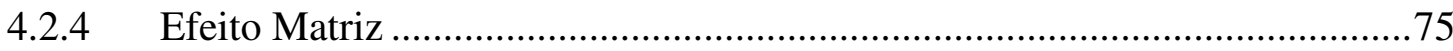

4.2.5 Ocorrência de defensivos agrícolas em amostras de água superficial do Rio

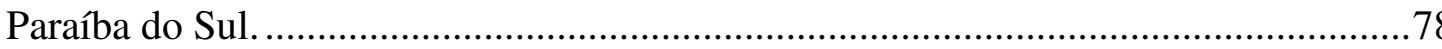

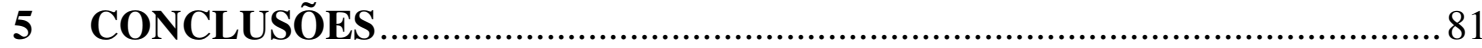

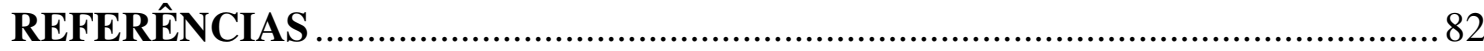




\section{INTRODUÇÃO}

\subsection{A Bacia do Rio Paraíba do Sul}

A bacia hidrográfica do Rio Paraíba do Sul (Figura 1) localiza-se na macrorregião hidrográfica do Atlântico Sudeste, uma das mais industrializadas do país, com cerca de 8000 indústrias instaladas e respondendo por cerca de 12\% do Produto Interno Bruto brasileiro. (SANTOS; SANTOS; FILHO, 2015). A área total de drenagem é de cerca de $55.500 \mathrm{~km}^{2}$ distribuída pelos estados de São Paulo (13.900 km²), Rio de Janeiro (20.900 km²) e Minas Gerais (20.700 km²). Abrange cerca de 184 municípios sendo 88 em Minas Gerais, 39 em São Paulo e 57 no Estado do Rio de Janeiro, com uma população total de aproximadamente 5 milhões de pessoas (AGÊNCIA NACIONAL DE ÁGUAS, 2016).

Figura 1- Representação do Mapa da bacia do Rio Paraíba do Sul.

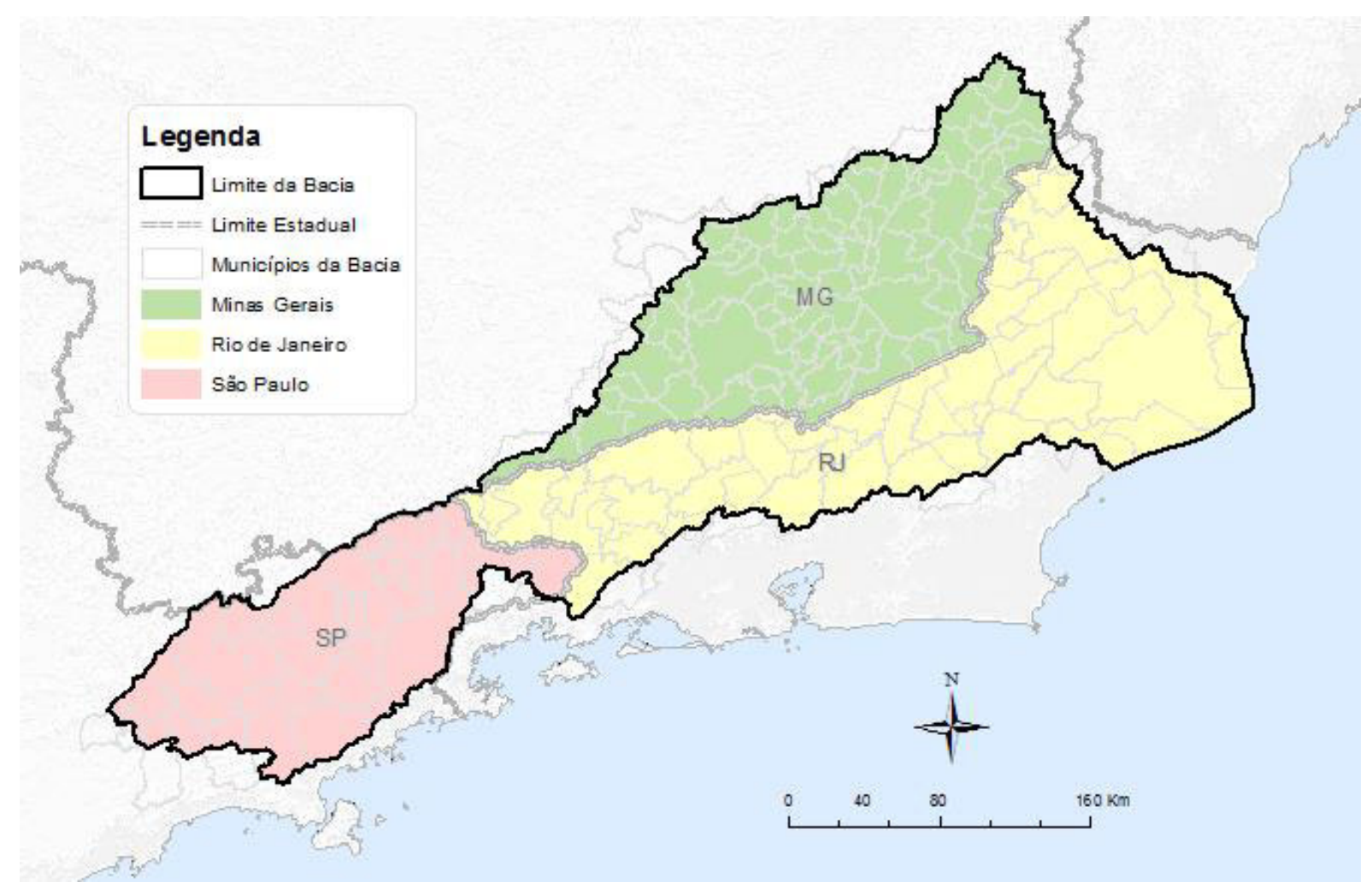

Fonte: CBH-OS 
O rio Paraíba do Sul resulta da confluência, próximo ao município de Paraibuna, dos rios Paraibuna, cuja nascente é no município de Cunha, e Paraitinga, que nasce no município de Areias, ambos no estado de São Paulo, e percorre $1400 \mathrm{~km}$ até sua foz, localizada no município de São João da Barra, no norte do estado do Rio de Janeiro. O comprimento do Rio Paraíba do Sul, calculado a partir da nascente, é de mais de $1.100 \mathrm{~km}$.

A acentuada urbanização e industrialização na região Sudeste, tem ocasionado o carregamento de grande quantidade de compostos orgânicos e inorgânicos para as águas do Rio Paraíba do Sul, submetendo-o assim a grandes impactos ambientais decorrentes de ação antrópica (SOUZA; BULHÕES, 2015). A bacia do Rio Paraíba do Sul é dividida em várias sub-bacias. Os municípios estudados neste trabalho estão localizados na bacia do Paraíba do Sul (municípios paulistas) e bacia do Médio Paraíba do Sul.

\subsection{Bacia Hidrográfica do Paraíba do Sul no Estado de São Paulo.}

A bacia do rio Paraíba do Sul que fica no estado de São Paulo possui cerca de 2 milhões de habitantes vivendo nas 36 cidades que fazem parte desta região. A principais atividades econômicas são agropecuárias (principalmente cultivo de arroz), industrial, pesquisa em ciência e tecnologia (com destaque para o setor aéreo espacial) e turismo religioso. Os principais rios desta parte da bacia são o Paraibuna, Paraitinga, Jaguari e Una. A figura 2 mostra um mapa da parte paulista da bacia (FEHIDRO)

Figura 2- Representação do Mapa da Bacia Hidrográfica da bacia do Paraíba do Sul no Estado de São Paulo.

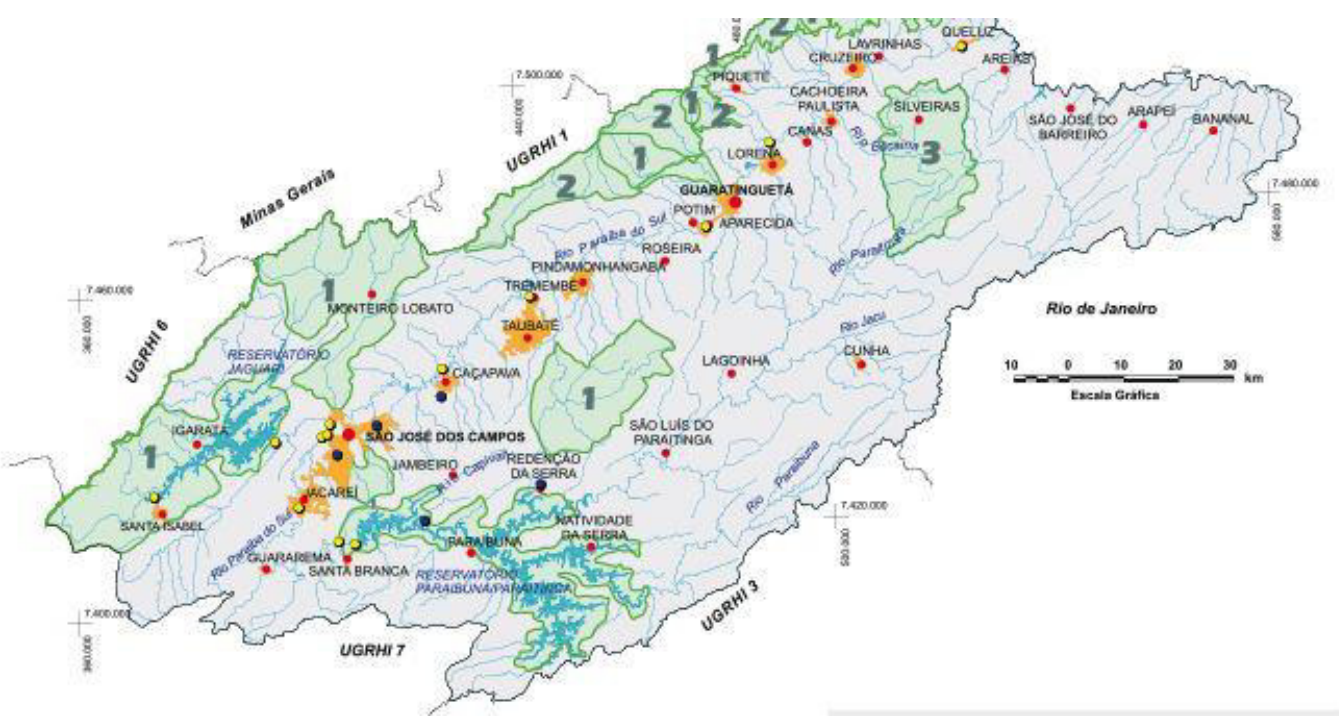

Fonte: CBH-PS 


\subsection{Bacia Hidrográfica do Médio Paraíba do Sul.}

A bacia hidrográfica do Médio Paraíba do Sul (Figura 2) fica no Estado do Rio de Janeiro, abrangendo 19 municípios, desde Resende até Três Rios, com uma população total de um milhão de habitantes. Na região, além do Rio Paraíba do Sul, estão inseridos alguns rios afluentes de domínio federal, como o Rio Preto e o Rio Bananal, e outros de domínio estadual como o Rio Pirapetinga, Rio Turvo e o Rio das Flores. Esta região é uma das subbacias formadoras do Rio Paraíba do Sul e as principais atividades econômicas na região estão divididas em industrial - automotiva, metalúrgica, siderúrgica, cimenteira, alimentícia - e agropecuária, com destaque para a criação de gado leiteiro (CBH MÉDIO PARAÍBA DO SUL, 2013).

Figura 3- Representação do Mapa da Bacia Hidrográfica do Médio Paraíba do Sul.

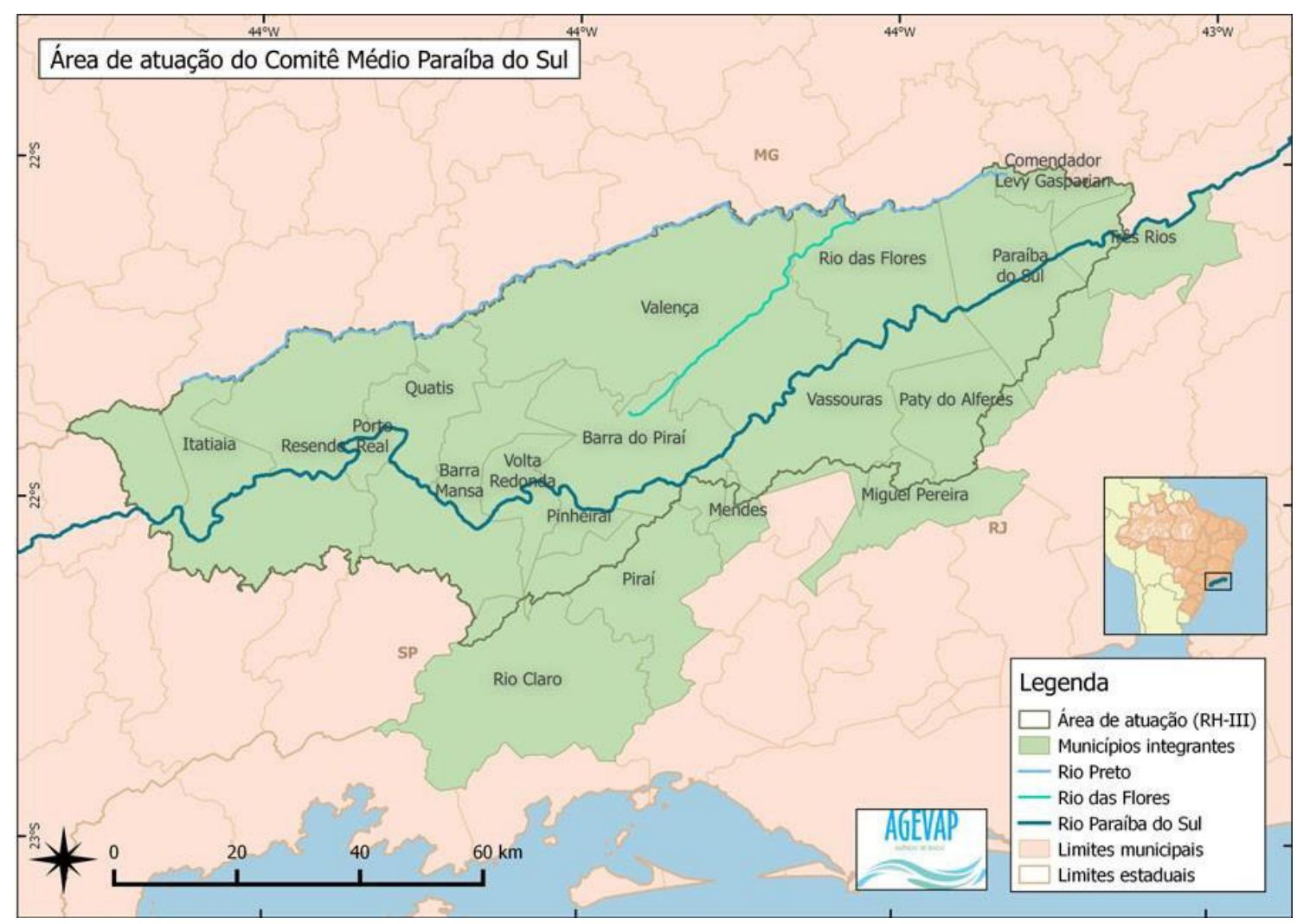

Fonte: AGEVAP 


\subsection{Micropoluentes}

Em tempos em que o Brasil tem enfrentado crises hidricas com regularidade, é natural que o interesse pela qualidade da água disponível aumente e também desperte a atenção sobre a questão dos micropoluentes. Micropoluentes são substâncias que se originam de atividades antropogênicas e aparecem em pequenas concentrações variando desde de microgramas até picogramas por litro - em águas naturais. Como exemplo, pode-se citar os produtos químicos industriais, produtos farmacêuticos e hormônios.

Dentre os micropoluentes existem aqueles conhecidos como "emergentes". Estes podem ser definidos como os poluentes cujo os limites de concentração no meio ambiente não estão contemplados em nenhuma norma regulatória que envolva parâmetros de qualidade da água, que ainda não foram anteriormente estudados e que podem ser potenciais causadores de danos aos ecossistemas ambientais, bem como à saúde e segurança humana (FARRÉ et al., 2008) . O termo "Micropoluente de Preocupação Emergente" (SAUVÉ; DESROSIERS, 2014) também tem sido utilizado com frequência. Assim, devido a grande utilização, os fármacos e os defensivos agricolas constituem as duas classes de compostos que estão entre as que merecem maior atenção.

\subsection{Os Fármacos}

\subsubsection{Panorama Geral}

Fármacos fazem parte de uma categoria de produtos industriais que apresenta uma das maiores demandas de produção mundial. Embora os dados exatos sejam rararmente divulgados, os produtos farmacêuticos têm sido comercializados, em grandes quantidades em todas as partes do globo.

O número de receitas prescritas é um bom indicador para se obter uma estimativa. Em 1995, na Alemanha foram aproximadamente 100 toneladas de drogas farmacêuticas receitadas ((TERNES, 1998)). Em 2000, no Reino Unido foi estimado que os 25 medicamentos mais vendidos tiveram um consumo de mais de 10 toneladas cada, sendo que os três que encabeçaram a lista (paracetamol, cloridrato de metilformina e ibuprofeno) tiveram o consumo projetado em mais de 100 toneladas durante o ano. (Jones et al, 2002). No Brasil não foram encontrados dados oficiais, porém acredita-se que as tendências 
mencionadas acima devam se manter ou até serem superiores, pois vários medicamentos são comercializados sem prescrição médica. Devido às ocorrências descritas acima, aliada a influência humana, as mais variadas classes de fármacos podem ser encontradas em diversos ecossistemas aquáticos causando um aumento da preocupação com a condição de micropoluentes dessas substâncias, que mesmo em concentrações muito baixas (no nível de traço) apresentam grande potencial de impacto (Shao et al 2009). Nos últimos anos, a ocorrência de compostos farmacologicamente ativos em diferentes corpos hídricos (seja em águas superficiais, do mar, subterrâneas ou mananciais) ocasionada pelo lançamento de efluentes e esgoto sem tratamento, tem sido reconhecida como uma das questões mais inquietantes na química ambiental (HERNÁNDEZ et al., 2007; RODRIGUEZ-MOZAZ et al., 2015).

Com o aumento da população, a inversão da pirâmide populacional (pessoas mais velhas na base e mais novas no topo) e o descobrimento de novas moléculas (dentro da União Europeia, por exemplo, são cerca de 3000 fármacos liberados para uso humano), o consumo destas substâncias tem aumentado consideravelmente (PETROVIĆ et al., 2014). Proporcionalmente, tem ocorrido o aumento da descarga de produtos contendo fármacos no meio ambiente, provenientes de excrementos, eliminação de medicamentos não utilizados ou expirados ou diretamente de descargas industriais (BORECKA et al., 2015a)(MOKH et al., 2017). Esta “alimentação" continua, representada na Figura 4, aliada a baixa eficiência dos tratamentos convencionais de esgoto (os processos são considerados lentos), é responsável pela chamada "pseudo" persistência dessas substâncias diretamente nos ambientes aquáticos. Neste contexto, pode-se afirmar que hoje, a principal via de entrada dos fármacos em meio ambientes aquáticos são as estações de tratamento de esgoto. 
Figura 4- Rotas dos fármacos até o meio ambiente.

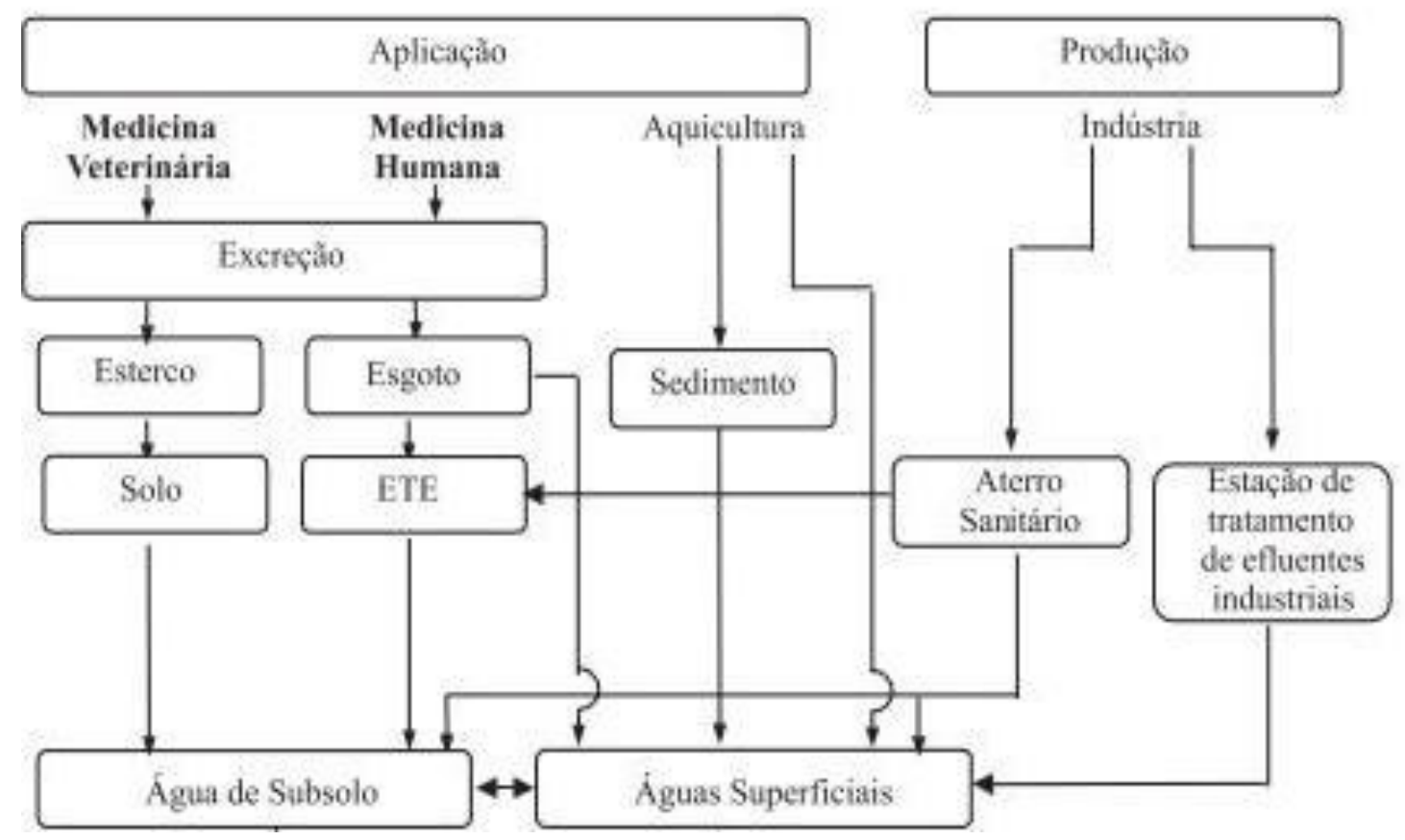

Fonte: BILA; DEZOTTI, 2003

Devido ao fato que estes produtos tem a estabilidade como uma de suas principais propriedades, eles podem ser apenas ligeiramente transformados ou mesmo permanecer inalterados durante sua passagem pelas estações de tratamento (ETEs). Existe ainda a possibilidade de estarem conjugados com outras moléculas polares, podendo ser fragmentados durante o tratamento de esgoto nestas mesmas ETEs, liberando os ativos originais para o ambiente aquático (CASTIGLIONI et al., 2004; TERNES, 2001). Existem estudos apontando indícios de que as substâncias de origem farmacêutica, muitas vezes não são completamente eliminadas durante o tratamento de águas residuais e também não são biodegradadas no ambiente (BILA; DEZOTTI, 2003; HERNÁNDEZ et al., 2007; TUNDISI, 2006; ZENOBIO et al., 2015)

Mesmo tendo sua toxidade estudada durante a fase de desenvolvimento, o potencial de contaminação ambiental e os mecanismos que ocorrem quando estes compostos estão no meio ambiente são pouco conhecidos (BORECKA et al., 2015). Assim o interesse na determinação desses contaminantes, somando-se a isto, o fato de que eles não estão inseridos na legislações brasileiras que regulamentam a qualidade da água e, portanto, podem ser elementos para futuras leis, o que depende de estudos sobre a sua toxicidade e efeitos potenciais ao meio ambiente e à saúde humana (AMÉRICO et al., 2012). 
Nesse sentido, investigações recentes têm sido desenvolvidas para melhorar o processo de tratamento de esgoto e contribuir para os cuidados com o ambiente (BILAL et al., 2019; LUMBAQUE et al., 2019; MIKLOS et al., 2019). Esses trabalhos são impulsionados, principalmente, pelos avanços na utilização das cromatografias líquida e gasosa acoplada à espectrometria de massa (GC-MS, GC MS/MS, LC-MS/MS)) o que permite a identificação e a possibilidade de rastreamento de micropoluentes orgânicos (KÜMMERER, 2002). Por conseguinte, nos últimos anos muitas análises ambientais têm sido realizadas em diversos países, em diversos tipos de matriz aquáticas e em corpos d'agua que sofrem diferentes tipos de influência antrópica utilizando as técnicas cromatográficas citadas acima, culminando em publicações de artigos e possibilitando assim o estabelecimento de padrões de análise e a verificação da qualidade das águas e efluentes (PETROVIĆ et al., 2014), (GONZALEZ-REY et al., 2015).

Os trabalhos citados a seguir, dão um panorama do que tem sido feito nos últimos anos no campo analítico/ambiental envolvendo a identificação e quantificação de compostos farmacêuticos em todo mundo, que confirmam as ações descritas no parágrafo anterior. (Todos utilizaram cromatografia - liquida ou gasosa - acoplada em um espectrometro de massas).

BORECKA et al., que em 2015 desenvolveram e validaram método para análise de a treze compostos farmacêuticos em águas do sul do Mar Báltico, na Polônia, região que abriga várias plantas industriais farmacêuticas e que tem como característica, devido as condições geográficas, uma "troca" de água limitada. O cetoprofeno foi o composto encontrado em maior concentração (135 ng/L) enquanto que trimetoprima, sulfametoxazol and enrofloxacina foram os detectados com maior frequência (BORECKA et al., 2015).

Em 2016, TLILI et al., desenvolveram método para analisar a presença 26 compostos farmacêuticos, sendo 18 antibióticos, nos Rios Canche e Cojeul, do norte da França, ambos situados em uma região de larga atividade industrial e agrícolas e que tem sido destino de efluentes urbanos. O ingrediente ativo mais encontrado nos rios foi a genfibrozila, com

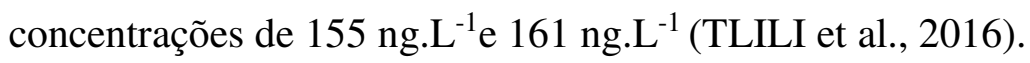

Ainda em 2016, em trabalho também desenvolvido com águas fluviais, K'OREJE et al., realizaram estudo envolvendo a análise de amostras de água dos Rios Ngong, Auji e Kisat, situados nas cidades de Nairobi e Kisumu, no Quênia. Ao todo, foram avaliados 24 compostos de classes farmacêuticas variadas - retrovirais, antibióticos, analgésicos, antiinflamatórios e drogas psiquiátricas. Os retrovirais lamivudina $\left(167 \mu \mathrm{g} . \mathrm{L}^{-1}\right)$, zidovudina (17 
$\left.\mu \mathrm{g} . \mathrm{L}-{ }^{1}\right)$ e nevirapina $\left(6 \mu \mathrm{g} \cdot \mathrm{L}^{-1}\right)$ foram a substâncias determinadas em maior concentração (K'OREJE et al., 2016)

Yang et al., realizaram em 2017 um estudo de caracterização das águas residuais de ETEs localizadas no delta do Rio das Pérolas, no sul da China. Além do desenvolvimento e validação do método, este trabalho determinou a eficiência do processo de tratamento destas ETEs para 93 compostos farmacêuticos (YANG et al., 2017).

No ano de 2018, Lesser et al., trabalharam com águas subterrâneas do aquífero do Vale Mezquital, próximo a Cidade do México para verificar o quanto estas águas já se encontram contaminadas. Várias classes de substâncias foram analisadas - dentre elas 118 princípios ativos farmacêuticos. A metiformina foi a encontrada com maior frequência, em concentrações compreendidas na faixa de 107 à 1310 ng.L ${ }^{-1}$ (LESSER et al., 2018).

\subsubsection{No Brasil}

No Brasil, os trabalhos pioneiros sobre a presença destes contaminantes em águas superficiais remontam a 1999, quando Ternes et al., testaram a eficiência de remoção em uma ETE na cidade do Rio de Janeiro, monitorando desreguladores endócrinos através de cromatografia gasosa acoplada a um detector de massas com triplo quadrupolo (GC MS/MS) (TERNES et al., 1999). Também em 1999, Stumpf et al, utilizando cromatografia gasosa (GC-MS) detectaram resíduos de fármacos em águas residuárias, brutas e tratadas no Estado do Rio de Janeiro. Os fármacos determinados e as respectivas maiores concentrações encontradas foram: ibuprofeno (10 ng.L $\left.\mathrm{L}^{-1}\right)$ diclofenaco $\left(60 \mathrm{ng} . \mathrm{L}^{-1}\right)$, naproxeno (50 ng. $\left.\mathrm{L}^{-1}\right)$ ácido clofíbrico (30 ng.L $\left.\mathrm{L}^{-1}\right)$ e bezafibrato (25 ng.L $\left.\mathrm{L}^{-1}\right)$ (STUMPF et al., 1999).

Em 2014, Campanha et al, utilizando LC-MS/MS encontraram no rio Monjolinho, localizado no município de São Carlos (SP), cafeína $\left(0,13 \mu \mathrm{g} . \mathrm{L}^{-1}\right)$, paracetamol $\left(3,67 \mu \mathrm{g} . \mathrm{L}^{-}\right.$ ${ }^{1}$ atenolol $\left(0,98 \mu \mathrm{g} \cdot \mathrm{L}^{-1}\right)$, ibuprofeno $\left(0,50 \mu \mathrm{g} \cdot \mathrm{L}^{-1}\right)$, naproxeno $\left(0,39 \mu \mathrm{g} \cdot \mathrm{L}^{-1}\right)$, diclofenaco $(0,23$ $\mu \mathrm{g} . \mathrm{L}^{-1}$ triclosan $\left(0,1 \mu \mathrm{g} . \mathrm{L}^{-1}\right)$, propranolol $\left(0,04 \mu \mathrm{g} . \mathrm{L}^{-1}\right)$ e carbamazepina $\left(0,12 \mu \mathrm{g} . \mathrm{L}^{-1}\right)$ (CAMPANHA et al., 2014).

Em trabalhos mais recentes, podemos destacar: Lopes et al., que em 2016 realizaram o monitoramento de paracetamol, ácido salicílico, diclofenaco e bisfenol A em quatro rios que fazem parte de um complexo de lagoas pertencentes a bacia de Jacarepaguá, na cidade do Rio de Janeiro. O bisfenol A foi o analito encontrado com maior frequência e em maior concentração (39,9 $\left.\mu \mathrm{g} . \mathrm{L}^{-1}\right)$ (RJ) (LOPES et al., 2016). 
Cortez et al., que em 2018 determinaram o perfil da concentração do antidepressivo losartan, em águas marítimas na baia de Santos/SP (variação na faixa de 0,2 até 8.6 ng.L ${ }^{-1}$ ) e sua influência ecotoxicológica sobre o mexilhão Perna perna (CORTEZ et al., 2018)

Já Reichert et al, também em 2018, monitoraram drogas psiquiátricas em efluente de um hospital na cidade de Santa Maria/RS. Olanzapina $\left(0,31-0,52 \mu \mathrm{g} \cdot \mathrm{L}^{-1}\right)$, clozapina $\left(0,56-0,97 \mu \mathrm{g} . \mathrm{L}^{-1}\right)$, haloperidol $\left(1,43-2,73 \mu \mathrm{g} . \mathrm{L}^{-1}\right)$, risperidone $\left(0,92-0,98 \mu \mathrm{g} . \mathrm{L}^{-1}\right) \quad \mathrm{e}$ clorpromazina $\left(0,52 \mu \mathrm{g} \mathrm{L}^{-1}\right)$ foram as drogas encontradas e quantificadas (REICHERT; SOUZA; MARTINS, 2019)

\subsection{Os Defensivos Agrícolas}

O agronegócio é hoje uma das principais atividades econômicas brasileiras. Estimativas mostram que ele contribui com cerca de $30 \%$ do Produto Interno Bruto (PIB), o que significa a geração de aproximadamente 350 bilhões de dólares anuais (MOREIRA et al., 2012), respondendo por cerca de um terço das exportações nacionais. Uma consequência disto é que o Brasil, segundo dados do Ministério do Desenvolvimento Agrário (MDA) e da Agência de Vigilância Sanitária Nacional (ANVISA), é o maior consumidor e produtor de agrotóxicos do mundo desde 2009. Aqui, o mercado desses produtos cresceu aproximadamente $176 \%$ desde primeira década deste século, quatro vezes mais do que a média mundial (DELLAMATRICE; MONTEIRO, 2014).

Os defensivos agrícolas têm sido empregados na proteção de culturas desde a década de 1940 (GRUNG et al., 2015). Em consequência, traços destes compostos químicos, bem como subprodutos provenientes da sua degradação tem sido detectados tanto em águas superficiais como em águas subterrâneas (FARRÉ et al., 2008). Este tipo de contaminação pode acarretar tanto em toxicidade aguda e crônica para os organismos aquáticos, acumulação de resíduos no ecossistema, perda de habitats e prejuízos à biodiversidade da região afetada, além de representar riscos para a saúde humana (SILVA; DAAM; CEREJEIRA, 2015).

As principais vias pelas quais os defensivos agrícolas chegam às águas superficiais são escoamento, arraste pelo vento (de partículas durante a pulverização) e drenagem. A quantidade de defensivos agrícolas transferida da lavoura para as águas superficiais dependerá de vários fatores, tais como características do solo, clima (abundância de chuvas e frequência de períodos de seca são fatores impactantes), práticas de manejo agrícola e 
propriedades físico-químicas dos compostos (PAPADAKIS et al., 2015). A remoção da mata ciliar e o manejo inadequado do solo e culturas, mesmo em áreas aptas para desenvolvimento agrícola, também potencializam o transporte de agrotóxicos do solo para corpos d'água em decorrência do escoamento superficial gerado pela ação da chuva ou irrigação da cultura nesses locais (LOURENÇATO, 2011).

Considerando que um sistema hídrico pode possuir muitas outras interligações com outros sistemas, a presença de qualquer contaminante pode resultar em contaminação distante das áreas em que foram originalmente aplicados (VEIGA et al., 2006). Além disto, o sedimento é constantemente lavado, reduzindo a concentração de compostos tóxicos neste compartimento e contaminando a coluna de água (BELUTTA et al., 2010). A capacidade de uma substância ser transportada pela água depende diretamente de fatores ligados a sua estabilidade, o estado físico do composto e a velocidade do fluxo do rio. De forma geral, a concentração do analito diminui continuamente à medida que a distância do ponto de contaminação aumenta.

A presença de defensivos agrícolas nas águas dos corpos hídricos pode obedecer a um modelo sazonal, que depende do tempo de aplicação e do mecanismo de transporte da molécula. Frequentemente, os agrotóxicos são aplicados em uma estação e transportados para as águas superficiais apenas dias ou semanas depois. O típico modelo sazonal inclui aumento da concentração nas primeiras chuvas e no final da estação, com acúmulo dos pesticidas transportados durante este período (KUIVILA; HLADIK, 2013).

A concentração da maioria dos defensivos agrícolas nos corpos d'água é baixa, devido ao fato de serem pouco solúveis em água e também ao efeito da diluição (DORES; DE-LAMONICA-FREIRE, 2001). No entanto, este comportamento dos compostos não exclui a possibilidade de que concentrações muito altas venham a ocorrer depois de pesadas chuvas, principalmente quando áreas próximas tenham sido recentemente tratadas com altas doses de um defensivo agrícola.

Vários estudos sobre a presença de defensivos agrícolas em rios brasileiros já foram realizados. Em 2004, Rissato et al. utilizaram cromatografia gasosa acoplada a um detector de captura de elétrons (GC/ECD) para a análise organoclorados nos rios Batalha e Bauru, localizados no Estado de São Paulo. O estudo foi desenvolvido durante 9 meses e o organoclorado encontrado em maior concentração foi o endosulfan (810 ng/L) (RISSATO et al., 2004).

Em 2005, Primel e colaboradores desenvolveram estudo na Bacia Hidrográfica dos Rios Vacacaí e Vacacaí-Mirim. Utilizando LC/UV, detectaram os ingredientes ativos 
encontrados com maior frequência foram a clomazona e o propanil (PRIMEL et al., 2005). Em outro estudo, realizado por Marchesan e colaboradores, envolvendo novamente os Rios Vacacaí e Vacacaí-Mirim (RS) foram encontrados resíduos de clomazona, propanil e quinclorac, sendo a clomazona o mais frequente. As maiores concentrações (máximo de 12 $\mu \mathrm{g} / \mathrm{L})$ foram encontradas durante a estação de crescimento das plantas e no período de chuvas. A técnica utilizada para análise também foi LC/UV (MARCHESAN et al., 2007).

Um outro estudo realizado por Veiga e colaboradores em águas superficiais e subterrâneas no município de Paty dos Alferes/RJ detectou contaminação por organofosforados e carbamatos em $70 \%$ das amostras. O método usado para a dosagem não envolveu técnicas cromatográficas e sim dosagem da inibição da enzima acetilcolinesterase. Estes valores foram encontrados para o período seco, o qual não é o mais crítico para a contaminação de águas por defensivos agrícolas, mostrando que a contaminação pode persistir por mais de uma estação (VEIGA et al., 2006)

No Rio Arroio Lino (RS), defensivos agrícolas utilizados na cultura do fumo (imidacloprida, atrazina e clomazona) foram detectados próximo as lavouras e no entorno dos rios, nos locais em que não havia mata ciliar (BORTOLUZZI; ZANELLA, 2006).

Os herbicidas triazinícos também tiveram destaques como o principal grupo de resíduos detectados nas águas do Rio Corumbataí (SP) por Armas e colaboradores. Neste trabalho, foram detectados resíduos de atrazina e ametrina em níveis acima do padrão expresso na Resolução CONAMA n. 357/05 (BRASIL, 2005), além de resíduos de simazina, hexazinona, glifosato e clomazone (ARMAS et al., 2007)

Na região do Pantanal (Estados do Mato Grosso e do Mato Grosso do Sul), Miranda e colaboradores, avaliaram através de GC/MS a contaminação do sedimento por defensivos agrícolas em dezessete rios. Entre os 23 pesticidas monitorados, foram detectados resíduos de piretroides (permetrina, lambda-cialotrina e deltametrina) e de organoclorados (DDT) (MIRANDA et al., 2008).

Belluta e colaboradores, utilizando LC/UV relataram a detecção de pesticidas organoclorados e piretroides no córrego do Cintra (Botucatu/SP. Os valores encontrados para piretroides foram 5,5 vezes maiores do que o limite estabelecido pela Portaria do Ministério da Saúde n. 2914/11 (BRASIL, 2011) em água para consumo humano (BELLUTA et al., 2010)

Em 2011, Jacomini e colaboradores utilizando LC - MS/MS avaliaram a contaminação dos Rios Sapucaí, Pardo e Mogi-Guaçu/SP pelo herbicida ametrina. Localizados próximo a locais de cultivo de cana-de-açúcar, onde o herbicida é bastante 
utilizado, foram detectados resíduos do composto nas águas e na biota do rio Mogi Guaçu e nos sedimentos dos três rios (. Nos sedimentos as concentrações foram consideradas altas, com potencial para remobilização dos produtos novamente para a coluna de água e também contaminação da biota) (JACOMINI et al., 2011).

MOREIRA et al., (2012) analisaram amostras de águas de chuva coletadas no campo e nas cidades de Campo Verde e Lucas do Rio Verde (MT). Foram encontrados resíduos de atrazina endosulfan, malation, metolaclor, metil paration e flutriafol. Os resíduos de atrazina foram os encontrados com mais frequência e foram os mais elevados $(47,21 \mu \mathrm{g} / \mathrm{L})$. Os mesmos compostos foram detectados tanto na zona rural como na urbana, evidenciando a importância da volatilização e do transporte pelos ventos dos pesticidas.

Mais recentemente, Valenzuela, Menezes e Cardeal, em um trabalho de desenvolvimento de um dispositivo de amostragem passiva, desenvolveram e validaram metodologia para 29 defensivos agricolas na bacia do Rio São Francisco. Os pesticidas detectados com maior frequência foram 4,4-DDE, 4,4-DDD e propazina (VALENZUELA; MENEZES; CARDEAL, 2018)

Em relação ao Rio Paraíba do Sul, Azevedo, Gerchom e Dos Reis, realizaram análises nas cidades de Resende e Campos de Goytacazes/RJ. A atrazina foi o pesticida encontrado em maior concentração, principalmente em proximidades de plantações e usinas de cana de açúcar de Campos dos Goytacazes (AZEVEDO; GERCHON; DOS REIS, 2004).

Em 2018, Starling, Amorim e Leão publicaram uma revisão sobre a ocorrência de contaminantes emergentes no Brasil. Este trabalho mostrava um panorama do que já foi feito em território nacional sobre o monitoramento de várias classes emergentes (fármacos, defensivos agrícolas, desreguladores endócrinos, etc) tendo como base, diversos artigos publicados em periódicos de relevância internacional (STARLING; AMORIM; LEÃO, 2018) 


\section{OBJETIVO}

O objetivo deste trabalho será averiguar a presença dos compostos farmacêuticos, cafeína, diclofenaco Ibuprofeno, naproxeno paracetamol e dos pesticidas, 2,4-D imidacloprida, atrazina, simazina e fipronil nas águas do Rio Paraíba do Sul, na região entre compreendida entre Jacareí e Volta Redonda. Serão contemplados 11 pontos de coleta neste segmento do rio.

\subsection{Objetivos Específicos}

- Desenvolvimento e validação de métodos analíticos para a quantificação de fármacos e defensivos agricolas por LC - MS/MS, bem como métodos de extração por fase sólida

- Verificação se existe alguma a influência das principais cidades da região na variação da concentração destas substâncias.

- Verificar a existência de algum padrão de sazonalidade dos compostos selecionados. 


\section{MATERIAIS E MÉTODOS}

\subsection{Equipamentos, materiais e reagentes utilizados}

3.1.1 Equipamentos

- Cromatógrafo Agilent, modelo 1200, acoplado a um espectrômetro de massa com triplo quadrupolo e ionização por eletrospray 6410.

- Balança analítica Shimatzu com 4 casas decimais, modelo AY247

- Sonda multiparâmetros YSI, modelo PRO DSS.

- Bomba peristáltica Ismatec com 4 canais.

- Ultra purificador de água Gehaka, modelo MS2000

\subsubsection{Reagentes: Padrões analíticos}

Todos os padrões analíticos utilizados foram da marca Sigma- Aldrich. Foram preparadas soluções estoques de cada analito na concentração de $1000 \mathrm{mg} . \mathrm{L}^{-1} \mathrm{em}$ metanol, que foram mantidas sob temperatura de $-20^{\circ} \mathrm{C}$ em freezer. A partir destas soluções estoque, foram preparadas soluções de trabalho em concentrações que variaram de $1 \mu \mathrm{g} . \mathrm{L}^{-1}$ até 500 $\mu \mathrm{g} . \mathrm{L}^{-1}$. O prazo de validade estipulado para as soluções foi de 3 meses, a partir da data de preparo. As soluções de trabalho foram preparadas no momento do uso.

- Acetonitrila, e Metanol grau HPLC, marca JT Baker para preparo de fase moveis.

- Hidróxido de Amônio, marca JT Baker para preparo de fase móveis

- Acetato de Amônio PA, marca JT Baker , para extração em fase sólida

- Ácido Fórmico PA, marca Sigma Aldrich, para extração em fase sólida.

\subsubsection{Materiais:}

- Cartuchos para extração em Fase Sólida HLB OASIS, marca Waters

- Cartuchos para extração em Fase Sólida Strata X-A, marca Phenomenex

- Filtro de Nylon para seringa de diâmetro de poro de $0,22 \mu \mathrm{m}$

- Filtros de fibra de vidro de diâmetro de poro 1,2 $\mu \mathrm{m}$, marca Membrane Solution

- Coluna de separação cromatográfica Zorbax SB - C18 com dimensões de 2,1 x $30 \mathrm{~mm}$ e tamanho de partícula de $3,5 \mu \mathrm{m}$. 


\subsection{Escolha dos analitos}

\subsubsection{Fármacos}

Os fármacos escolhidos foram, cafeína, diclofenaco, ibuprofeno, naproxeno e paracetamol. O critério de escolha baseou-se em:

- Todos estes princípios ativos fazem parte da categoria dos analgésicos e antiinflamatórios, portanto, podem ser vendidos sem a prescrição médica.

- A cafeína não possui atividade farmacológica, mas está presente em grande parte das formulações desta classe de princípios ativos, além de ser considerada um contaminante antrópico (CANELA et al., 2014)

- $\quad$ Facilidade em se obter o padrão analítico.

- Diclofenaco, ibuprofeno e naproxeno, já foram estudados anteriormente no Rio Paraíba do Sul (STUMPF et al., 1999).

\subsubsection{Defensivos Agrícolas}

O principal critério de escolha para os defensivos agrícolas, foi baseado nas culturas mais predominantes na região do Vale do Paraíba paulista e no Médio Paraíba, acompanhado do volume de vendas dos mesmos.

Na parte paulista o cultivo de arroz tem ampla predominância. Nela estão presentes as maiores áreas de cultivo de arroz irrigado do Estado de São Paulo. A Tabela 1. apresenta os dez municípios com maior número de hectares utilizados na cultura do arroz no período compreendido entre os anos 2006 e 2010 (IPEA, 2016). 
Tabela 1- Os dez municípios do Estado de SP com maior área ocupada (hectares) pelo cultivo de arroz entre os anos de 2006 e 2010.

\begin{tabular}{cccccc}
\hline Município & $\mathbf{2 0 0 6}$ & $\mathbf{2 0 0 7}$ & $\mathbf{2 0 0 8}$ & $\mathbf{2 0 0 9}$ & $\mathbf{2 0 1 0}$ \\
\hline Pindamonhangaba* & 2.800 & 2.900 & 2.600 & 2.400 & 2.400 \\
Guaratinguetá* & 2.325 & 2.400 & 2.012 & 2.032 & 2.032 \\
Itapeva & 800 & 940 & 760 & 1.200 & 1.200 \\
Roseira* & 800 & 800 & 700 & 700 & 700 \\
Itaberá & 60 & 60 & 266 & 500 & 500 \\
Mogi Guaçu & 600 & 420 & 420 & 420 & 420 \\
Canas* & 500 & 500 & 414 & 409 & 409 \\
Pedrinhas Paulista & 600 & 435 & 400 & 400 & 400 \\
Batatais & 200 & 200 & 250 & 300 & 300 \\
Tarumã & 400 & 330 & 330 & 300 & 300 \\
\hline
\end{tabular}

Fonte: Ipea. *Cidades pertencentes ao Vale do Paraíba Paulista.

Já no Médio Paraíba, a atividades agrícola mais proeminente na região é o cultivo do eucalipto para extração de lenha A área cultivada em cada cidade, até 2014, da referida cultura era de: 800 hectares em Resende, 550 hectares em Barra Mansa e 800 hectares em Volta Redonda (IBGE, 2016). A criação bovina na região também se destaca. Em 2015, existiam cerca de 90000 cabeças de gado bovino na região (IBGE, 2016), o que demanda a ocorrência de área agrícola para pastagens. Assim, consultou-se quais os defensivos agrícolas que estes três tipos de cultivo teriam em comum e quais eram os mais vendidos nos Estados de São Paulo e do Rio de Janeiro (MAPA, 2016).

Como o número total de ingredientes ativos comum as três culturas é extenso e seria inviável trabalhar com todos eles, mais um refinamento foi feito, desta vez considerando o volume de vendas destes ingredientes nos Estados do RJ e SP (IBAMA, [s.d.]).

Assim, os defensivos agrícolas escolhidos por esta metodologia de triagem foram, fipronil, atrazina, simazina, imidacloprida, bentazona e ácido diclofenoxiacético (2,4 -D). 


\subsection{Definição dos pontos de amostragem}

A área de estudo deste trabalho, envolveu as maiores cidades da parte paulista da Bacia do Paraíba do Sul e do Médio Paraíba, situada no Estado do Rio de Janeiro.

A tabela 2 apresenta a localização geográfica e física de cada um dos 11 pontos de amostragem escolhidos, enquanto as Figuras de 5 até 15 representam o mapa dos locais onde serão coletadas as amostras:

Tabela 2- Pontos de amostragem, suas coordenadas geográficas e sua localização.

\begin{tabular}{|c|c|c|}
\hline Ponto & Localização & Coordenadas \\
\hline $\mathrm{P} 1$ & Jacareí (SP) & $23^{\circ} 18^{\prime} 28.5^{\prime \prime S} 45^{\circ} 58^{\prime} 33.4^{\prime \prime} \mathrm{W}$ \\
\hline $\mathrm{P} 2$ & São José dos Campos (SP) & $23^{\circ} 11^{\prime} 45.1^{\prime \prime S} 45^{\circ} 55^{\prime} 49.2^{\prime \prime} \mathrm{W}$ \\
\hline P3 & $\begin{array}{l}\text { Caçapava } \\
\text { (SP) }\end{array}$ & $23^{\circ} 04^{\prime} 44.5^{\prime \prime} \mathrm{S} 45^{\circ} 42^{\prime} 37.0^{\prime \prime} \mathrm{W}$ \\
\hline P4 & Taubaté (SP) & $22^{\circ} 57^{\prime} 40.3^{\prime \prime S} 45^{\circ} 33^{\prime} 17.5^{\prime \prime} \mathrm{W}$ \\
\hline P5 & $\begin{array}{l}\text { Pindamonhangaba } \\
\text { (SP) }\end{array}$ & $22^{\circ} 54^{\prime} 42.6^{\prime \prime S} 45^{\circ} 28^{\prime} 15.3^{\prime \prime} \mathrm{W}$ \\
\hline P6 & Guaratinguetá & $22^{\circ} 47^{\prime} 25.4^{\prime \prime S} 45^{\circ} 10^{\prime} 43.6^{\prime \prime} \mathrm{W}$ \\
\hline P7 & Lorena & $22^{\circ} 42^{\prime} 01.1^{\prime \prime S} 45^{\circ} 07^{\prime} 08.2^{\prime \prime} \mathrm{W}$ \\
\hline P8 & Lavrinhas (SP) & $22^{\circ} 33^{\prime} 59.9^{\prime \prime} \mathrm{S} \quad 44^{\circ} 54^{\prime} 28.85^{\prime \prime O}$ \\
\hline P9 & Resende (RJ) & $22^{\circ} 27^{\prime} 56.8^{\prime \prime S} 44^{\circ} 26^{\prime} 09.3^{\prime \prime} \mathrm{W}$ \\
\hline $\mathrm{P} 10$ & Barra Mansa (RJ) & $22^{\circ} 31^{\prime} 31.0^{\prime \prime S} 44^{\circ} 11^{\prime} 21.9^{\prime \prime} \mathrm{W}$ \\
\hline P11 & Volta Redonda (RJ) & $22^{\circ} 28^{\prime} 42.0^{\prime \prime} \mathrm{S} 44^{\circ} 03^{\prime} 47.0^{\prime \prime} \mathrm{W}$ \\
\hline
\end{tabular}

Fonte: Arquivo pessoal 
Figura 5 - Fotografia do ponto de amostragem 1.

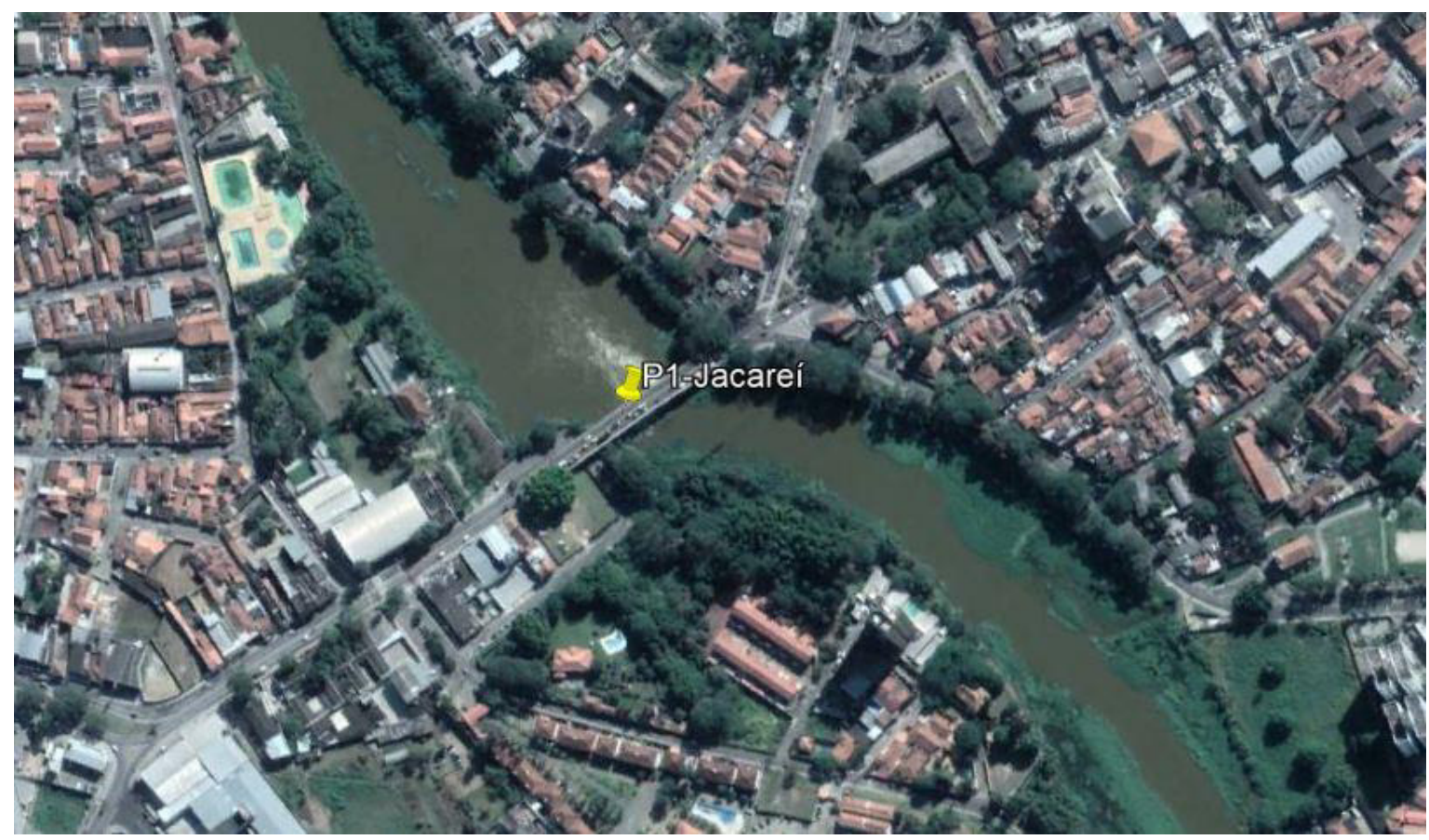

Fonte: Google Earth

Figura 6- Fotografia do ponto de amostragem 2.

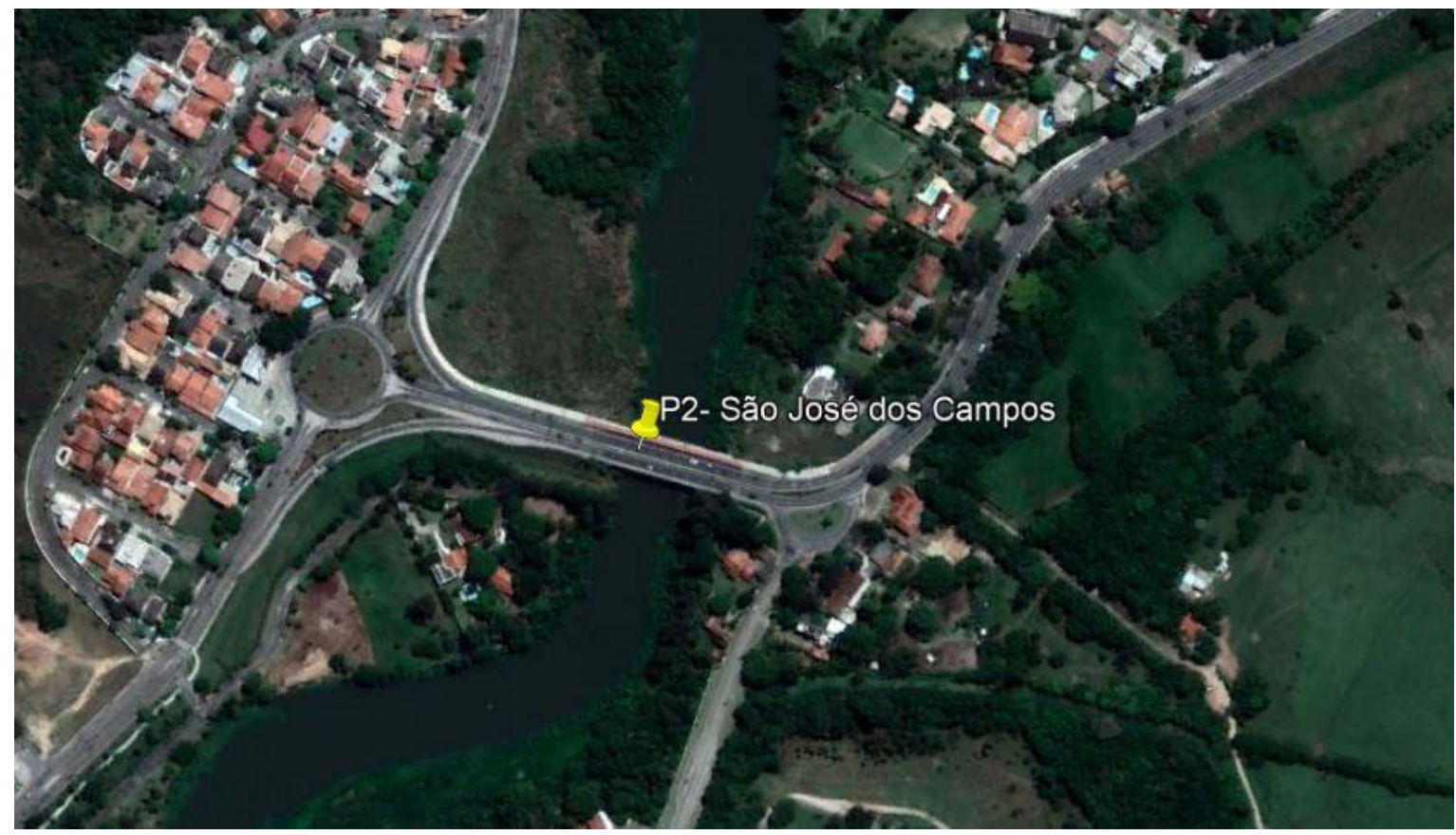

Fonte: Google Earth 
Figura 7- Fotografia do ponto de amostragem 3.

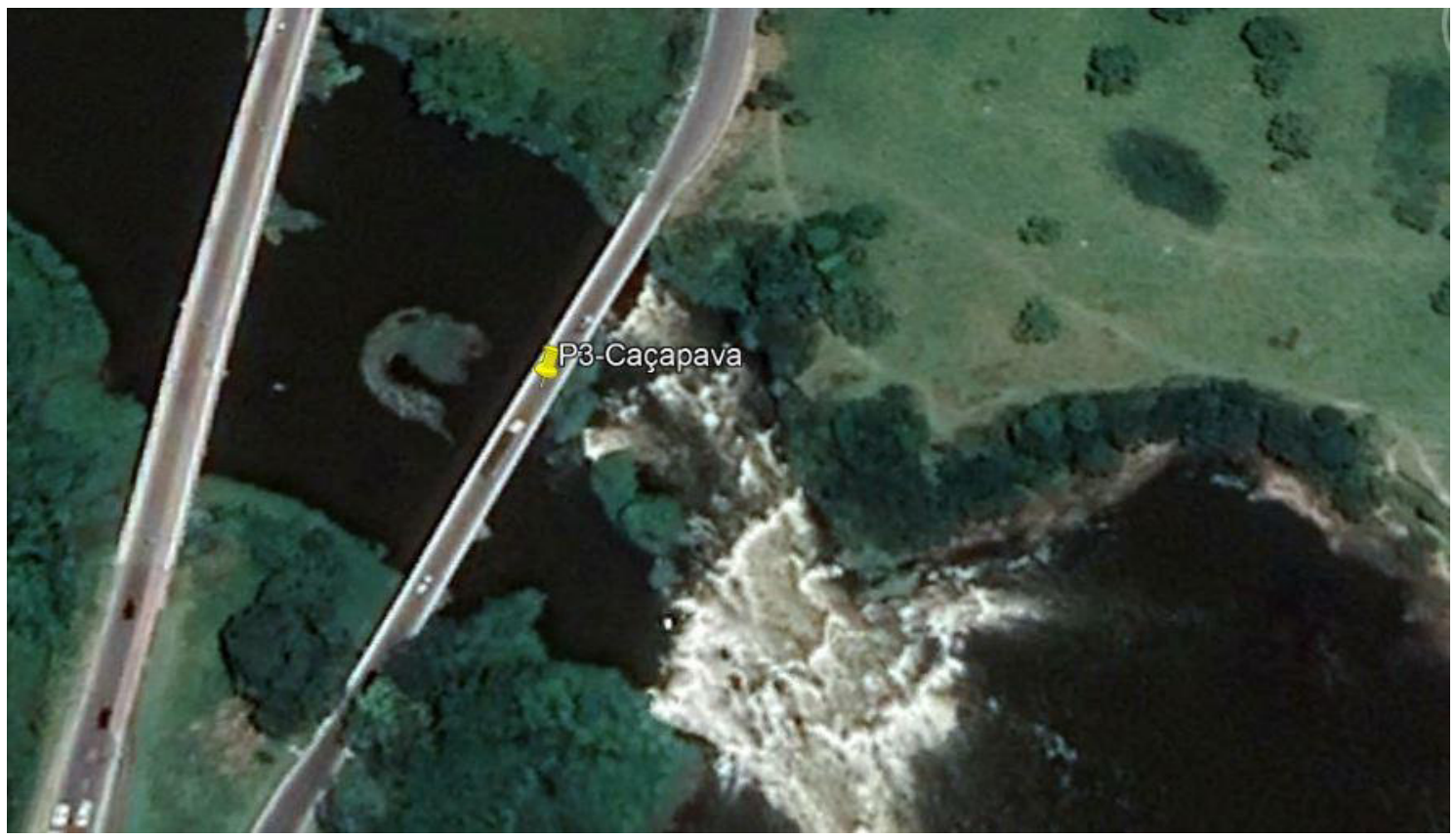

Fonte: Google Earth

Figura 8- Fotografia do ponto de amostragem 4.

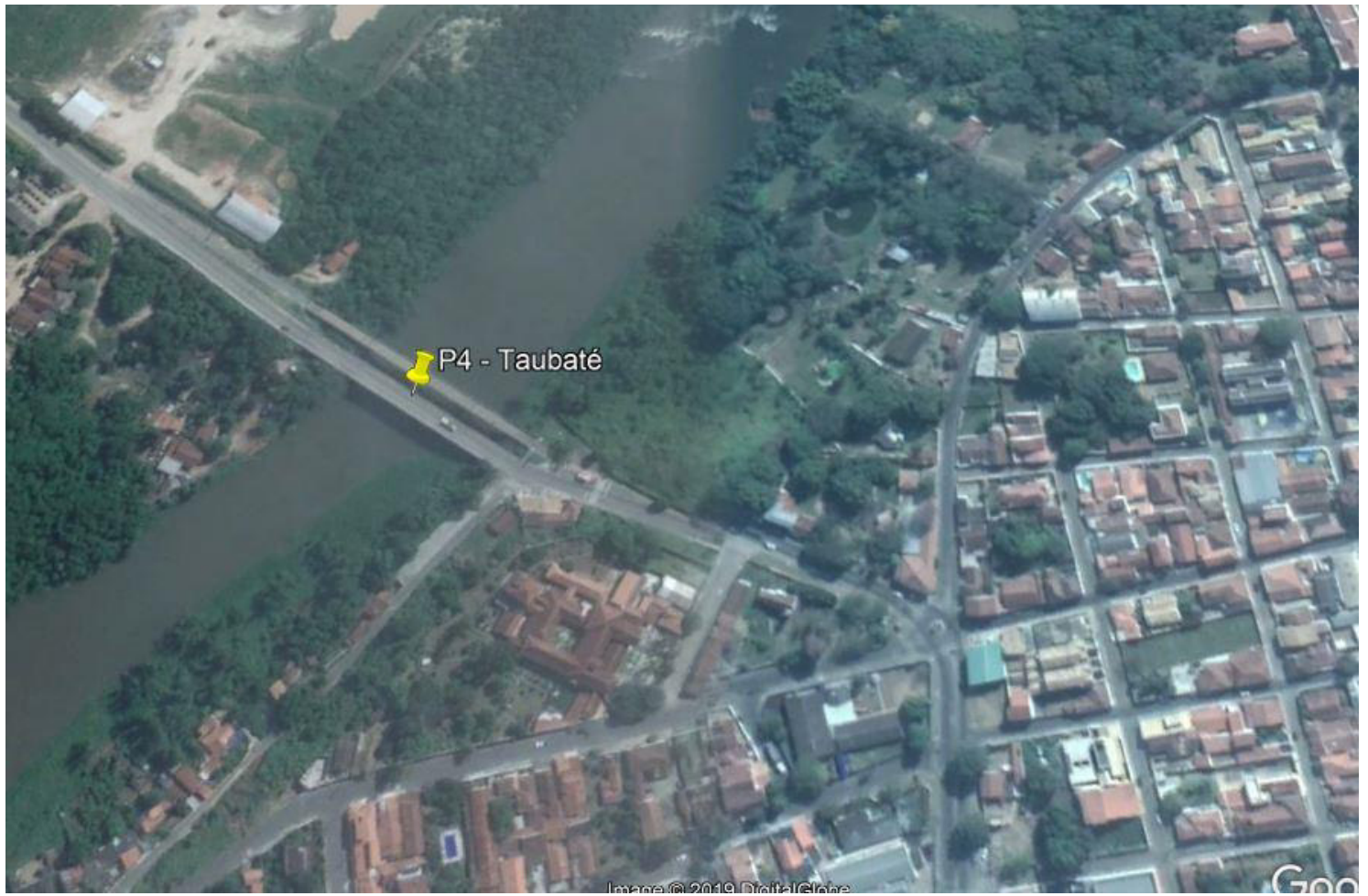

Fonte: Google Earth 
Figura 9- Fotografia do ponto de amostragem 5.

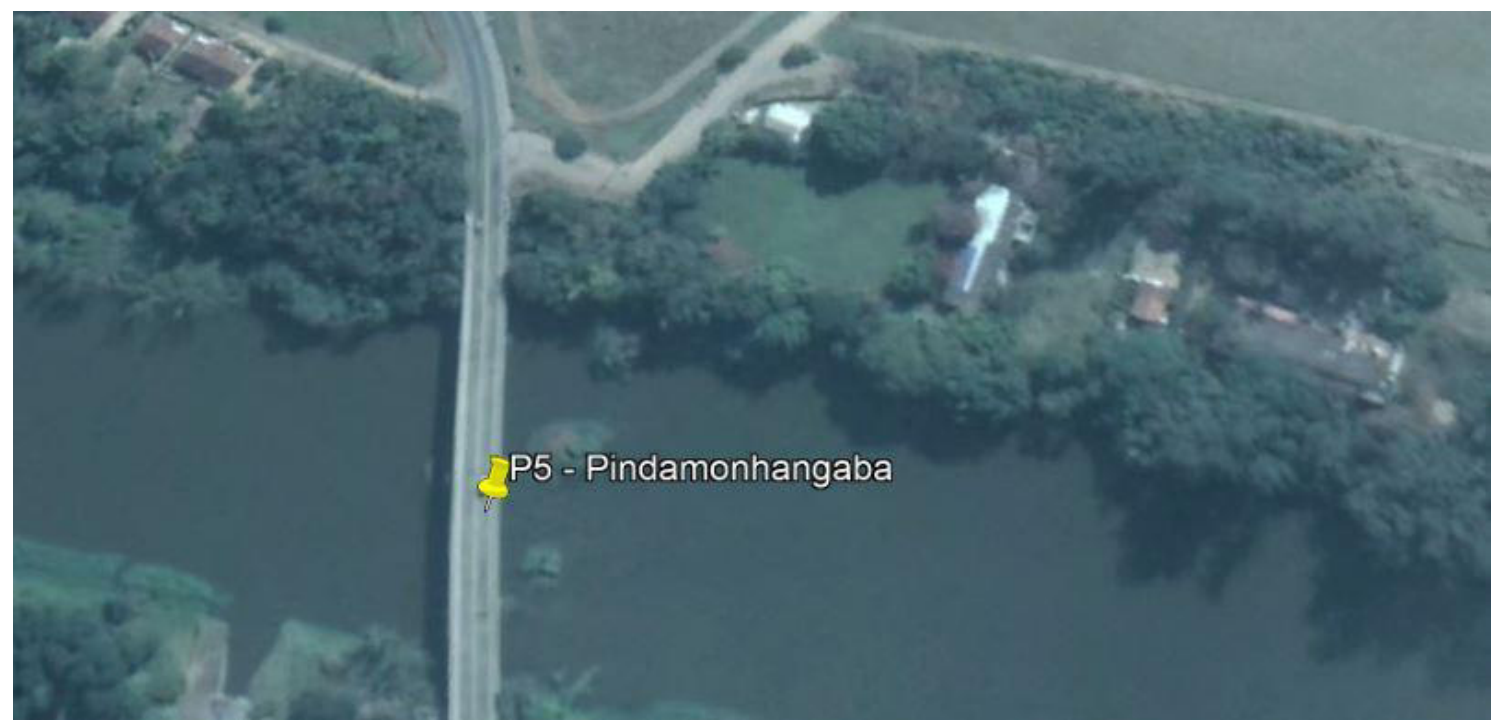

Fonte: Google Earth

Figura 10- Fotografia do ponto de amostragem 6.

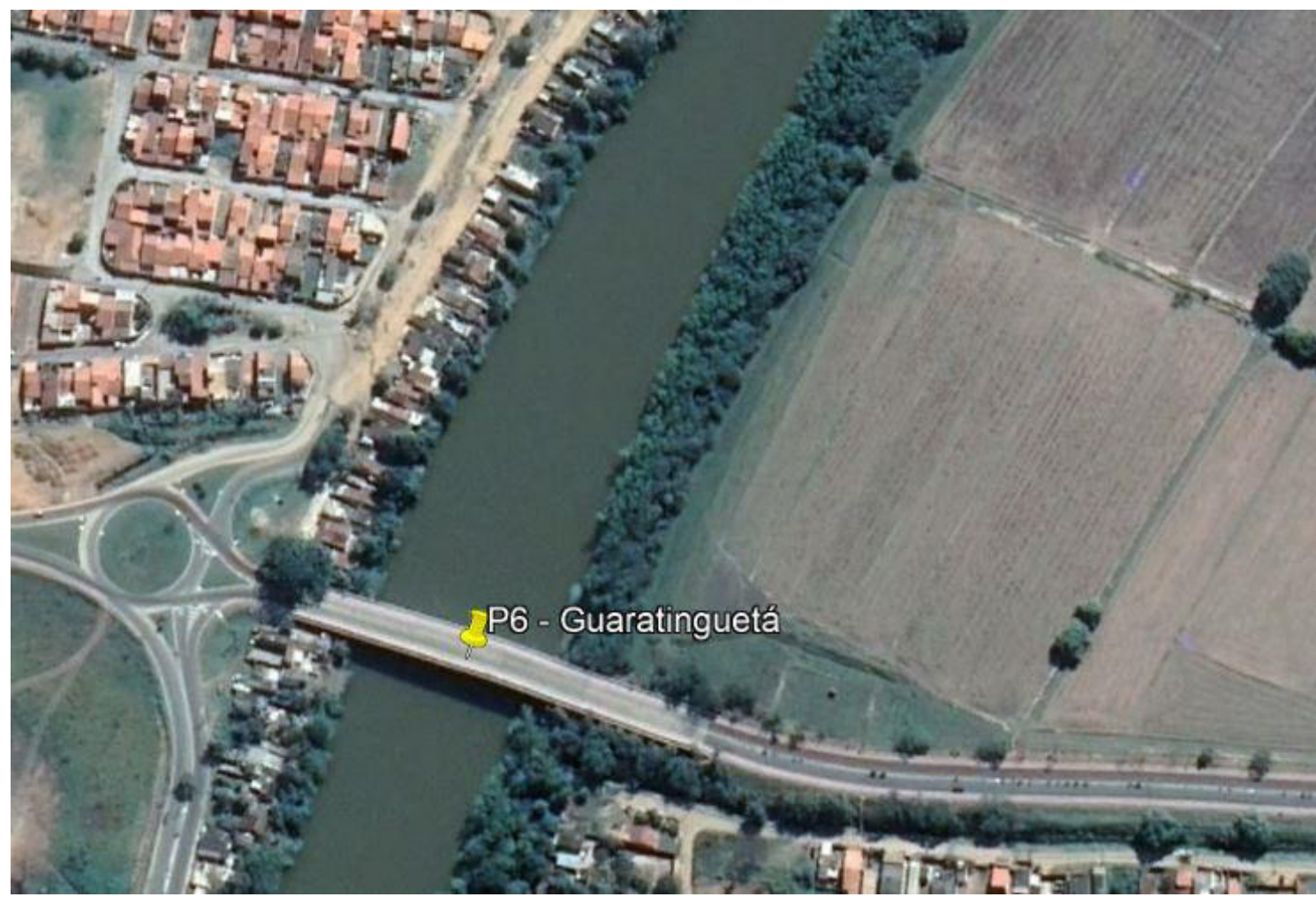

Fonte: Google Earth 
Figura 11- Fotografia do ponto de amostragem 7.

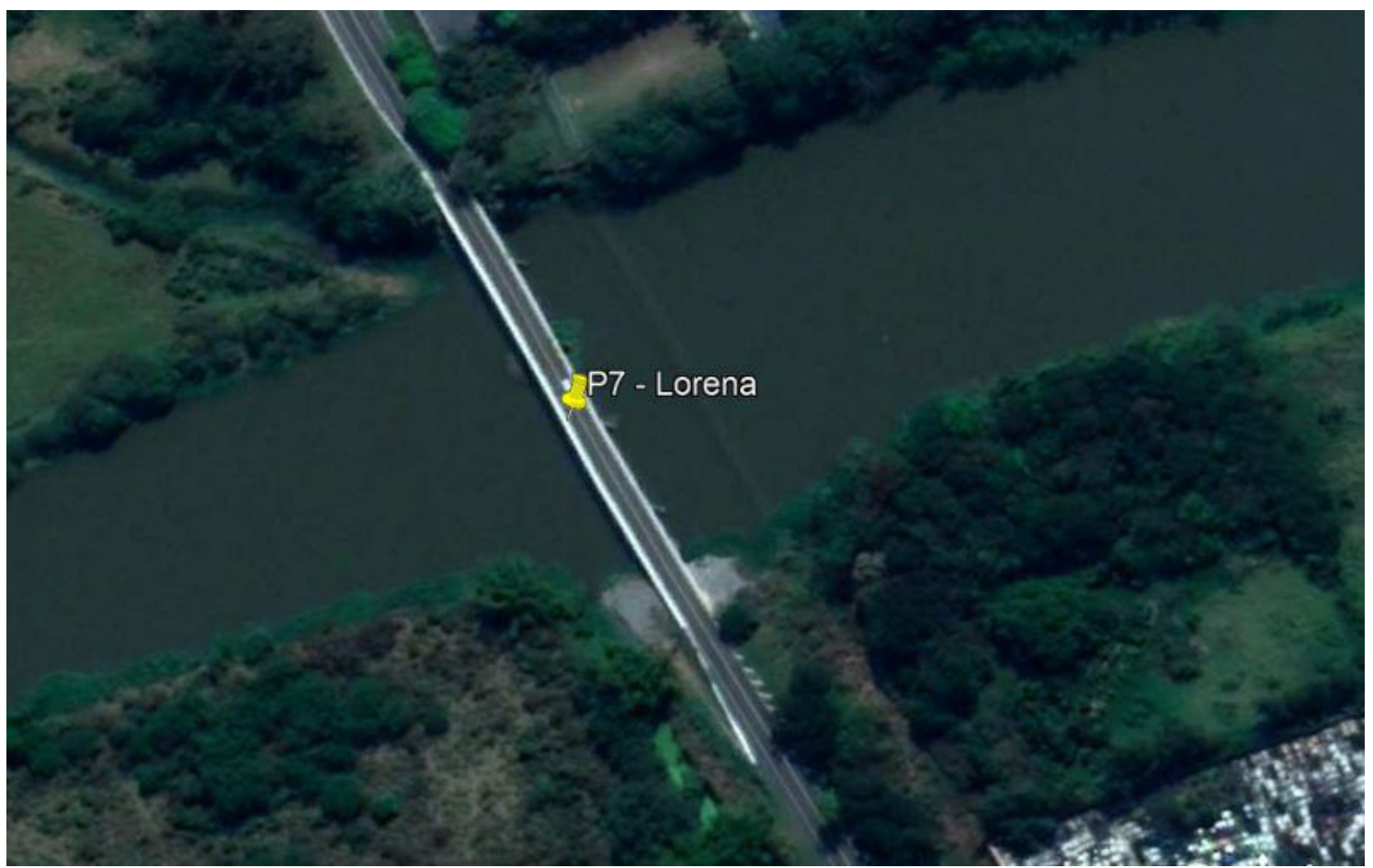

Fonte: Google Earth

Figura 12- Fotografia do ponto de amostragem 8.

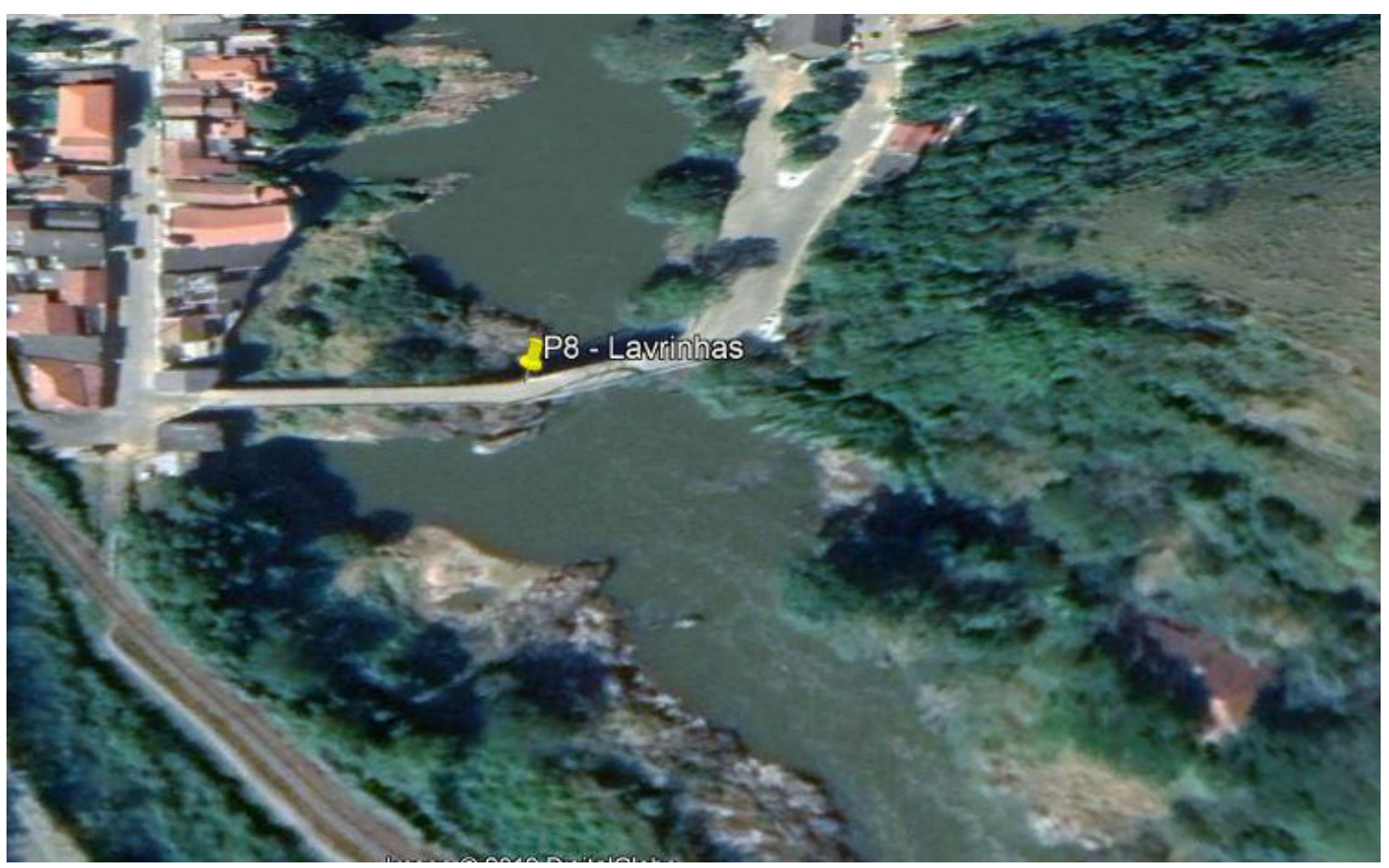

Fonte: Google Earth 
Figura 13- Fotografia do ponto de amostragem 9.

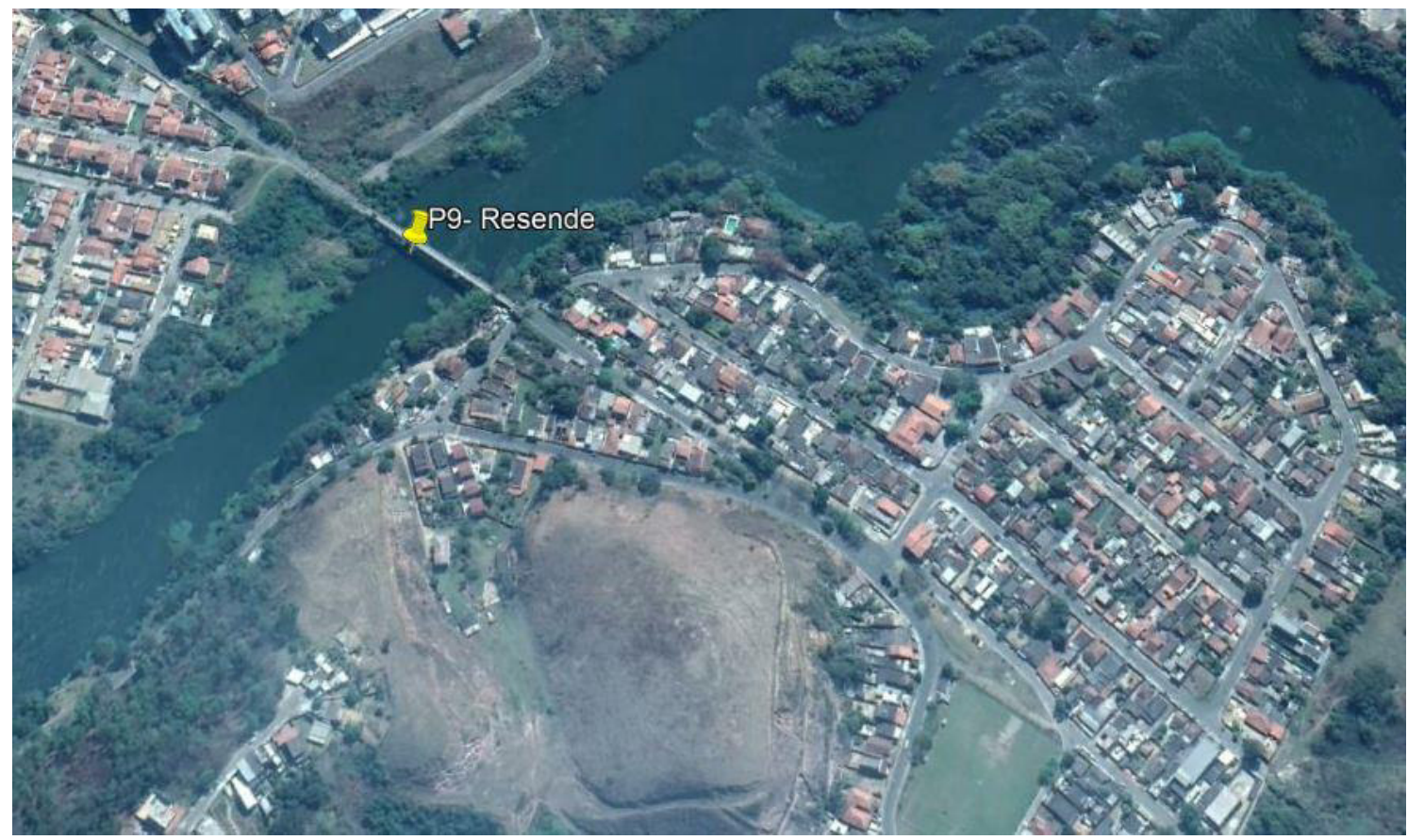

Fonte: Google Earth

Figura 14- Fotografia do ponto de amostragem 10.

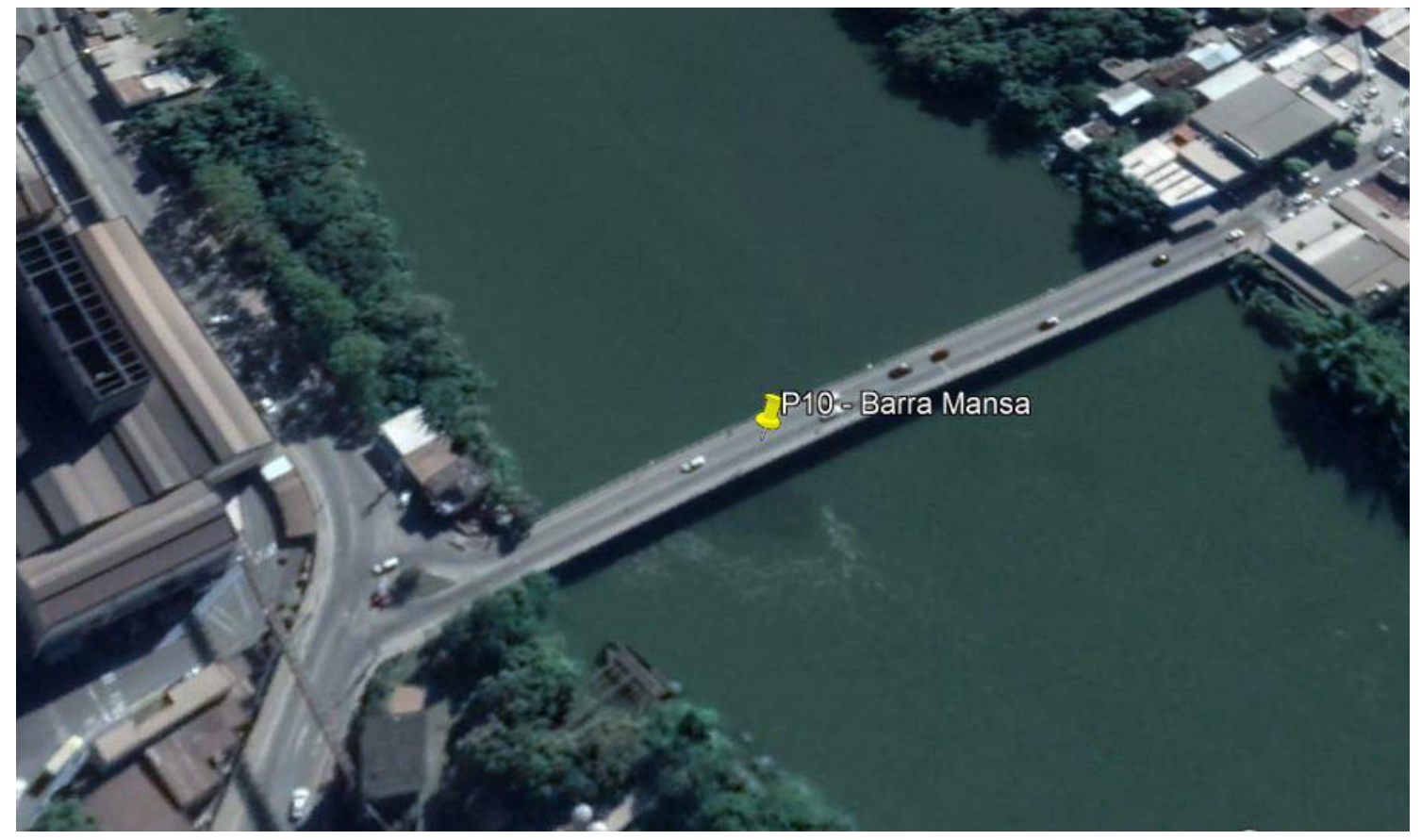

Fonte: Google Earth 
Figura 15- Fotografia do ponto de amostragem 11.

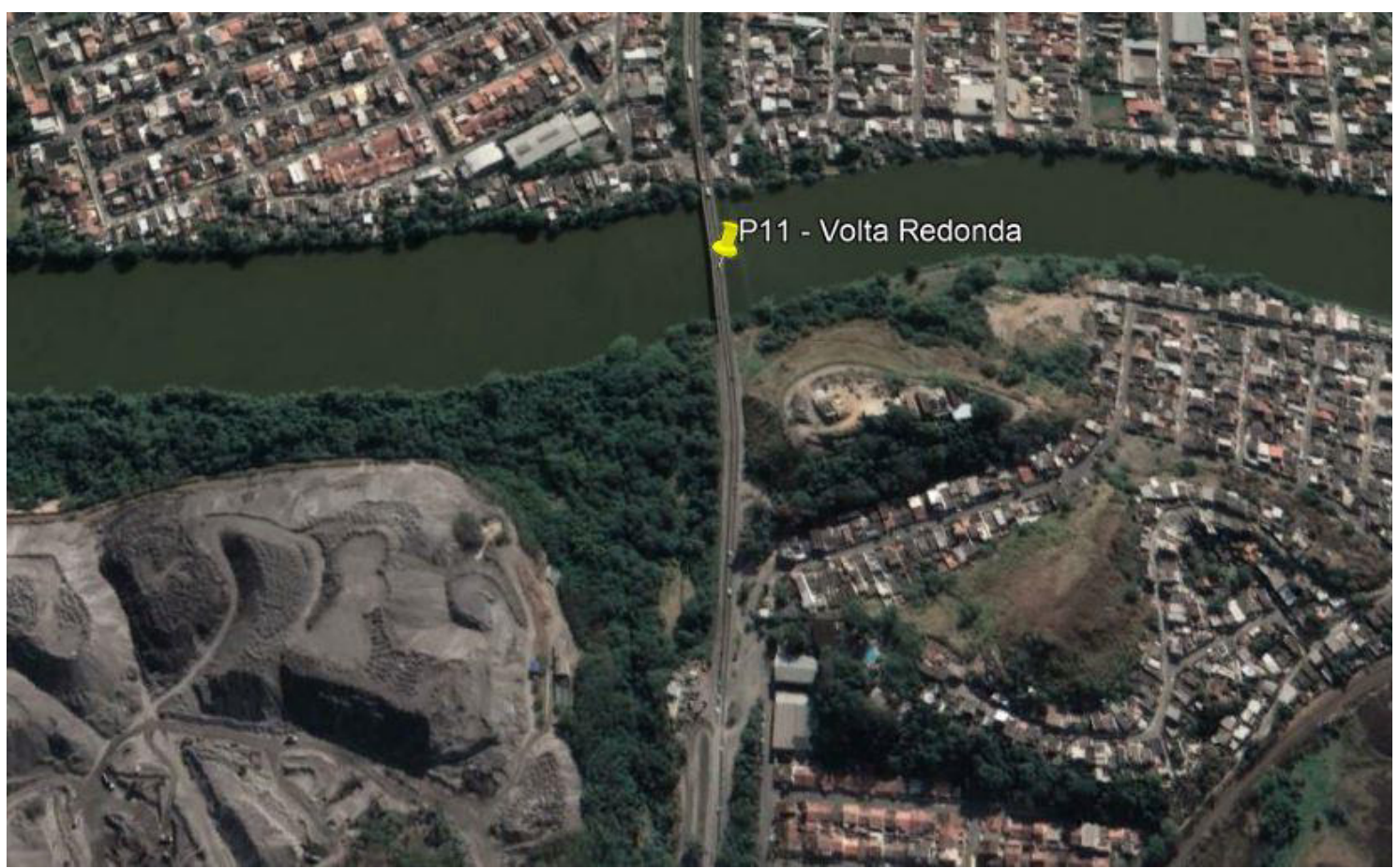

Fonte: Google Earth

\subsection{Desenvolvimento de metodologia analítica.}

$\mathrm{Na}$ etapa de desenvolvimento da metodologia analítica realizaram-se os testes para se obter o melhor cromatograma possível, sempre priorizando:

- Picos simétricos, ou seja, o mais próximo do formato gaussiano, sem prolongamentos ("caudas"), subidas graduais da linha de base antes do pico principal e sem picos duplos (“ombros”).

- Corrida que consuma o menor tempo possível.

- Boa resolução entre os picos (embora utilizando-se LC-MS/MS, a coeluição de dois picos possa ser contornada)

Além disso, durante o desenvolvimento da metodologia definiu-se a melhor proporção entre os solventes e otimizou-se parâmetros da fonte de ionização do espectrômetro de massas para que a resposta de cada analito fosse maximizada. A sequência destes testes é listada a seguir. 


\subsubsection{Determinação do íon precursor}

Este teste foi realizado para se determinar qual o íon precursor de cada composto a ser analisado. Utilizou-se formiato de amônio: metanol (50:50) como fase móvel e injetouse $10 \mu \mathrm{l}$ da solução de $1 \mathrm{ppm}$ cada analito separadamente A coluna de separação cromatográfica não é utilizada nesta etapa. A fonte de ionização foi utilizada em sua condição padrão: Voltagem de $4000 \mathrm{~V}$, temperatura de $350^{\circ} \mathrm{C}$, pressão do nebulizador de 40 psi e fluxo do gás de secagem de $9 \mathrm{~L} /$ minuto.

\subsubsection{Determinação das energias de colisão e dos íons produto.}

Foram determinadas as energias de colisão que irão gerar os fragmentos mais intensos (íons produto) de cada analito. As energias de colisão foram testadas em valores que variaram em um intervalo de 0 até $35 \mathrm{~V}$ e os fragmentos com maior intensidade de resposta foram selecionados. Para este experimento, foram injetados separadamente $5 \mu \mathrm{L}$ da solução padrão 1ppm de cada composto.

\subsubsection{Escolha da fase móvel e do melhor aditivo.}

O aditivo é adicionado a fase móvel com o objetivo de auxiliar a ionização dos analitos. Esses aditivos devem ser voláteis e presentes em baixas concentrações, com a finalidade de se evitar que apareça alguma interferência neste processo de ionização. Os aditivos testados foram hidróxido de amônio $\left(\mathrm{NH}_{4} \mathrm{OH}\right)$, formiato de amônio $\left(\mathrm{NH}_{4} \mathrm{HCOO}\right)$ e ácido acético $\left(\mathrm{H}_{3} \mathrm{CCOOH}\right)$. Os modificadores orgânicos testados foram metanol e acetonitrila.

\subsubsection{Otimização dos parâmetros da fonte de ionização (ESI).}

No modo negativo, foram testados a tensão do capilar, temperatura e fluxo do gás de secagem (nitrogênio) e a pressão do nebulizador. Foi feito um planejamento experimental de $2^{3}$. Cada parâmetro foi testado em seu valor mínimo e máximo. As combinações estão descritas na Tabela 3.

(O item 4.4.3 e o item 4.4.4, foram realizados injetando-se $10 \mu \mathrm{L}$ de uma mistura de padrões na concentração de $1 \mathrm{ppm}$. Como resposta, foi considerada a área do íon de quantificação). 
Tabela 3 - Valores dos parâmetros em cada condição testada da fonte.

\begin{tabular}{ccccc}
\hline Condição & $\begin{array}{c}\text { Tensão } \\
(\text { Volts })\end{array}$ & $\begin{array}{c}\text { Temperatura } \\
\left({ }^{\circ} \mathbf{C}\right)\end{array}$ & $\begin{array}{c}\text { Pressão } \\
\text { Nebulizador } \\
(\mathbf{p s i})\end{array}$ & $\begin{array}{c}\text { Vazão do gás } \\
(\mathbf{m L} / \mathbf{L})\end{array}$ \\
\hline 1 & 3000 & 300 & 20 & 6 \\
2 & 4000 & 300 & 20 & 13 \\
3 & 3000 & 350 & 20 & 13 \\
4 & 4000 & 350 & 20 & 6 \\
5 & 3000 & 300 & 50 & 13 \\
6 & 4000 & 300 & 50 & 6 \\
7 & 3000 & 350 & 50 & 6 \\
8 & 4000 & 350 & 50 & 13 \\
\hline
\end{tabular}

Fonte: Arquivo Pessoal

Uma outra condição denominada "condição zero" também foi testada. Esta condição contemplou o ponto médio de cada parâmetro, ou seja: Tensão: $3500 \mathrm{~V}$, Temperatura: $325^{\circ} \mathrm{C}$, Pressão do Nebulizador: 35 psi e Vazão do gás: $9 \mathrm{~mL} / \mathrm{L}$.

\subsection{Validação de metodologia analítica}

Após a definição do método - fase móvel, tempo de corrida, tempo de retenção de cada analito e condições da fonte de ionização foi necessário a comprovação que o mesmo atente alguns requisitos estatísticos. A esta etapa se dá o nome de validação, onde foram realizados os seguintes testes:

\subsubsection{Linearidade.}

Para se verificar se o método responde proporcionalmente a alterações de concentração dos analitos, foram preparadas soluções padrão dos mesmos nas seguintes concentrações: $1,10,20,30,40,50,60,70,80,90$ e $100 \mu$ g.L $\mathrm{L}^{-1}$. Cada solução padrão foi injetada 3 vezes. Após o fim das injeções, plotou-se um gráfico da resposta em função da concentração calculou-se o coeficiente de correlação para cada um dos compostos. 


\subsubsection{Limite de Quantificação e Limite de Detecção (LQ e LD).}

O limite de quantificação é a concentração mínima que um analito pode ser quantificado com precisão e exatidão significativas e o limite de identificação é a concentração mínima que um analito pode ser identificado com precisão e exatidão. Os limites de quantificação foram determinados utilizando-se parâmetros que podem ser obtidos do gráfico da linearidade. No caso, usa-se para o cálculo do Limite de Quantificação a expressão $L Q=10 \times S a \div b$ enquanto que para o Limite de Detecção utiliza-se $L D=3 \times$ $S a \div b$, onde Sa corresponde ao desvio padrão do valor do ponto onde a reta $\mathrm{a}+\mathrm{bx}$ cruza o eixo y e b é igual ao valor do coeficiente angular da referida reta.

\subsubsection{Precisão e Exatidão.}

Precisão e exatidão avaliam quanto um método é capaz de reproduzir resultados e quanto eles se aproximam do valor real de uma concentração. Neste ensaio, amostras de 500 $\mathrm{mL}$ de água ultrapura foram fortificadas em 3 níveis de concentração dos analitos: baixo (20 ng. $\left.\mathrm{L}^{-1}\right)$ médio (50 ng. $\left.\mathrm{L}^{-1}\right)$ e alto $\left(80 \mathrm{ng} . \mathrm{L}^{-1}\right)$. Cada nível foi selecionado de acordo com a curva analítica e feito em triplicata. Em seguida, cada uma das 9 amostras foi submetida ao processo descritos no item 4.8.2.

Após a análise de cada uma delas, calculou- se a recuperação de cada analito e o desvio padrão dos resultados de cada nível e o desvio padrão geral.

\subsubsection{Efeito Matriz}

Para a determinação do efeito matriz, foi feito um pool entre as amostras de água dos 11 pontos coletadas durante o verão. Foram misturados $100 \mathrm{~mL}$ de cada amostra, resultando em um volume final de $1100 \mathrm{~mL}$. Em seguida foram utilizados $500 \mathrm{~mL}$ deste mix para o procedimento de extração em fase sólida.

Após filtração, extração, eluição e secagem, a amostra resultante foi ressuspendida em uma solução padrão de trabalho contendo cada analito estudado na concentração de $1 \mathrm{mg} . \mathrm{L}^{-1}$. Então, a partir desta última amostra, foram preparadas soluções com o mesmo valor de concentração das amostras utilizadas para a determinação da linearidade $(1,10,20,30$, $\left.40,50,60,70,80,90,100 \mu \mathrm{g} . \mathrm{L}^{-1}\right)$. Injetou-se as mesmas em triplicata e traçou-se um gráfico área x concentração. A reta obtida foi comparada com reta obtida quando se utiliza somente padrões analíticos diluídos no solvente, sem contato com a matrix da amostra. 


\subsection{Plano de Amostragem}

Foram feitas coletas em cada estação climática do ano iniciando-se em janeiro de 2018 (verão), depois em abril (outono), julho (inverno), encerrando-se em outubro de 2018 (primavera), em um total de 4 coletas, totalizando um total de 44 amostras. Cada ponto foi amostrado com auxílio de um balde de plástico. Foram coletados 2 litros de amostra em cada ponto, que eram transferidos para frasco âmbar e armazenados em gelo até a volta para o laboratório.

A limpeza das vidrarias utilizadas nas campanhas de amostragem, seguiram as recomendações do guia de coleta e amostragem da CETESB (CETESB, 2011).

\subsection{Clean-up das amostras}

\subsubsection{Filtração}

Ao se chegar ao laboratório, esperava-se as amostras coletadas atingirem a temperatura ambiente para depois serem filtrada sem membrana de fibra de vidro de porosidade $1,2 \mathrm{~mm}$ com o auxílio de uma bomba de vácuo, para a retirada de sólidos em suspensão.

\subsubsection{Extração em Fase sólida}

Após a etapa de filtração, $500 \mathrm{~mL}$ de cada amostra filtrada foram percolados através de cartucho Oasis HLB, com ajuda de bomba peristáltica em um fluxo de em uma vazão programada de $7 \mathrm{~mL} \cdot \mathrm{min}^{-1}$ para a extração dos analitos de interesse. O sistema para a extração foi o mesmo desenvolvido por Sodré e colaboradores (SODRÉ; ANTONIO; FIGUEIREDO, 2010). Este sistema pode ser visto na Figura 16. 
Figura 16- Sistema de Extração em Fase sólida para concentração das amostras.

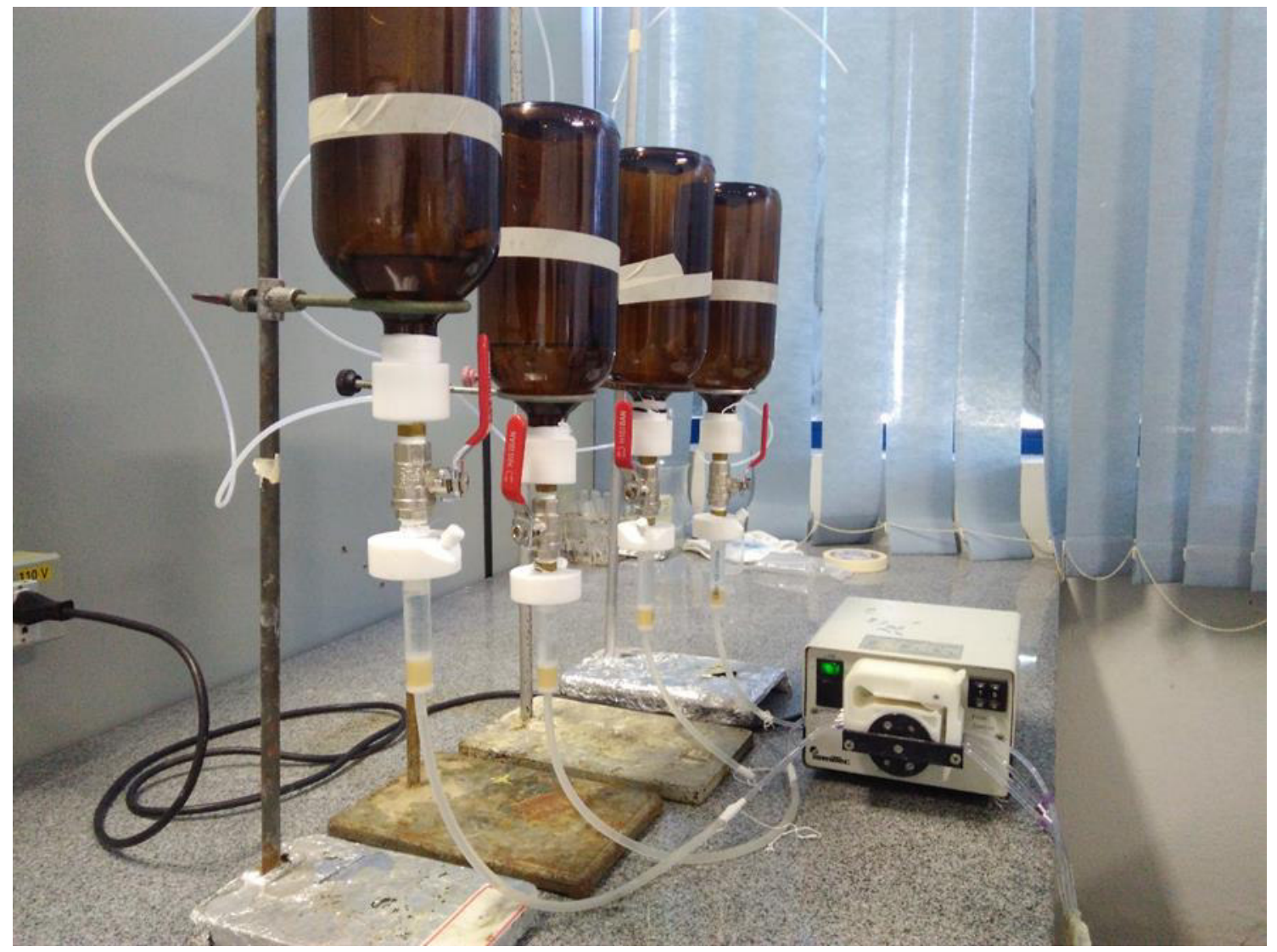

Fonte: Arquivo Pessoal

Os cartuchos foram previamente ativados com $4 \mathrm{~mL}$ de metanol e $4 \mathrm{~mL}$ de água ultrapura. Após a extração, os cartuchos foram secos a vácuo.

A eluição destes analitos foi realizada com auxílio de um manifold, adicionando-se $4 \mathrm{~mL}$ de metanol seguido de $4 \mathrm{~mL}$ de acetonitrila que foram coletados em tubos de ensaio. Após o processo de eluição ser concluído, as amostras resultantes foram secadas completamente com nitrogênio e depois ressuspendidas em solução água: metanol (proporção de 70:30) para a análise cromatográfica. 


\section{RESULTADOS E DISCUSSÕES}

\subsection{Fármacos}

Os fármacos estudados estão representados na Tabela 4, juntamente com algumas propriedades que serão importantes na discussão de alguns tópicos no decorrer do trabalho.

Tabela 4- Os fármacos estudados e algumas de suas propriedades físico químicas.

Composto

Fonte: Arquivo Pessoal

\subsubsection{Desenvolvimento de metodologia analítica}

\subsubsection{Determinação dos íons precursores, das energias de colisão e dos íons produto}

Como esperado, os íons precursores determinados no modo positivo apresentaram a relação massa /carga com uma unidade a mais que a massa molar do composto (casos de cafeína e paracetamol) enquanto que aqueles analisados no modo negativo apresentaram relação massa/carga com uma unidade a menos que massa molar do composto (diclofenaco, ibuprofeno e paracetamol). Somente os íons determinados nesta etapa irão sofrer 
fragmentação que resultará na formação dos íons produtos, que serão essenciais para a quantificação e a confirmação da identidade de cada analito. A energia necessária para a formação destes íons é dependente de cada analito. Os íons produtos de quantificação (aqueles com resposta de maior intensidade) e os íons de confirmação (fragmentos com a segunda e a terceira resposta de maior intensidade). A tabela 5 sumariza os íons precursores formados, seus respectivos íons produtos (de quantificação e confirmação) e a energia de colisão necessária para a formação de cada um.

Tabela 5- Íons precursores, Íons produtos de quantificação (Íon Quant.) e Íons produto de confirmação (Íon Conf.) e a energia de colisão de cada analito.

\begin{tabular}{|c|c|c|c|c|c|c|c|c|}
\hline Composto & $\begin{array}{l}\text { Modo } \\
\text { da } \\
\text { Fonte }\end{array}$ & $\begin{array}{c}\text { Íon } \\
\text { Precursor } \\
(\mathbf{m} / \mathbf{z})\end{array}$ & $\begin{array}{l}\text { Ílon } \\
\text { Quant. } \\
\text { (m/z) }\end{array}$ & $\begin{array}{c}\text { Energia } \\
\text { de } \\
\text { Colisão } \\
(\mathrm{eV})\end{array}$ & $\begin{array}{l}\text { Íon } \\
\text { Conf. } \\
(\mathbf{m} / \mathbf{z})\end{array}$ & $\begin{array}{c}\text { Energia } \\
\text { de } \\
\text { Colisão } \\
(\mathrm{eV})\end{array}$ & $\begin{array}{l}\text { Íon } \\
\text { Conf. } \\
(\mathbf{m} / \mathbf{z})\end{array}$ & $\begin{array}{c}\text { Energia } \\
\text { de } \\
\text { Colisão } \\
(\mathrm{eV})\end{array}$ \\
\hline Cafeína & + & 195,2 & 138,1 & 15 & 69,1 & 20 & 110,3 & 20 \\
\hline Diclofenaco & - & 294,1 & 251,1 & 0 & 178,1 & 10 & 34,9 & 5 \\
\hline Ibuprofeno & - & 205,1 & 161,0 & 0 & n.e. & n.e. & n.e. & n.e. \\
\hline Naproxeno & - & 229,1 & 169,1 & 20 & 185,0 & 0 & n.e. & n.e. \\
\hline Paracetamol & + & 152,2 & 110,1 & 15 & 65,2 & 30 & 93,1 & 20 \\
\hline
\end{tabular}

Fonte Arquivo Pessoal.

ne: não encontrado.

Cafeína, diclofenaco e paracetamol apresentaram 3 fragmentos, sendo que o de maior intensidade foi escolhido como o fragmento de quantificação, enquanto os outros serão os fragmentos de confirmação. O naproxeno apresentou dois fragmentos (um de quantificação e outro de confirmação) enquanto o Ibuprofeno apresentou apenas um fragmento, que será usado para a quantificação.

- Composição da fase móvel para os compostos analisados no modo negativo.

O método desenvolvido por Boleda e colaboradores (BOLEDA; GALCERAN; VENTURA, 2013) serviu como ponto de partida para o desenvolvimento da metodologia para ibuprofeno, naproxeno e diclofenaco. O referido método utiliza acetonitrila e ácido acético como modificador orgânico e aditivo respectivamente, e de fato esta alternativa se 
apresentou como a melhor combinação para estes analitos. Foram testadas combinações com outro modificador orgânico (metanol) e dois outros aditivos (hidróxido de amônio e ácido fórmico), mas que não a presentaram boas respostas (formato do pico, sensibilidade baixa e eluição no tempo morto). Assim, utilizou-se uma fase móvel com composição ácido acético $0,04 \%$ e acetonitrila. O gradiente utilizado no método para é mostrado na Tabela 6 .

Tabela 6- Gradiente utilizado para a eluição de ibuprofeno, naproxeno e diclofenaco tendo Ácido Acético 0,04\%: Acetonitrila como fase móvel.

\begin{tabular}{ccc}
\hline Tempo (minutos) & Ácido Acético (\%) & Acetonitrila (\%) \\
\hline 0 & 95 & 5 \\
6 & 70 & 30 \\
9 & 70 & 30 \\
10 & 95 & 5 \\
\hline
\end{tabular}

Fonte: Arquivo Pessoal

4.1.1.2 Otimização dos parâmetros da fonte de ionização (ESI).

Após a definição da fase móvel e do gradiente a ser aplicado, definiu-se a a melhor condição da fonte de ionização, segundo item 4.4.4.

A Tabela 7 mostra o valor das áreas de cada composto em função da condição da fonte aplicada.

Tabela 7- Área do pico de cada composto em função das condições da fonte de ionização

\begin{tabular}{cccc}
\hline Condição* $^{*}$ & Diclofenaco & Ibuprofeno & Naproxeno \\
\hline 0 & 33667 & 6248 & 50453 \\
1 & 7119 & 2088 & 23261 \\
2 & 22917 & 5919 & 48686 \\
3 & 29730 & 4543 & 23132 \\
4 & 23613 & 5004 & 47787 \\
5 & 34010 & 7368 & 57366 \\
6 & 17944 & 4700 & 55064 \\
7 & 22480 & 4815 & 39577 \\
8 & 41331 & 5728 & 30133 \\
\hline
\end{tabular}

Fonte: Arquivo pessoal

* Descritas na Tabela 3. 
A Figura 17 representa graficamente os resultados obtidos para as condições de 0 à 8 da Tabela 7.

Figura 17- Representação gráfica dos valores das áreas em função das condições da fonte.

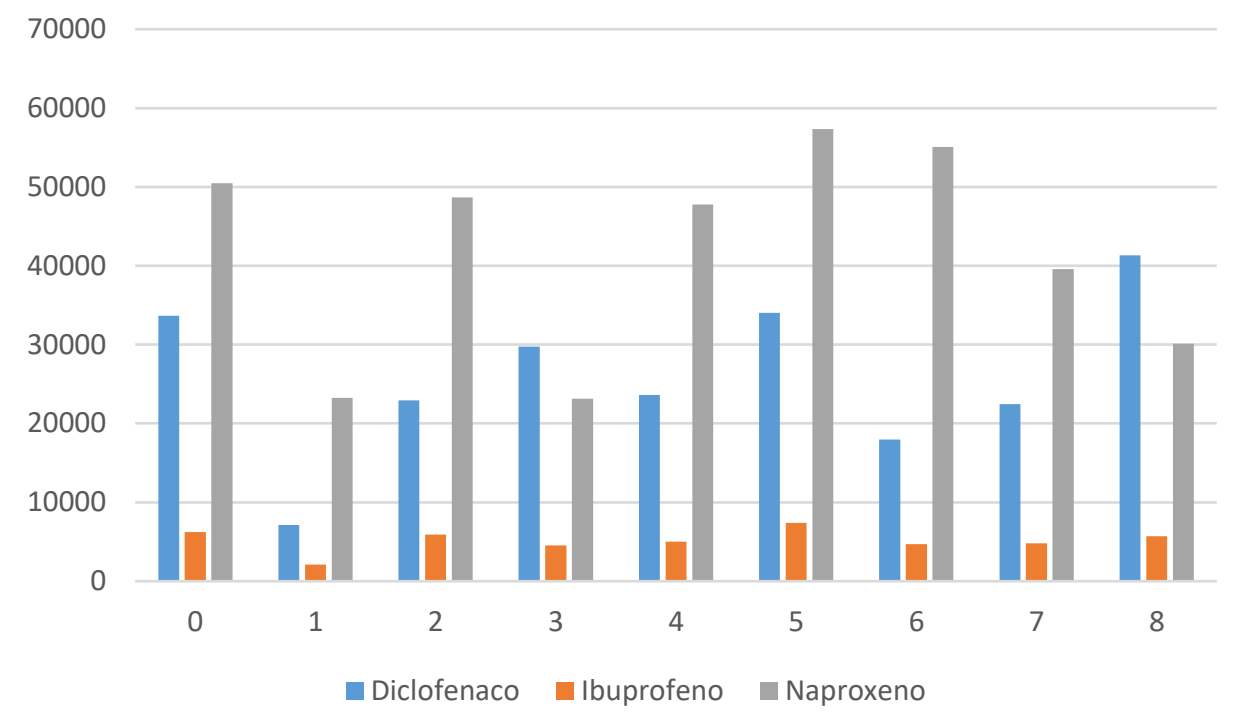

Fonte: Arquivo Pessoal.

A condição 5 apresentou intensidade acima dos demais e por este motivo foi a escolhida para ser a condição da fonte de ionização, para o seguimento dos experimentos. A Figura 18 (TIC) e a Figura 19 (fragmentos) apresentam os cromatogramas obtidos nesta condição.

Figura 18- Cromatogramas de corrente iônica total (TIC) da separação de ibuprofeno, diclofenaco e naproxeno eluídos na condição 5 (ver tabela 3 ) do teste de otimização das condições da fonte de ionização utilizando ácido acético $0,04 \%$ : acetonitrila como fase móvel.

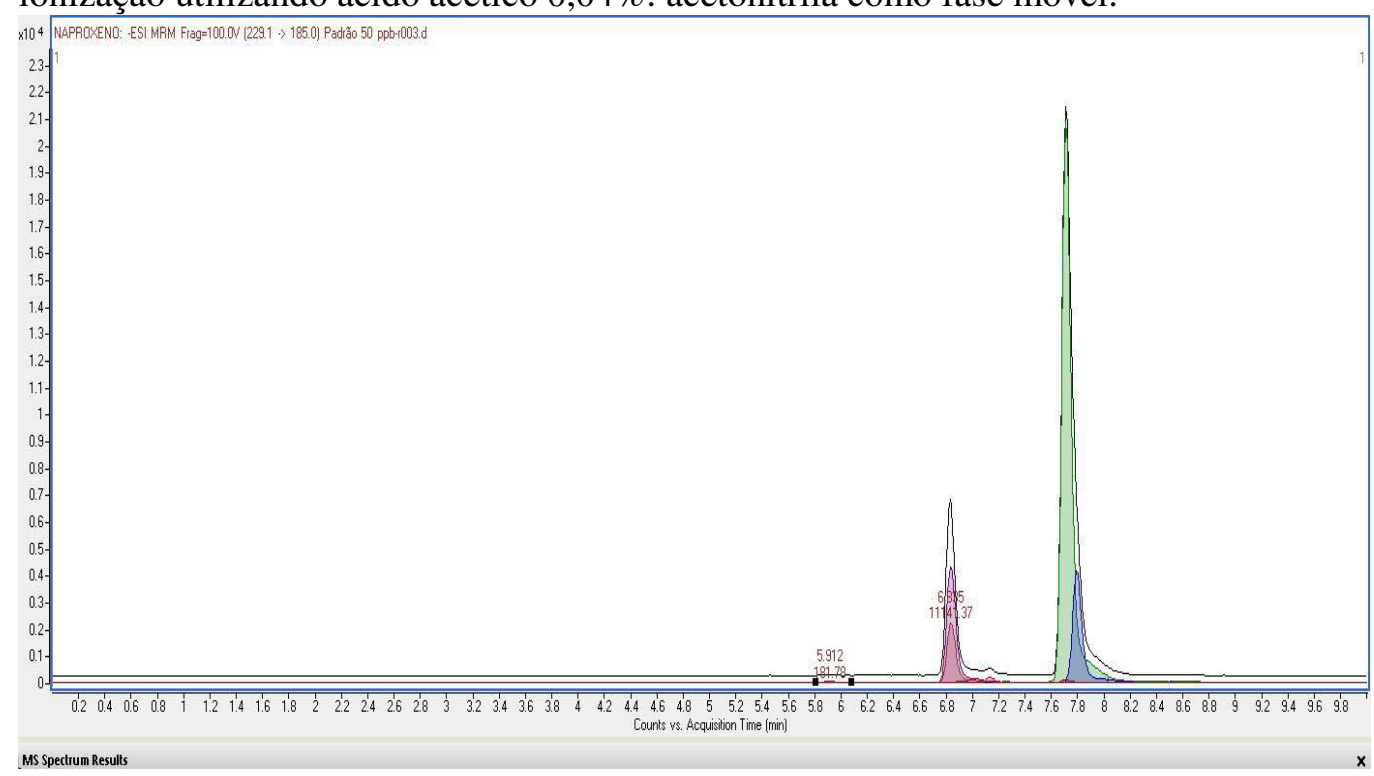

Fonte: Arquivo Pessoal. 
Figura 19- Cromatogramas de cada fragmento (MRM) da separação de ibuprofeno, diclofenaco e naproxeno eluídos na condição 5 (ver tabela 3 ) do teste de otimização das condições da fonte de ionização utilizando ácido acético $0,04 \%$ : acetonitrila como fase móvel

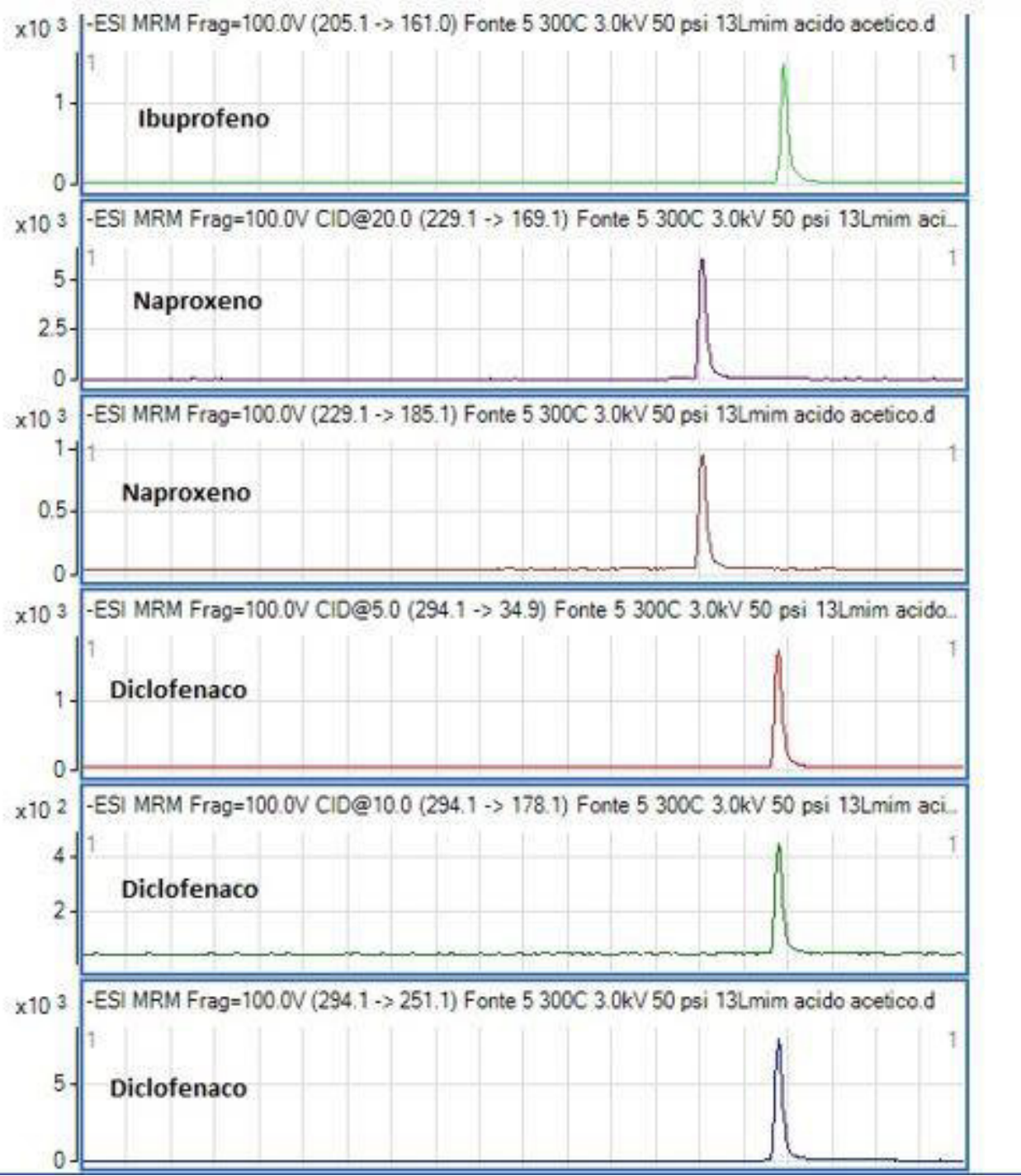

Fonte: Arquivo Pessoal.

Apesar do ibuprofeno (transição 205,1 para 161,0) e diclofenaco (fragmentos com transições de 294,1 para 178,1, 294,1 para 34,9 e 294,1 para 251,1) estarem coeluindo, (tempo de retenção de 8 minutos) isto não representa problemas quanto a quantificação, já que os fragmentos poderão ser mesurados separadamente no detector. O naproxeno (fragmentos de transição 229,1 para 165,1 e 229,1 para 185,1) apresentou tempo de retenção de 6,8 minutos. 
4.1.1.3 Composição da fase móvel para os compostos analisados no modo positivo

Para os analitos do modo positivo (paracetamol e cafeína), a composição da fase móvel foi hidróxido de amônio $0,01 \%$ e metanol. Esta foi a única composição que não resultou em picos duplos para o paracetamol. A corrida cromatográfica foi feita em modo isocrático na proporção 80 (Hidróxido de amônio 0,01\%): 20 (metanol).

- Otimização dos parâmetros da fonte de ionização (ESI).

Após a definição da composição da fase móvel, definiu-se a a melhor condição da fonte de ionização, segundo item 4.4.4. A Tabela 8 mostra o valor das áreas de cada composto em função da condição da fonte aplicada.

Tabela 8- Área de cada composto em função das condições da fonte de ionização.

\begin{tabular}{cll}
\hline Condição & Paracetamol & Cafeína \\
\hline 0 & 867561 & 153216 \\
1 & 561743 & 125483 \\
2 & 531221 & 95887 \\
3 & 799637 & 46497 \\
4 & 919113 & 171687 \\
5 & 904884 & 145641 \\
6 & 810977 & 132871 \\
7 & 736295 & 148157 \\
8 & 793348 & 125728 \\
\hline
\end{tabular}

Fonte: Arquivo Pessoal.

A Figura 20- Representação gráfica dos valores das áreas em função das condições da fonte representa graficamente estes valores em função da condição da fonte. 
Figura 20- Representação gráfica dos valores das áreas em função das condições da fonte.

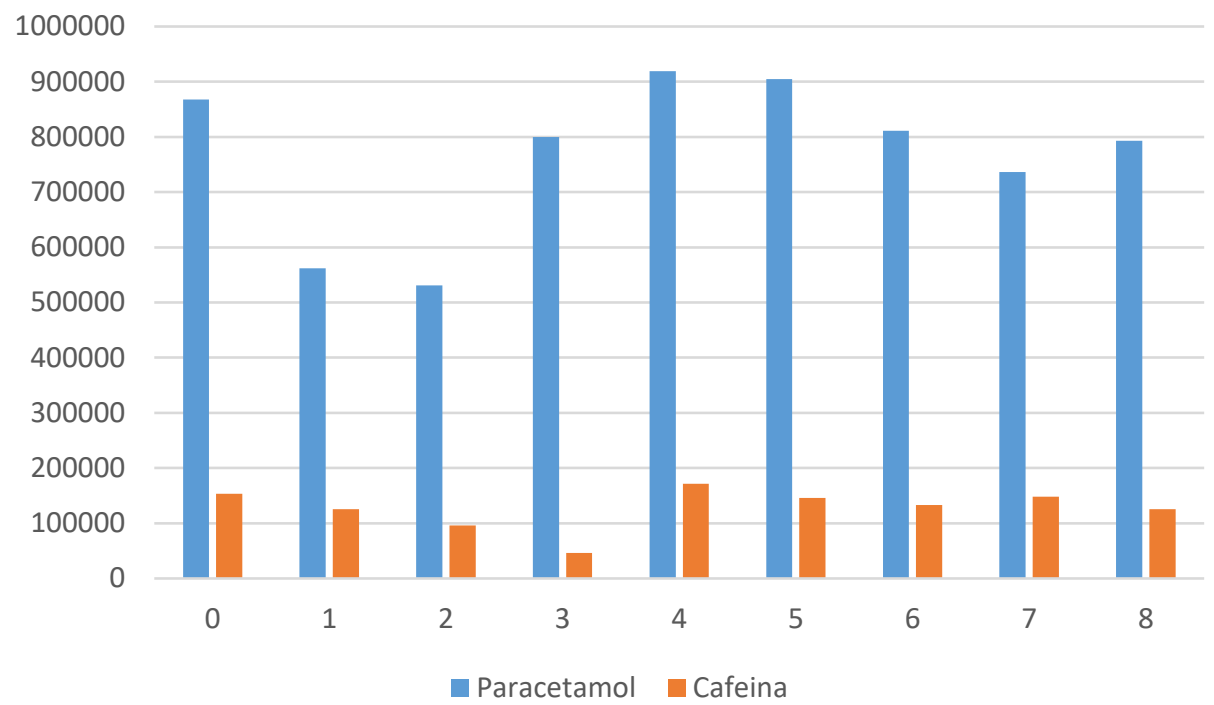

Fonte: Arquivo Pessoal.

A condição 4 apresentou a melhores respostas e por isso foi escolhida para o prosseguimento dos experimentos com cafeína e paracetamol. A Figura 21 (TIC) e a

Figura 22(fragmentos) apresentam os cromatogramas obtidos nestas condições.

Figura 21- Cromatogramas de corrente iônica total (TIC) da separação de cafeína e paracetamol eluídos na condição 4 (ver tabela 3 ) do teste de otimização das condições da fonte de ionização utilizando metanol: hidróxido de amônio $0,01 \%$ como fase móvel.

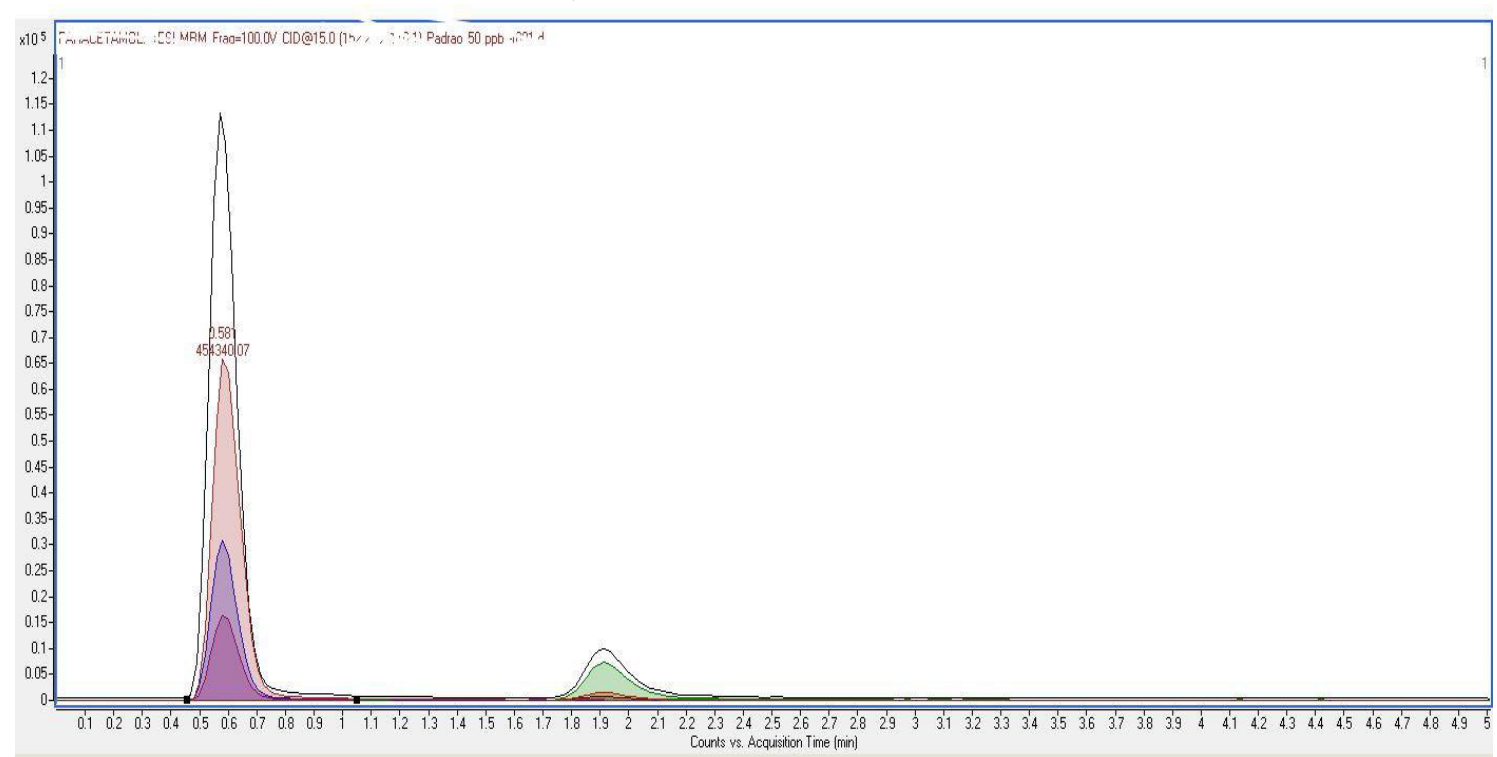

Fonte: Arquivo Pessoal. 
Figura 22- Cromatogramas de cada fragmento (MRM) da separação de cafeína , e paracetamol eluídos na condição 4 (ver tabela 3) do teste de otimização das condições da fonte de ionização utilizando hidróxido de amônio 0,01\%: metanol como fase móvel.

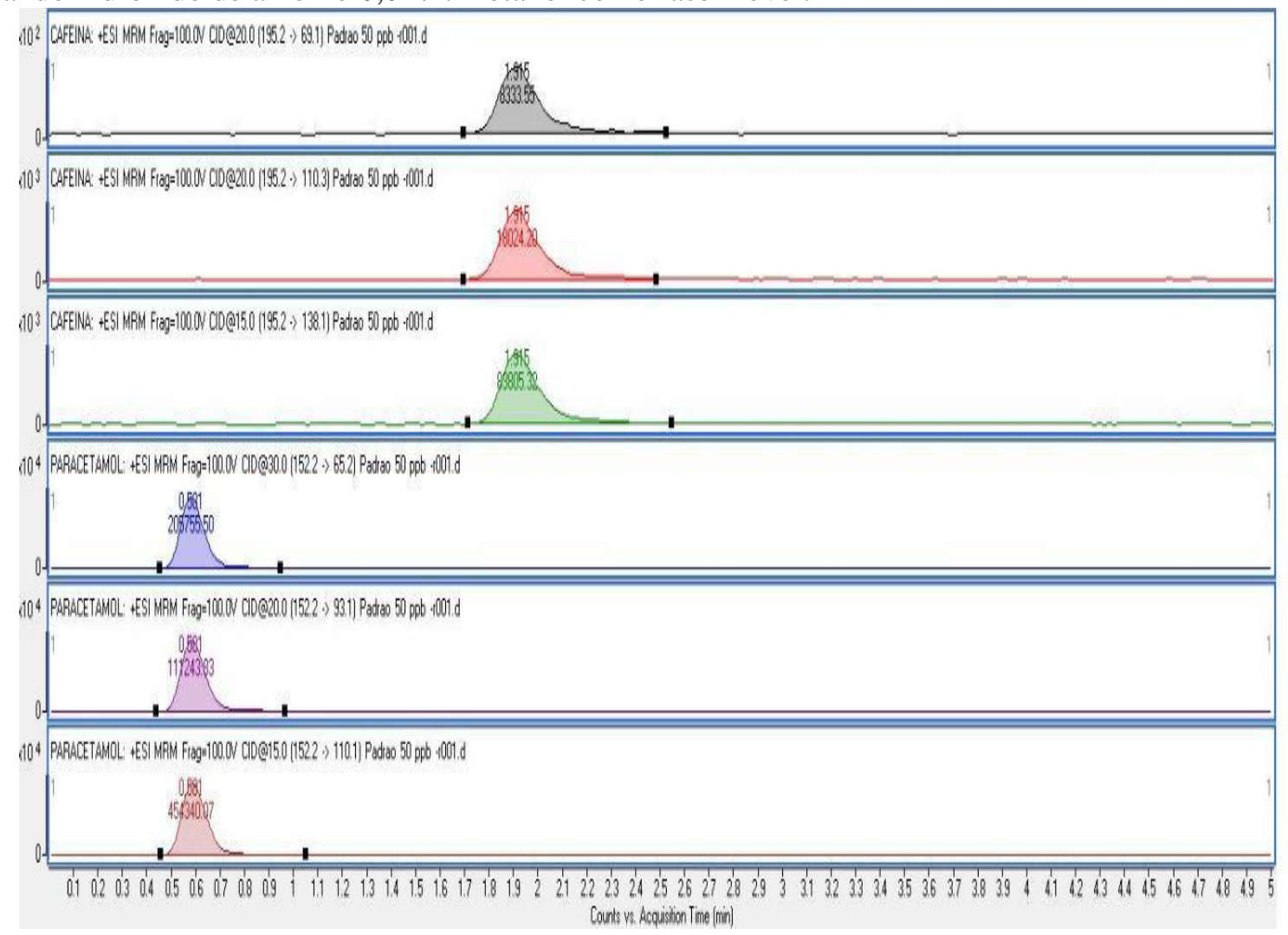

Fonte: Arquivo Pessoal.

Portanto, as condições da fonte de ionização escolhidas para serem validadas no caso dos fármacos foram:

- Diclofenaco, ibuprofeno e naproxeno: Voltagem de $3000 \mathrm{~V}$, temperatura de $300^{\circ} \mathrm{C}$, pressão no nebulizador de 50 psi e vazão de gás igual a 9 L.min ${ }^{-1}$.

- Cafeína e paracetamol: voltagem de $4000 \mathrm{~V}$, temperatura de $350^{\circ} \mathrm{C}$, pressão no nebulizador de 20 psi e vazão de gás igual a 6 L. min $^{-1}$.

\subsubsection{Validação da metodologia analítica}

\subsubsection{Linearidade}

A resposta do detector mostrou-se linear para os 5 compostos, porém em diferentes faixas de trabalho Diclofenaco, ibuprofeno e naproxeno mostram-se lineares no intervalo de $10-100 \mu \mathrm{g} \cdot \mathrm{L}^{-1}$, pois não apresentaram resposta para a concentração de $1 \mu \mathrm{g} . \mathrm{L}^{-1}$. O paracetamol apresentou-se linear para a faixa de $1-100 \mu \mathrm{g} . \mathrm{L}^{-1}$, enquanto que para a cafeína, 
houve-se a necessidade de aumentar a esta faixa de concentração até $500 \mu \mathrm{g} . \mathrm{L}^{-1}$, pois a concentração encontrada em algumas amostras superou os $100 \mu \mathrm{g} . \mathrm{L}^{-1}$. O coeficiente de determinação das retas ajustadas $\left(\mathrm{R}^{2}\right)$ apresentou valores maiores que 0,99. A seguir, as figuras de 23 até 27, demostram graficamente o o comportamento linear dos analítos.

Figura 23- Gráfico da variação das áreas em função concentração de paracetamol.

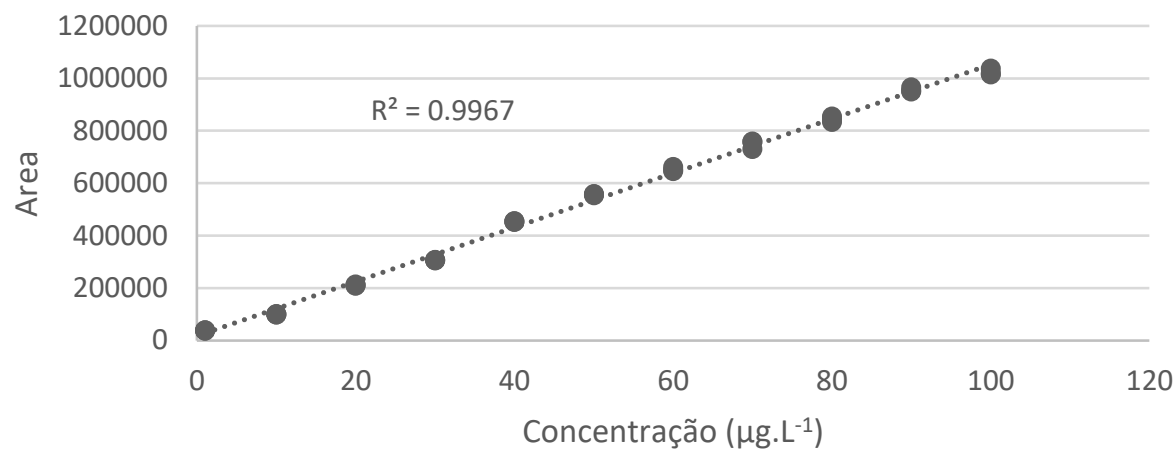

Fonte: Arquivo Pessoal

Figura 24- Gráfico da variação das áreas em função concentração de cafeína.

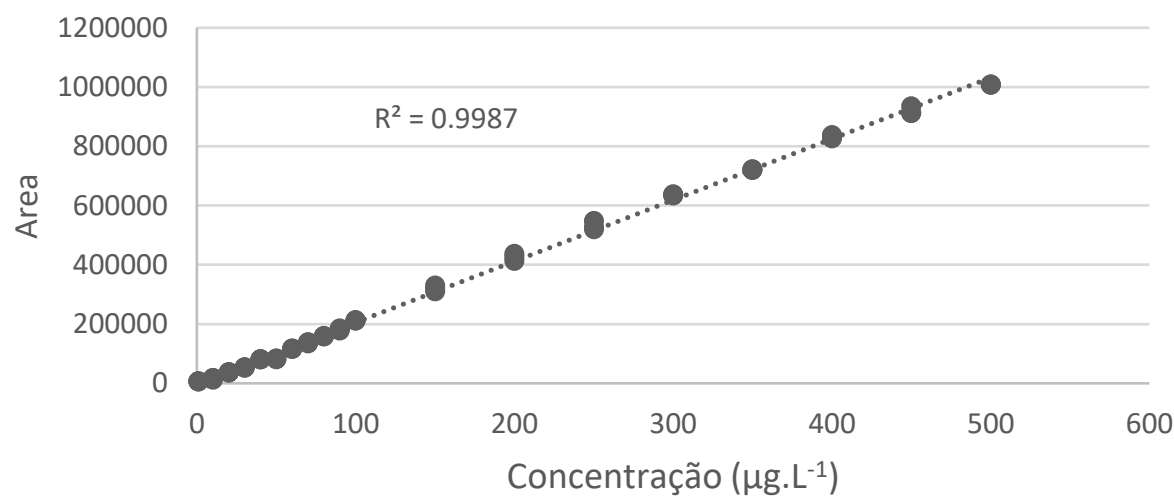

Fonte: Arquivo Pessoal.

Figura 25- Gráfico da variação da área em função concentração de diclofenaco.

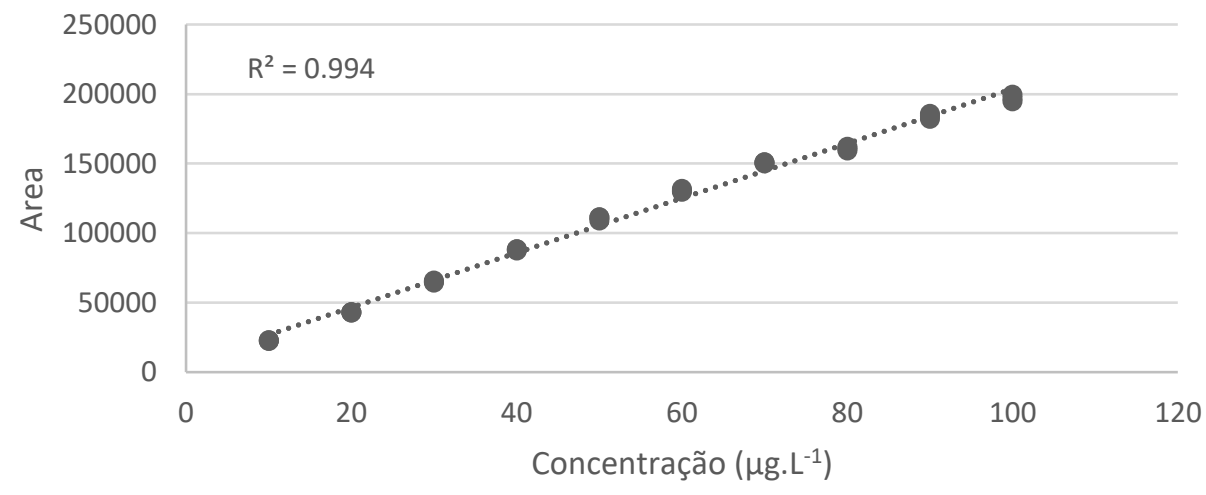

Fonte: Arquivo Pessoal. 
Figura 26- Gráfico da variação da área em função concentração de Naproxeno.

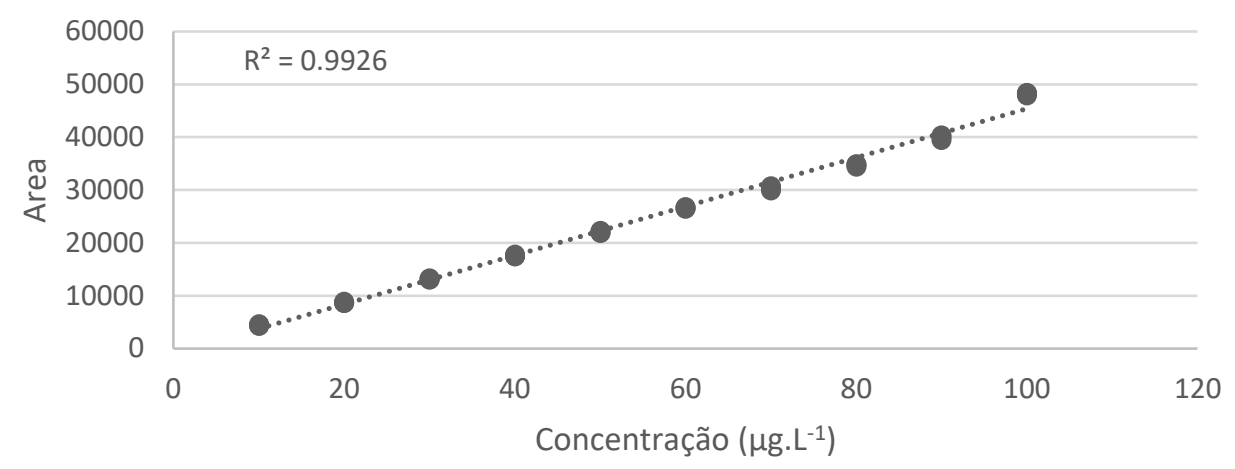

Fonte: Arquivo Pessoal

Figura 27- Gráfico da variação da área em função concentração de Ibuprofeno.

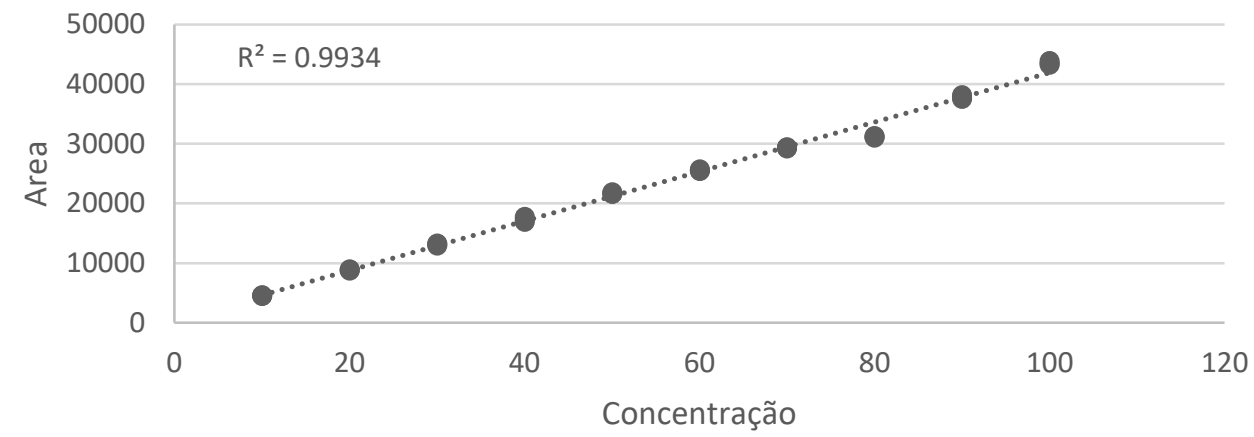

Fonte: Arquivo Pessoal

4.1.2.2 Limite de detecção (LD) e Limite de quantificação (LQ)

O limite de detecção e o limite de quantificação foram calculados de acordo com as expressões: $L Q=10 \times S a \div b$ e $L D=3 \times S a \div b$, descritas no item 4.5.2. A Tabela 9 mostra os valores utilizados para o cálculo e os respectivos valores de LQ e LD para os analitos.

Tabela 9- Cálculo dos limites de quantificação do método (LQm), instrumental (LQi) e limites de detecção do método (LDm) e instrumental (LDi).

\begin{tabular}{ccccccc}
\hline Analito & Sa & $\mathbf{b}$ & $\begin{array}{c}\text { LQm } \\
\left(\mathbf{n g . L} \mathbf{-}^{-1}\right)\end{array}$ & $\begin{array}{c}\mathbf{L D m} \\
\left(\mathbf{n g . L ^ { - 1 }}\right)\end{array}$ & $\begin{array}{c}\text { LQi } \\
\left(\boldsymbol{\mu g . L ^ { - 1 }}\right)\end{array}$ & $\begin{array}{c}\text { LDi } \\
\left(\boldsymbol{\mu g . L ^ { - 1 }}\right)\end{array}$ \\
\hline Cafeina & 2312,9 & 2065,9 & 11,2 & 3,4 & 11,2 & 3,4 \\
Diclofenaco & 1792,5 & 1965,1 & 9,7 & 2,1 & 9,7 & 2,1 \\
Ibuprofeno & 396,7 & 414,6 & 9,6 & 2,9 & 9,6 & 2,9 \\
Naproxeno & 468,8 & 462,5 & 10,1 & 3,0 & 10,1 & 3,0 \\
Paracetamol & 6285,5 & 10349,1 & 6,1 & 1,8 & 6,1 & 1,8 \\
\hline
\end{tabular}

Fonte: Arquivo Pessoal. Sa: erro padrão do ponto de intersecção da reta da linearidade no eixo Y. b= coeficiente angular da reta da linearidade. 


\subsubsection{Extração Por fase Sólida:}

Quando o procedimento da extração por fase sólida foi realizado somente fortificandose $500 \mathrm{~mL}$ água ultrapura com os analitos para uma concentração final de $50 \mathrm{ng} / \mathrm{L}$ de cada um deles e utilizando-se os cartuchos HLB OASIS, sem ajuste prévio de $\mathrm{pH}$, a taxa de recuperação apresentou valores de recuperação superiores a 80\% para paracetamol e cafeína, porém inferiores a $50 \%$ para o diclofenaco, ibuprofeno e o naproxeno. Posteriormente, outros dois testes foram repetidos com este mesmo cartucho, porém ajustando-se o $\mathrm{pH}$ da água ultrapura para os valores de 3,0 e 7,0, com ácido fórmico 10\% e hidróxido de sódio $0,1 \mathrm{M}$ respectivamente, porem a taxa de recuperação continuou inferior a $50 \%$.

Desta maneira, testou-se a estratégia utilizada por GAFFNEY e colaboradores (GAFFNEY et al., 2014) de se utilizar EDTA na etapa de extração das amostras. Ajustou-se a concentração final de EDTA na amostra de $500 \mathrm{~mL}$ de água ultrapura para o valor de 5 mg.mL $L^{-1}$ e realizou-se a fortificação com os analitos. Os resultados das taxas de recuperação (\%) de cada analito em cada um destes experimentos são apresentados na Tabela10.

Tabela 10- Taxa de recuperação $(\%)$ dos analitos em $500 \mathrm{~mL}$ de água ultrapura fortificada na concentração de 50 ng. $\mathrm{L}^{-1}$.

\begin{tabular}{ccccc}
\hline Analito & $\begin{array}{c}\text { Sem ajuste de } \\
\mathbf{p H}\end{array}$ & $\begin{array}{c}\text { pH ajustado } \\
\text { para 3,0 }\end{array}$ & $\begin{array}{c}\text { pH ajustado } \\
\text { para 7,0 }\end{array}$ & $\begin{array}{c}\text { EDTA } \\
(\mathbf{5 m g . L}\end{array}$ \\
\hline Cafeína & $84 \%$ & $<10 \%$ & $66 \%$ & $78 \%$ \\
Diclofenaco & $<10 \%$ & $<10 \%$ & $37 \%$ & $25 \%$ \\
Ibuprofeno & $26 \%$ & $39 \%$ & $47 \%$ & $87 \%$ \\
Naproxeno & $13 \%$ & $22 \%$ & $30 \%$ & $36 \%$ \\
Paracetamol & $87 \%$ & $31 \%$ & $62 \%$ & $69 \%$ \\
\hline
\end{tabular}

Fonte: Arquivo Pessoal.

Utilizando-se EDTA ocorreu uma melhora significativa na recuperação do ibuprofeno e, porém, o naproxeno e o diclofenaco continuaram com recuperações baixas. Em muitos trabalhos com estes analitos não fazem a utilização de nenhum tipo de ajuste prévio na amostra (BOLEDA; GALCERAN; VENTURA, 2013; GRACIA-LOR; SANCHO; HERNÁNDEZ, 2011; K'OREJE et al., 2016; VANDERFORD et al., 2003), mesmo utilizando o mesmo tipo de cartucho. (HLB - OASIS). 
Como o objetivo é chegar em uma taxa de recuperação mínima de 50\%, optou-se por testar um outro tipo de cartucho. O escolhido foi o Strata -XA, um cartucho de troca aniônica, pois ibuprofeno, diclofenaco e naproxeno são ácido fracos, possuindo o grupamento carboxila $(\mathrm{COOH})$ e todos possuem pKa em torno de 4 (ver Tabela 4$)$, logo, no pH da amostra (em torno de 7,0), eles sempre estarão em sua forma ionizada.

No caso de um cartucho de troca aniônica, as diferenças no procedimento são a eluição, que é feita utilizando-se ácido fórmico em concentrações de 5 a $10 \%$ no solvente uma etapa de lavagem com acetato de amônia pH 7,0 antes da eluição. Utilizando-se cartucho Strata-XA, as recuperações médias do ibuprofeno, naproxeno e diclofenaco tiveram um valor acima de 50\%, porém cafeína e paracetamol apresentaram recuperações baixas, o que era esperado pelas características químicas de ambos.

Deste modo, optou-se por fazer duas extrações. Uma utilizando cartuchos HLB OASIS e outra utilizando-se Strata-XA. A Tabela 11 mostra os valores da recuperação média de cada analito com o cartucho Strata XA. Estes dois procedimentos foram utilizados para fazer a precisão e a exatidão do método

Tabela 11- Recuperação dos analitos quando se utiliza cartucho de troca aniônica Strata XA.

\begin{tabular}{cc}
\hline Analito & Recuperação \\
\cline { 2 - 3 } Cafeina & $33 \%$ \\
Diclofenaco & $58 \%$ \\
Ibuprofeno & $81 \%$ \\
Naproxeno & $66 \%$ \\
Paracetamol & $41 \%$ \\
\hline
\end{tabular}

Fonte: Arquivo Pessoal

\subsubsection{Precisão e Exatidão}

Nesta etapa a repetitividade do método foi avaliada bem como sua capacidade de gerar resultados próximos ao real. Foram preparadas amostras dos analitos em 3 níveis de concentração. Além da recuperação, foram calculados os desvios padrões relativos das recuperações de cada nível e o desvio padrão geral entre as 9 preparações. Aqui não houve um critério para aceitação ou reprovação, mas sim uma verificação da variância do nosso sistema. 
A Tabela 12 mostra o resultado médio das recuperações de cada nível. Entre parênteses o desvio padrão relativo de cada nível. A última coluna (DPR\%) representa o desvio padrão relativo entre as 9 recuperações de cada analito.

Tabela 12- Recuperações médias (\%) para cada nível de concentração e a recuperação média (\%) e o desvio padrão relativo entre as 9 recuperações. Entre parênteses o desvio padrão relativo de cada nível.

\begin{tabular}{cccccc}
\hline Analito & Baixo & Médio & Alto & $\begin{array}{c}\text { Recuperação } \\
\text { média } \\
\text { (9 amostras) }\end{array}$ & $\begin{array}{c}\text { DPR\% } \\
\text { 9mostras }\end{array}$ \\
\hline Cafeína & $66,0(8,2)$ & $76,3(5,9)$ & $82,0(5,6)$ & 75,8 & 10,9 \\
Diclofenaco & $42,0(14,3)$ & $50,3(14,6)$ & $50,3(12,0)$ & 47.5 & 15,8 \\
Ibuprofeno & $52,3(9,7)$ & $55,3(8,1)$ & $72,3(7,0)$ & 60.5 & 18,6 \\
Naproxeno & $50,7(6,9)$ & $51,3(8,8)$ & $59,7(11,2)$ & 54.3 & 12,0 \\
Paracetamol & $65,7(6,2)$ & $74,4(2,7)$ & $77,0(6,0)$ & 73.1 & 7,9 \\
\hline
\end{tabular}

Fonte: Arquivo próprio.

Obs: para a cafeína, as concentrações de cada nível foram $50 \mu \mathrm{g} . \mathrm{L}^{-1}, 200 \mu \mathrm{g} . \mathrm{L}^{-1}$ e $400 \mu \mathrm{g} . \mathrm{L}^{-1}$. Para os demais analitos, 20,50 e $80 \mu \mathrm{g} . \mathrm{L}^{-1}$.

Pode-se concluir que os níveis médios e altos das concentrações apresentam uma recuperação maior pois conforme se aumenta a concentração, os erros instrumentais envolvidos no processo são atenuados. O diclofenaco apresentou a menor recuperação média, sendo, portanto, o analito ao qual o método se apresentou menos exato, enquanto o ibuprofeno apresentou o maior desvio padrão relativo médio, sendo o que apresenta menor repetitividade.

\subsubsection{Efeito Matriz}

O efeito matriz foi calculado em termos da sensibilidade da curva com adição de padrão na amostra e uma curva no solvente. $\mathrm{O}$ resultado foi indicado em porcentagem da alteração da sensibilidade da curva no solvente em relação à curva na matriz com a adição de padrão. O valor negativo indica que a matriz causa supressão de sinal. Se valores positivos são obtidos, há indicação de que a matriz induz ao enriquecimento do sinal analítico. Se nenhum valor é obtido, a matriz não causa efeito (MONTAGNER et al., 2014a).

Segundo Trufelli e colaboradores (TRUFELLI et al., 2010)o efeito de matriz pode ser identificado ao se comparar a sensibilidade da curva analítica entre um padrão externo $(\alpha)$ e por adição de padrão no extrato $(\alpha \mathrm{m})$, de acordo com a equação:

$$
\text { Efeito de matriz }(\%)=[(\alpha m / \alpha s)-1)] * 100
$$

Onde $\alpha$ é o coeficiente angular da reta ajustada. 
As figuras 28,29,30,31 e 32 mostram a representação gráfica das curvas feitas no solvente e as curvas feitas na matriz para os 5 analitos.

Figura 28 - Curvas analíticas obtidas no solvente e na matriz para Naproxeno.

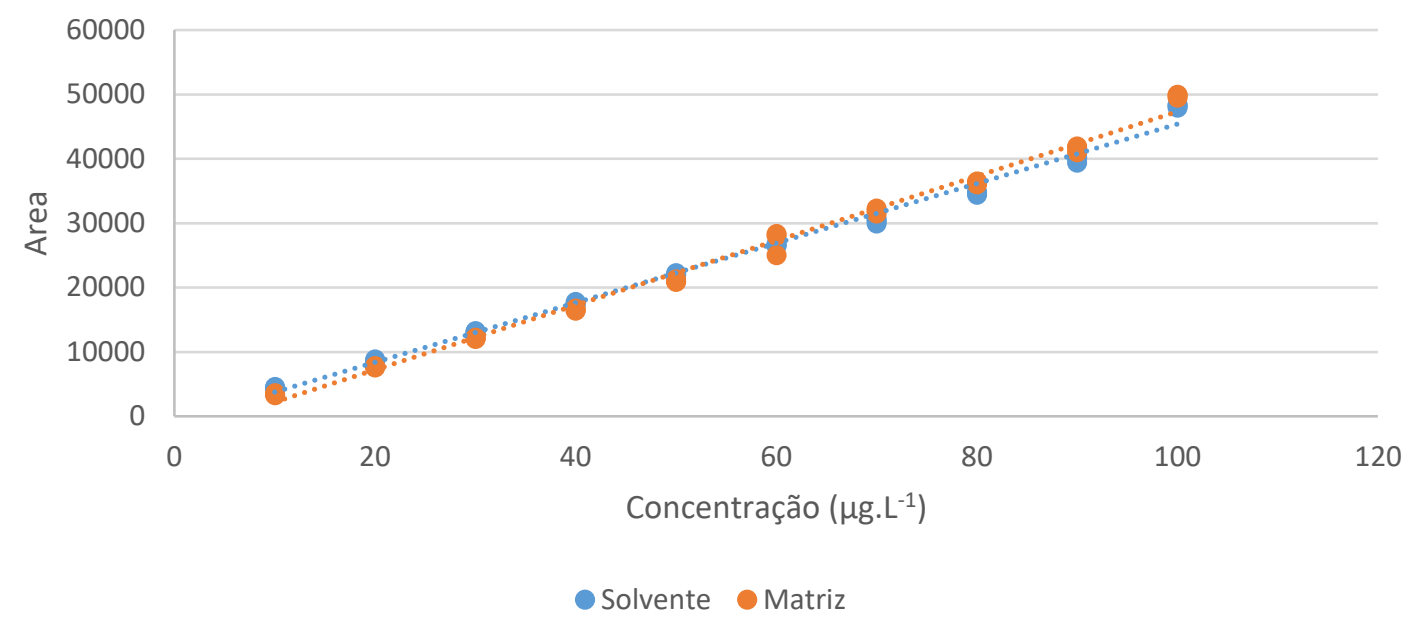

Fonte: Arquivo Pessoal.

Figura 29- Curvas analíticas obtidas no solvente e na matriz para diclofenaco.

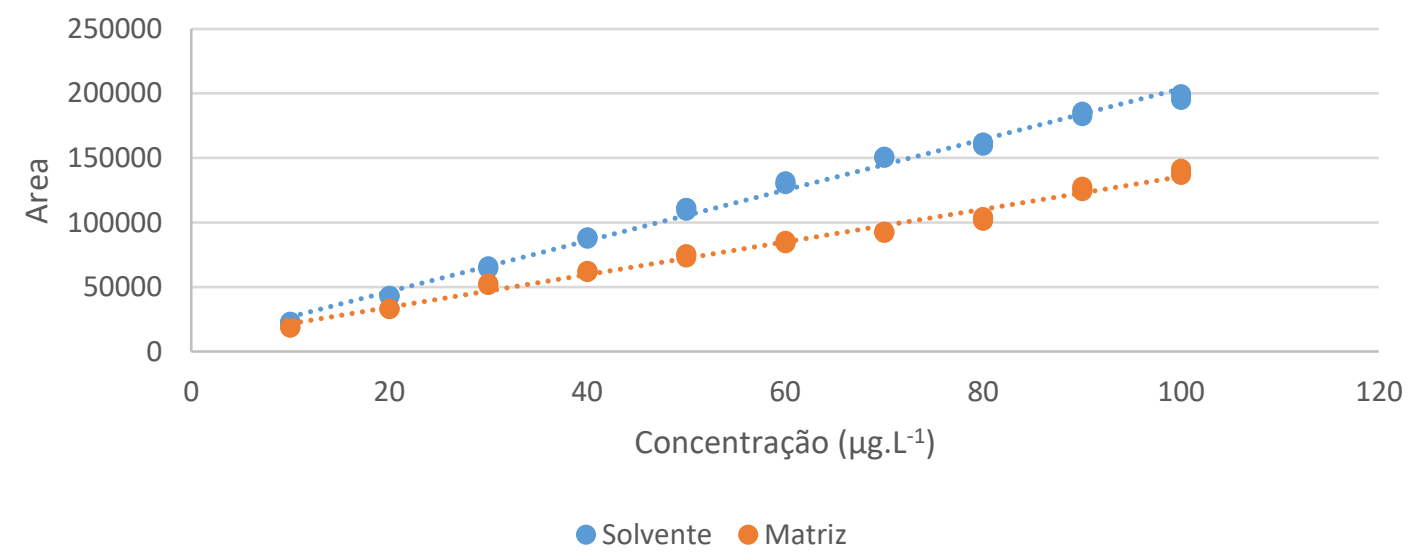

Fonte: Arquivo Pessoal.

Figura 30- Curvas analíticas obtidas no solvente e na matriz para Ibuprofeno.

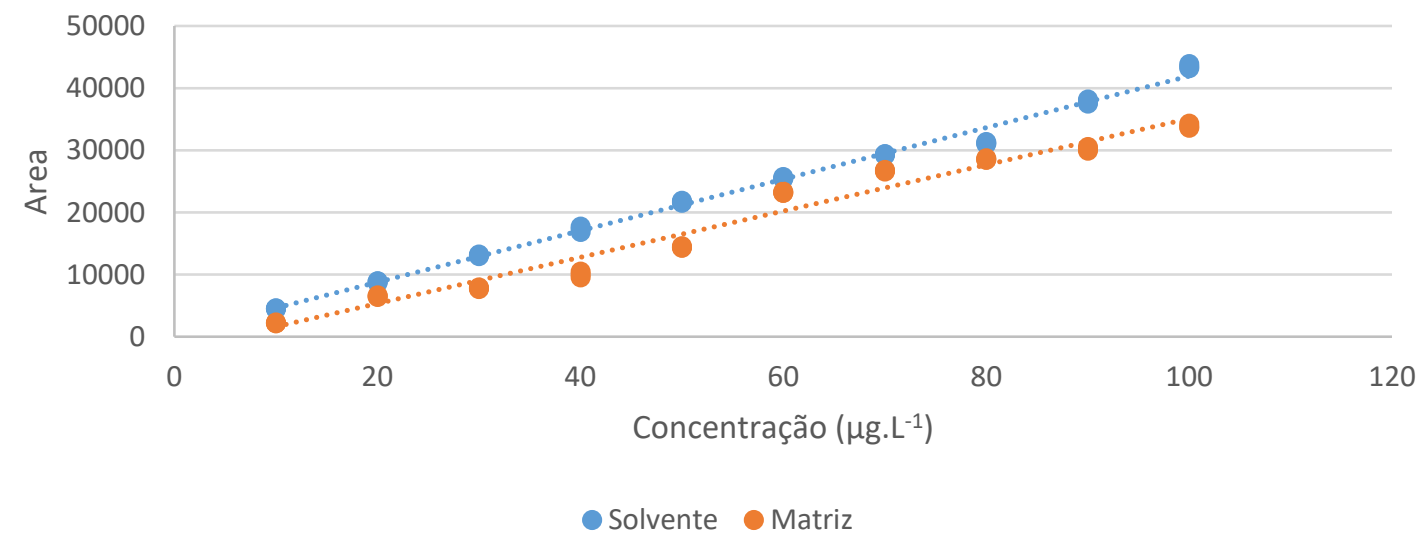

Fonte: Arquivo Pessoal 
Figura 31- Curvas analíticas obtidas no solvente e na matriz para paracetamol.

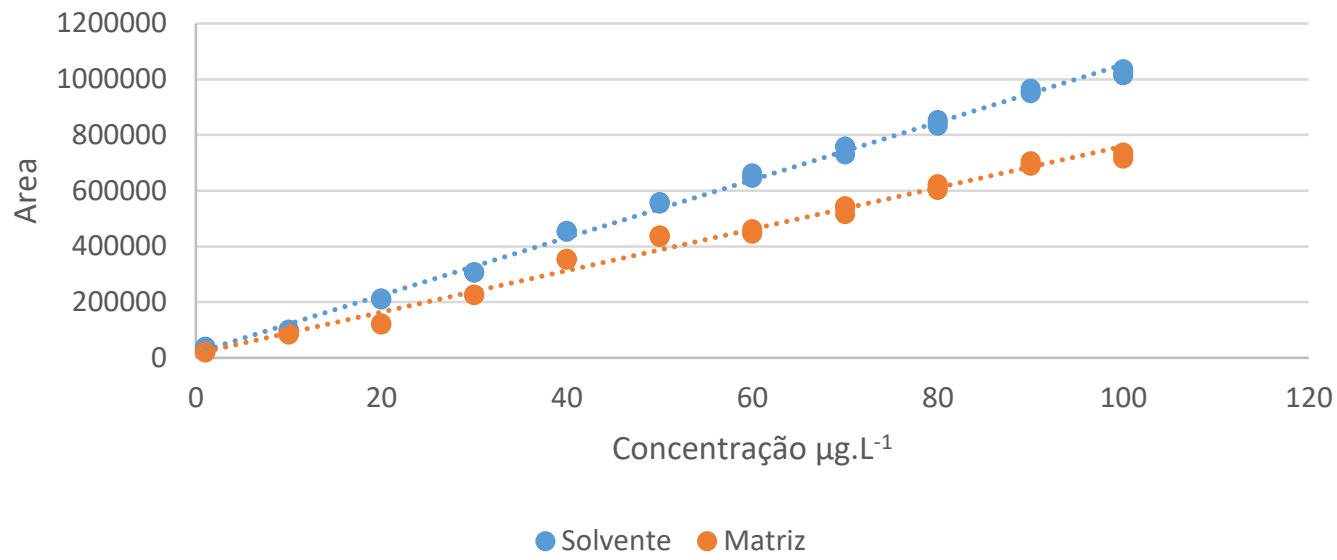

Fonte: Arquivo Pessoal

Figura 32- Curvas analíticas obtidas no solvente e na matriz para cafeína.

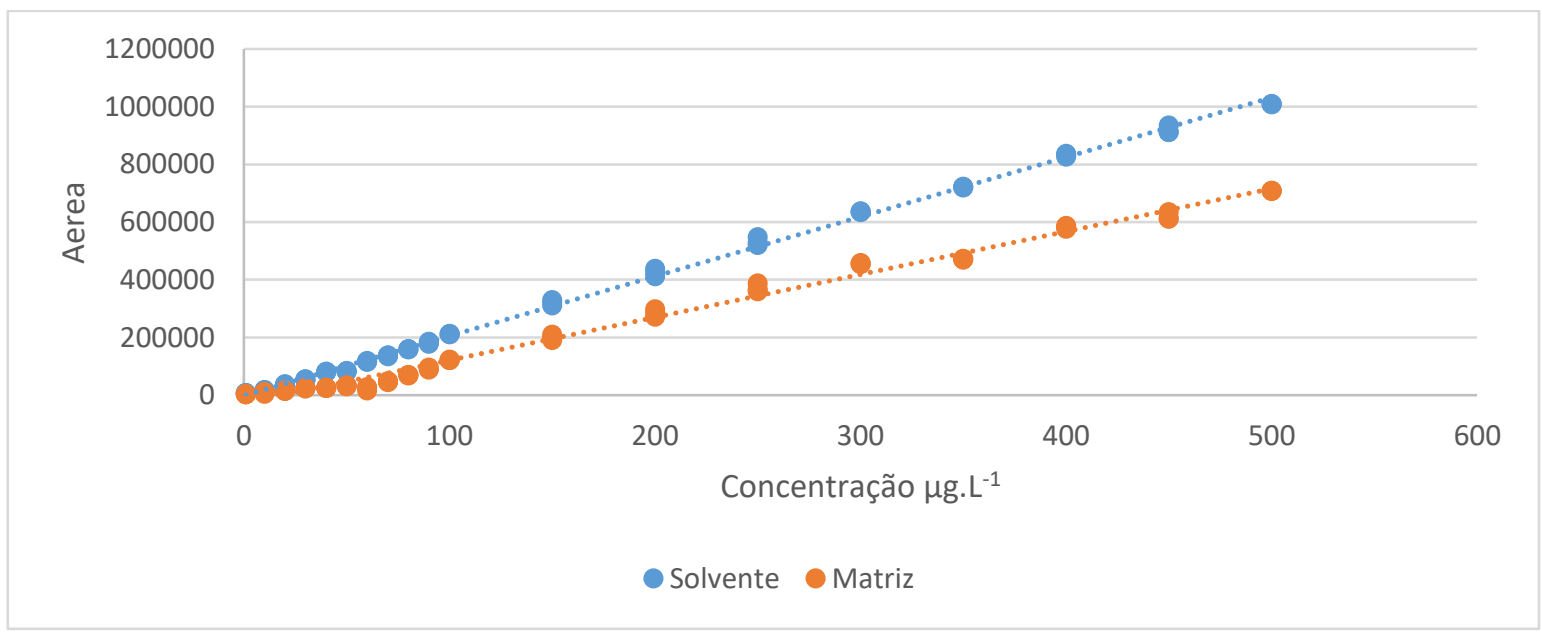

Fonte: Arquivo Pessoal

A Tabela 13 mostra os resultados do efeito matriz obtido para cada um dos 5 analitos

Tabela 13-Valores de $\alpha$ s, $\alpha$ m e do efeito matriz calculado para cada analito

\begin{tabular}{cccc}
\hline Analito & $\boldsymbol{\alpha S}$ & $\boldsymbol{\alpha m}$ & Efeito matriz (\%) \\
\hline Cafeína & 2086 & 1487 & -28.7 \\
Diclofenaco & 1965 & 1266 & $-35,6$ \\
Ibuprofeno & 412 & 372 & -9.7 \\
Naproxeno & 501 & 462 & -7.8 \\
Paracetamol & 10349 & 7443 & -28.1
\end{tabular}

Fonte: Arquivo Pessoal 
Todos os analitos apresentaram efeito matriz negativo, ou seja, existe perda do sinal. O diclofenaco o maior deles (35,6\%). Cafeína e paracetamol apresentaram efeitos matriz bem elevados $(28,7 \%$ e $28,1 \%)$ enquanto que Naproxeno e Ibuprofeno apresentaram supressão de sinal menor que $10 \%$. O efeito matriz é um fator indesejável e se trato muitas vezes de um obstáculo difícil de se superar. Gracia-Lor e colaboradores usaram padrões isotópicos marcados (GRACIA-LOR; SANCHO; HERNÁNDEZ, 2011) como padrões internos para minimizar o efeito matriz.

\subsubsection{Ocorrência de fármacos em águas superficiais do rio Paraíba do Sul}

Amostras de água superficial do rio Paraíba do Sul foram investigadas em 11 pontos, sendo cada um de um município diferente, dentro da região de maior densidade demográfica da bacia do rio do Paraíba do Sul. No total foram coletadas 44 amostras. A cafeína foi o analito que foi identificado com maior frequência, em 100\% das amostras, seguido pelo ibuprofeno, com $98 \%$ de frequência enquanto paracetamol (43\%) e diclofenaco (30\%) foram identificados em menos da metade das amostras. O naproxeno não foi identificado em nenhuma das amostras. A Tabela 14 apresenta a concentração de cada fármaco em cada uma das 44 amostras.

A cafeína foi detectada e quantificada em todas as 44 amostras, apresentando concentrações que variaram de 16 ng.L $\mathrm{L}^{-1}$ (Barra Mansa/verão) até 385 ng.L-1 (Taubaté/inverno). A presença de cafeína em todo o curso do rio que percorre a região é preocupante devido a cafeína ser um indicador de efluente doméstico não tratado (DAFOUZ et al., 2018; HILLEBRAND et al., 2012). As concentrações maiores apareceram em regiões demograficamente mais habitadas e com cidades que possuem altas taxas de tratamento de esgoto - Taubaté tem $100 \%$ do esgoto tratado (DEEPASK) - e a concentração menor aparece em uma cidade com a pior taxa de tratamento de esgoto das cidades envolvidas no trabalho ( Barra Mansa, com taxa de tratamento de esgoto $<4 \%$ ). Pode-se observar que as cidades do Estado do Rio de Janeiro apresentaram as menores concentrações de cafeína. Isto pode estar relacionado a presença de um reservatório (Represa do Funil) na cidade de Itatiaia, antes do rio Paraíba do Sul chegar até a cidade de Resende esse fato pode ter gerado uma “zona morta" onde ocorreria uma concentração de substâncias.

No Brasil, considerando somente águas superficiais, a cafeína já foi quantificada em concentrações que variaram de 0,3 ng. $\mathrm{L}^{-1}$ até 14955 ng. $\mathrm{L}^{-1}$ (CAMPANHA et al., 2014; MONTAGNER et al., 2014; RODRIGUES et al., 2014) dando um indicativo de que o sistema de tratamento de efluentes brasileiro, de um modo geral, precisa de cuidados. 
Já o Ibuprofeno teve concentrações que variaram de 24,0 ng. L ${ }^{-1}$ (Resende/Outono) até 13,4 ng.L $\mathrm{L}^{-1}$ (Lavrinhas/Verão). Embora não tenha sido quantificado em todas as amostras, sua presença foi detectada em 43 das 44 amostras. Em 1999, Stumpf e colaboradores (STUMPF et al., 1999) já tinham estudado o Ibuprofeno no rio Paraíba do Sul. Embora em apenas uma área em comum com a deste trabalho (Resende). Embora tenha usado técnica instrumental diferente (GC-MS), o ibuprofeno não foi detectado nas amostras de Resende. Considerando somente águas superficiais no Brasil, as concentrações variaram entre 1,65 ng ng. $\mathrm{L}^{-1}$ até 14,3 ng. $\mathrm{L}^{-1}$ (CAMPANHA et al., 2014; RODRIGUES et al., 2014)

O diclofenaco foi quantificado em apenas 2 amostras e detectado em 13 das 44 amostras. As concentrações encontradas foram 11,7 ng. $\mathrm{L}^{-1}$ e $14,1 \mathrm{ng}$. $\mathrm{L}^{-1}$, ambas em Resende, no verão e no inverno respectivamente. O diclofenaco também foi estudado por Stumpf (no mesmo estudo do Ibuprofeno), e nas amostras de Resende, a concentração obtida foi de $20 \mathrm{ng}$. $\mathrm{L}^{-1}$. No Brasil, em águas superficiais, a concentração de diclofenaco tem variado de $0.3 \mathrm{ng}$. $\mathrm{L}^{-1}$ até $760 \mathrm{ng}$. L ${ }^{-1}$ (RODRIGUES et al., 2014; THOMAS et al., 2014).

O paracetamol foi detectado em apenas 19 amostras. Sua concentração variou de 13,7 ng. $\mathrm{L}^{-1}$ até 19,6 ng. $\mathrm{L}^{-1}$, o que chega a ser surpreendente, já que este analito, ao lado do ácido acetilsalicílico, está entre os analgésicos mais utilizados no Brasil (STARLING; AMORIM; LEÃO, 2018) além de ser muito utilizado em pacientes que contraíram dengue ( a região esteve sob epidemia nos anos 2015 e 2016). No Brasil, Campanha e colaboradores encontraram paracetamol na concentração de 30,4 ng. L $\mathrm{L}^{-1}$ no Rio Monjolinho, no interior de São Paulo

O naproxeno não foi identificado em nenhuma amostra. Uma explicação poderia vir do consumo baixo (não está entre os analgésicos mais consumidos) embora no estudo de Stumpf e colaboradores em 1999 (STUMPF et al., 1999), o naproxeno tenha sido quantificado em amostras de água do Rio Paraíba do Sul. na cidade de Resende na concentração de $30 \mathrm{ng}$. $\mathrm{L}^{-1}$. 
Tabela 14 - Concentração em ng. $\mathrm{mL}^{-1}$ dos fármacos estudados neste trabalho para cada amostra analisada. LQ: limite de quantificação, LD: limite de detecção

\begin{tabular}{|c|c|c|c|c|c|c|}
\hline Ponto & Data & Cafeína & Diclofenaco & Ibuprofeno & Naproxeno & Paracetamol \\
\hline \multirow{4}{*}{ Jacareí } & $23 / 01 / 2018$ & 264 & $<\mathrm{LD}$ & $<\mathrm{LD}$ & $<\mathrm{LD}$ & $<\mathrm{LD}$ \\
\hline & $24 / 04 / 2018$ & 251 & $<\mathrm{LD}$ & $<\mathrm{LQ}$ & $<\mathrm{LD}$ & $<\mathrm{LD}$ \\
\hline & $24 / 07 / 2018$ & 362 & $<\mathrm{LQ}$ & 14,6 & $<\mathrm{LD}$ & 17,4 \\
\hline & $23 / 10 / 2018$ & 234 & $<\mathrm{LQ}$ & $<\mathrm{LQ}$ & $<\mathrm{LD}$ & 16,5 \\
\hline \multirow{4}{*}{ São José } & $23 / 01 / 2018$ & 267 & $<\mathrm{LD}$ & $<\mathrm{LQ}$ & $<\mathrm{LD}$ & $<\mathrm{LD}$ \\
\hline & $24 / 04 / 2018$ & 233 & $<\mathrm{LD}$ & $<\mathrm{LQ}$ & $<\mathrm{LD}$ & $<\mathrm{LD}$ \\
\hline & $24 / 07 / 2018$ & 381 & $<\mathrm{LQ}$ & 18,3 & $<\mathrm{LD}$ & 19,6 \\
\hline & $23 / 10 / 2018$ & 287 & $<\mathrm{LQ}$ & 15,9 & $<\mathrm{LD}$ & 15,4 \\
\hline \multirow{4}{*}{ Caçapava } & $23 / 01 / 2018$ & 285 & $<\mathrm{LQ}$ & 20,9 & $<\mathrm{LD}$ & $<\mathrm{LD}$ \\
\hline & $24 / 04 / 2018$ & 276 & $<\mathrm{LQ}$ & 17,8 & $<\mathrm{LD}$ & $<\mathrm{LD}$ \\
\hline & $24 / 07 / 2018$ & 301 & $<\mathrm{LQ}$ & 19,1 & $<\mathrm{LD}$ & $<\mathrm{LQ}$ \\
\hline & $23 / 10 / 2018$ & 382 & $<\mathrm{LQ}$ & $<\mathrm{LQ}$ & $<\mathrm{LD}$ & $<\mathrm{LQ}$ \\
\hline \multirow{4}{*}{ Taubaté } & $23 / 01 / 2018$ & 385 & $<\mathrm{LD}$ & $<\mathrm{LQ}$ & $<\mathrm{LD}$ & $<\mathrm{LD}$ \\
\hline & $24 / 04 / 2018$ & 260 & $<\mathrm{LD}$ & $<\mathrm{LQ}$ & $<\mathrm{LD}$ & $<\mathrm{LD}$ \\
\hline & $24 / 07 / 2018$ & 389 & $<\mathrm{LD}$ & $<\mathrm{LQ}$ & $<\mathrm{LD}$ & $<\mathrm{LQ}$ \\
\hline & $23 / 10 / 2018$ & 273 & $<\mathrm{LD}$ & $<\mathrm{LQ}$ & $<\mathrm{LD}$ & $<\mathrm{LQ}$ \\
\hline \multirow{4}{*}{$\begin{array}{c}\text { Pindamonhan } \\
\text { gaba }\end{array}$} & $23 / 01 / 2018$ & 121 & $<\mathrm{LD}$ & $<\mathrm{LQ}$ & $<\mathrm{LD}$ & $<\mathrm{LD}$ \\
\hline & $24 / 04 / 2018$ & 140 & $<\mathrm{LQ}$ & $<\mathrm{LQ}$ & $<\mathrm{LD}$ & $<\mathrm{LD}$ \\
\hline & $24 / 07 / 2018$ & 192 & $<\mathrm{LQ}$ & $<\mathrm{LQ}$ & $<\mathrm{LD}$ & $<\mathrm{LD}$ \\
\hline & $23 / 10 / 2018$ & 154 & $<\mathrm{LQ}$ & $<\mathrm{LQ}$ & $<\mathrm{LD}$ & $<\mathrm{LD}$ \\
\hline \multirow{4}{*}{ Guaratinguetá } & $23 / 01 / 2018$ & 156 & $<\mathrm{LQ}$ & 14,3 & $<\mathrm{LD}$ & $<\mathrm{LD}$ \\
\hline & $24 / 04 / 2018$ & 151 & $<\mathrm{LQ}$ & $<\mathrm{LQ}$ & $<\mathrm{LD}$ & $<\mathrm{LD}$ \\
\hline & $24 / 07 / 2018$ & 170 & $<\mathrm{LQ}$ & 17,1 & $<\mathrm{LD}$ & 15,7 \\
\hline & $23 / 10 / 2018$ & 175 & $<\mathrm{LQ}$ & $<\mathrm{LQ}$ & $<\mathrm{LD}$ & $<\mathrm{LQ}$ \\
\hline \multirow{4}{*}{ Lorena } & $23 / 01 / 2018$ & 98 & $<\mathrm{LD}$ & $<\mathrm{LQ}$ & $<\mathrm{LD}$ & $<\mathrm{LD}$ \\
\hline & $24 / 04 / 2018$ & 81 & $<\mathrm{LD}$ & $<\mathrm{LQ}$ & $<\mathrm{LD}$ & $<\mathrm{LD}$ \\
\hline & $24 / 07 / 2018$ & 101 & $<\mathrm{LQ}$ & $<\mathrm{LQ}$ & $<\mathrm{LD}$ & $<\mathrm{LQ}$ \\
\hline & $23 / 10 / 2018$ & 94 & $<\mathrm{LD}$ & $<\mathrm{LQ}$ & $<\mathrm{LD}$ & $<\mathrm{LQ}$ \\
\hline \multirow{4}{*}{ Lavrinhas } & $25 / 01 / 2018$ & 56 & $<\mathrm{LQ}$ & 13,4 & $<\mathrm{LD}$ & $<\mathrm{LQ}$ \\
\hline & $26 / 04 / 2018$ & 76 & $<\mathrm{LQ}$ & 16,1 & $<\mathrm{LD}$ & $<\mathrm{LQ}$ \\
\hline & $26 / 07 / 2018$ & 93 & $<\mathrm{LQ}$ & 16,9 & $<\mathrm{LD}$ & $<\mathrm{LQ}$ \\
\hline & $25 / 10 / 2018$ & 86 & $<\mathrm{LD}$ & $<\mathrm{LQ}$ & $<\mathrm{LD}$ & $<\mathrm{LQ}$ \\
\hline \multirow{4}{*}{ Resende } & $25 / 01 / 2018$ & 67 & 11,7 & 17,0 & $<\mathrm{LD}$ & $<\mathrm{LD}$ \\
\hline & $26 / 04 / 2018$ & 95 & $<\mathrm{LQ}$ & 24,0 & $<\mathrm{LD}$ & $<\mathrm{LD}$ \\
\hline & $24 / 07 / 2018$ & 26 & 14,8 & 18,0 & $<\mathrm{LD}$ & $<\mathrm{LQ}$ \\
\hline & $25 / 01 / 2018$ & 22 & $<\mathrm{LQ}$ & $<\mathrm{LQ}$ & $<\mathrm{LD}$ & $<\mathrm{LQ}$ \\
\hline \multirow{4}{*}{ Barra Mansa } & $25 / 01 / 2018$ & 16 & $<\mathrm{LQ}$ & $<\mathrm{LQ}$ & $<\mathrm{LD}$ & $<\mathrm{LD}$ \\
\hline & $26 / 04 / 2018$ & 21 & $<\mathrm{LQ}$ & $<\mathrm{LQ}$ & $<\mathrm{LD}$ & $<\mathrm{LQ}$ \\
\hline & $26 / 07 / 2018$ & 23 & $<\mathrm{LQ}$ & 16,0 & $<\mathrm{LD}$ & 13,7 \\
\hline & $25 / 01 / 2018$ & 19 & $<\mathrm{LQ}$ & $<\mathrm{LQ}$ & $<\mathrm{LD}$ & $<\mathrm{LQ}$ \\
\hline \multirow{4}{*}{$\begin{array}{c}\text { Volta } \\
\text { Redonda }\end{array}$} & $25 / 01 / 2018$ & 23 & $<\mathrm{LQ}$ & $<\mathrm{LQ}$ & $<\mathrm{LD}$ & $<\mathrm{LQ}$ \\
\hline & $26 / 04 / 2018$ & 35 & $<\mathrm{LQ}$ & $<\mathrm{LQ}$ & $<\mathrm{LD}$ & $<\mathrm{LQ}$ \\
\hline & $26 / 07 / 2018$ & 41 & $<\mathrm{LQ}$ & $<\mathrm{LQ}$ & $<\mathrm{LD}$ & $<\mathrm{LQ}$ \\
\hline & $25 / 01 / 2018$ & 31 & $<\mathrm{LQ}$ & $<\mathrm{LQ}$ & $<\mathrm{LD}$ & $<\mathrm{LQ}$ \\
\hline
\end{tabular}

Fonte: Arquivo Pessoal. 


\subsection{Defensivos agrícolas.}

Os defensivos agrícolas estudados neste trabalho estão representados na

Tabela 15, juntamente com algumas propriedades que serão importantes na discussão de alguns tópicos no decorrer do trabalho.

\subsubsection{Desenvolvimento de metodologia analítica.}

4.2.1.1 Determinação dos íons precursores, das energias de colisão e dos íons produto.

Como esperado, os íons precursores determinados no modo positivo apresentaram a relação massa /carga com uma unidade a mais que a massa molar do composto (casos de cafeína e paracetamol) enquanto que aqueles analisados no modo negativo apresentaram relação massa/carga com uma unidade a menos que massa molar do composto (diclofenaco, ibuprofeno e paracetamol). Somente os íons determinados nesta etapa irão sofrer fragmentação que resultará na formação dos íons produtos, que serão essenciais para a quantificação e a confirmação da identidade de cada analito. A energia necessária para a formação destes íons é dependente de cada analito. Os íons produtos de quantificação (aqueles com resposta de maior intensidade) e os íons de confirmação (fragmentos com a segunda e a terceira resposta de maior intensidade). A Tabela 15 sumariza os íons precursores formados, seus respectivos íons produtos (de quantificação e confirmação) e a energia de colisão necessária para a formação de cada um. 
Tabela 15- Os defensivos agrícolas estudados e algumas de suas propriedades físico-químicas.

\begin{tabular}{|c|c|c|c|c|}
\hline Composto & Estrutura & $\begin{array}{c}\text { Solubilidade } \\
\text { em água } \\
\left(25^{\circ} \mathrm{C}\right)\end{array}$ & $\log P$ & pKa \\
\hline $\begin{array}{c}\text { Ácido } \\
\text { Diclorofenoxiacético } \\
(2,4-D)\end{array}$ & & $677 \mathrm{mg} . \mathrm{L}^{-1}$ & 2,81 & 2,73 \\
\hline Atrazina & & $35 \mathrm{mg} \cdot \mathrm{L}^{-1}$ & 2,7 & 1,70 \\
\hline Bentazona & & $500 \mathrm{mg} \cdot \mathrm{L}^{-1}$ & 2,80 & 3,30 \\
\hline Fipronil & & $1,9 \mathrm{mg} \cdot \mathrm{L}^{-1}$ & 4,0 & NA \\
\hline Imidacloprida & & $610 \mathrm{mg} \cdot \mathrm{L}^{-1}$ & 0,6 & NA \\
\hline Simazina & & $5 \mathrm{mg} \cdot \mathrm{L}^{-1}$ & 2.3 & 1.6 \\
\hline
\end{tabular}

Fonte: Arquivo Pessoal. 
Tabela 16- Íons Precursores, Íons Produtos de Quantificação (Íon Quant.), Íons Produtos de Confirmação (Íon Conf.) e Energia de colisão de cada defensivo agrícola.

\begin{tabular}{|c|c|c|c|c|c|c|c|c|}
\hline Composto & $\begin{array}{l}\text { Modo } \\
\text { da } \\
\text { Fonte }\end{array}$ & $\begin{array}{c}\text { Íon } \\
\text { Precursor } \\
(\mathbf{m} / \mathbf{z})\end{array}$ & $\begin{array}{l}\text { Íon } \\
\text { Quant. } \\
(\mathbf{m} / \mathbf{z})\end{array}$ & $\begin{array}{c}\text { Energia } \\
\text { de Colisão } \\
(\mathrm{eV})\end{array}$ & $\begin{array}{l}\text { Íon } \\
\text { Conf. } \\
(\mathbf{m} / \mathbf{z})\end{array}$ & $\begin{array}{c}\text { Energia } \\
\text { de Colisão } \\
(\mathrm{eV})\end{array}$ & $\begin{array}{l}\text { Íon } \\
\text { Conf. } \\
(\mathbf{m} / \mathbf{z})\end{array}$ & $\begin{array}{c}\text { Energia } \\
\text { de Colisão } \\
(\mathrm{eV})\end{array}$ \\
\hline 2,4-D & - & 218,9 & 163,0 & 18 & 161,0 & 14 & 125,0 & 12 \\
\hline Atrazina & + & 216,2 & 174,1 & 20 & 103,9 & 20 & n.e & n.e \\
\hline Bentazona & - & 239,1 & 197,0 & 25 & 175,0 & 25 & 132 & 25 \\
\hline Fipronil & - & 434,9 & 330,00 & 10 & 250,0 & 15 & 183,0 & 30 \\
\hline Imidacloprida & + & 256,0 & 175,1 & 15 & 208,9 & 10 & n.e & n.e \\
\hline Simazina & + & 202,0 & 104,0 & 25 & 124,0 & 15 & 132 & 15 \\
\hline
\end{tabular}

Fonte: Arquivo Pessoal:

n.e: não encontrado.

2,4-D, bentazona e simazina apresentaram 3 fragmentos, sendo que o de maior intensidade foi escolhido como o fragmento de quantificação, enquanto os outros serão os fragmentos de confirmação. A imidacloprida e a atrazina apresentaram dois fragmentos cada (um de quantificação e outro de confirmação) enquanto o Fipronil apresentou apenas um fragmento, que será usado para a quantificação.

- $\quad$ Composição da fase móvel.

Para os defensivos agrícolas, tanto para aqueles analisados com a fonte no modo positivo, quanto para aqueles analisados no modo negativo, utilizou-se ácido fórmico $0,1 \%$ e metanol como componentes da fase móvel, porém com um gradiente de eluição próprio para cada um dos grupos. Estes gradientes de eluição são mostrados na Tabela 17 e na Tabela 18. 
Tabela 17- Gradiente utilizado para a eluição de 2,4-D, bentazona e fipronil tendo ácido Fórmico 0,1\%: metanol como fase móvel.

\begin{tabular}{ccc}
\hline Tempo (minutos) & Ácido Acético (\%) & Acetonitrila (\%) \\
\hline 0 & 80 & 20 \\
5 & 20 & 60 \\
6 & 20 & 80 \\
11 & 80 & 20
\end{tabular}

Fonte: Arquivo Pessoal.

Tabela 18- Gradiente utilizado para a eluição de atrazina, imidacloprida e simazina, tendo ácido Fórmico $0,1 \%$ e metanol como fase móvel.

\begin{tabular}{ccc}
\hline Tempo (minutos) & Ácido Acético (\%) & Acetonitrila (\%) \\
\hline 0 & 80 & 20 \\
3 & 40 & 60 \\
10 & 80 & 20
\end{tabular}

Fonte: Arquivo Pessoal.

4.2.1.2 Otimização dos parâmetros da fonte de ionização (ESI) para defensivos agrícolas no modo negativo

Após a definição da fase móvel e do gradiente a ser aplicado, definiu-se a melhor condição da fonte de ionização, segundo item 4.4.4. A Tabela 19 mostra o valor das áreas de cada composto em função da condição da fonte aplicada.

Tabela 19- Área de cada composto em função das condições da fonte de ionização.

\begin{tabular}{cccc}
\hline Condição* & $\mathbf{2 , 4 ~ D}$ & Bentazona & Fipronil \\
\hline 0 & 4287 & 34678 & 81496 \\
1 & 3821 & 36267 & 80768 \\
2 & 3174 & 26789 & 90567 \\
3 & 11567 & 41828 & 93134 \\
4 & 2567 & 21382 & 86429 \\
5 & 8787 & 37893 & 96167 \\
6 & 5282 & 31851 & 87454 \\
7 & 7456 & 39876 & 83523 \\
8 & 8717 & 41828 & 93134 \\
\hline
\end{tabular}

Fonte: Arquivo pessoal.

* Descritas na Tabela 3. 
A Figura 33 representa graficamente os resultados obtidos para as condições de 0 à 8 da Tabela 19.

Figura 33- Representação gráfica dos valores das áreas dos picos do 2,4 D, bentazona, e fipronil em função das condições da fonte.

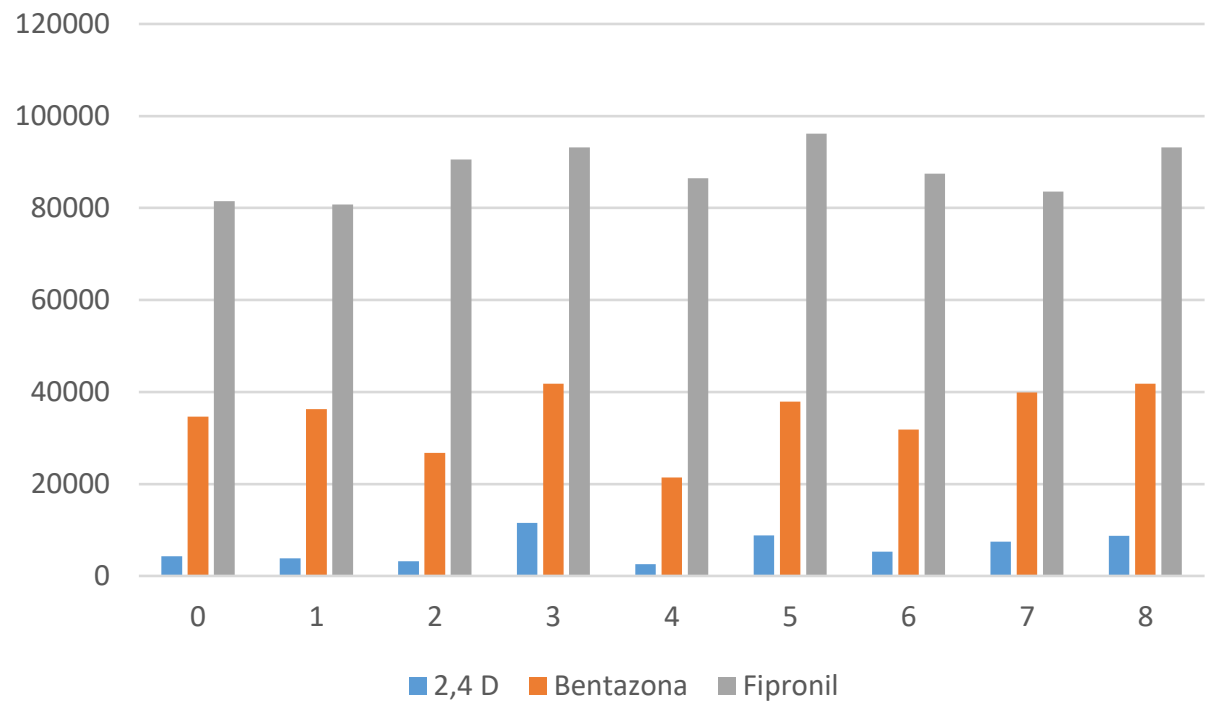

Fonte: Arquivo pessoal

A condição 3 foi aquela que apresentou as maiores respostas para 2,4 D e para a bentazona. Mesmo não sendo a condição que mostrou maior resposta para o fipronil, a resposta para este composto foi elevada. Por este motivo, a condição 3 foi a escolhida para ser a condição da fonte de ionização, para o seguimento dos experimentos. A Figura 18 (TIC) e a Figura 19 (fragmentos) apresentam os cromatogramas obtidos nesta condição.

Figura 34 - Cromatogramas de corrente iônica total (TIC) da separação de 2,4-D, bentazona e fipronil eluídos na condição 3 (ver tabela 3 ) do teste de otimização das condições da fonte de ionização utilizando ácido fórmico $0,1 \%$ : metanol como fase móvel.

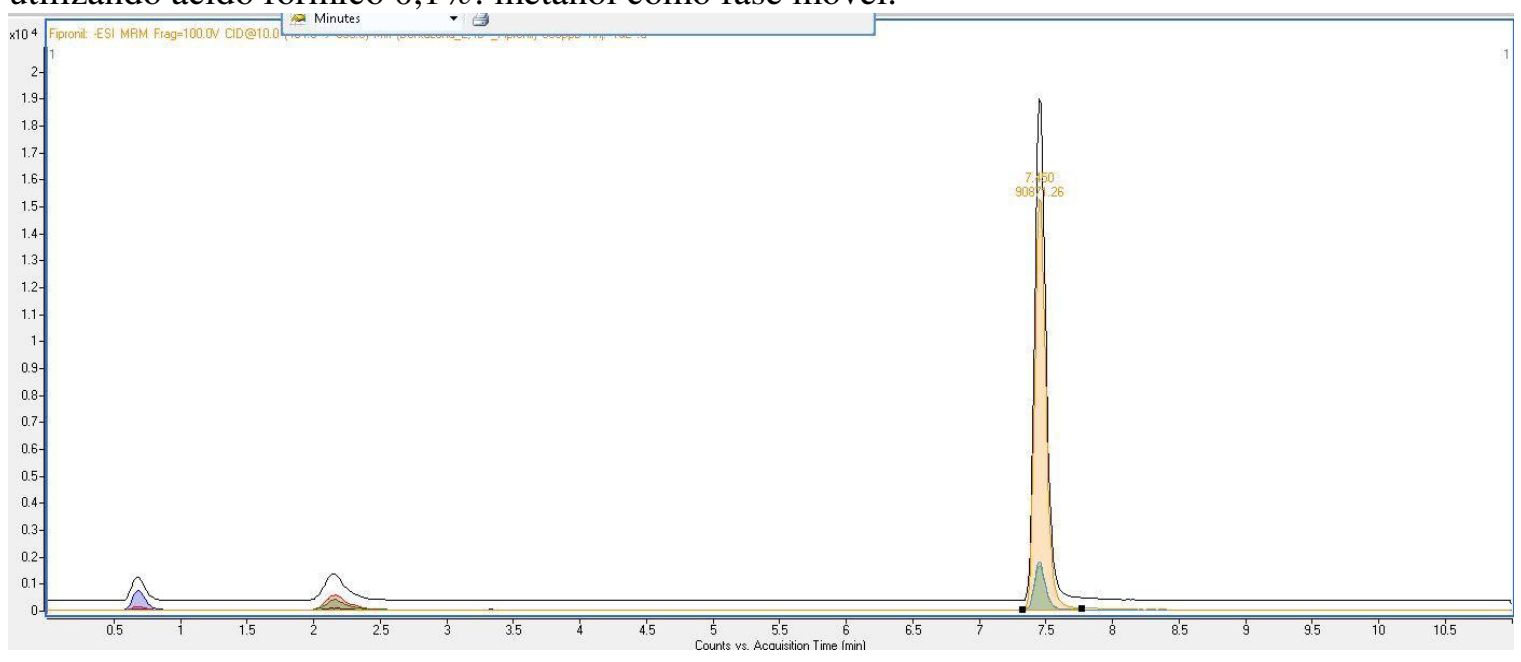

Fonte: Arquivo Pessoal. 
Figura 35- Cromatogramas de cada fragmento (MRM) da separação de 2,4-D, bentazona e fipronil eluídos na condição 3 (ver tabela 3) do teste de otimização das condições da fonte de ionização utilizando ácido fórmico $0,1 \%$ : metanol como fase móvel.

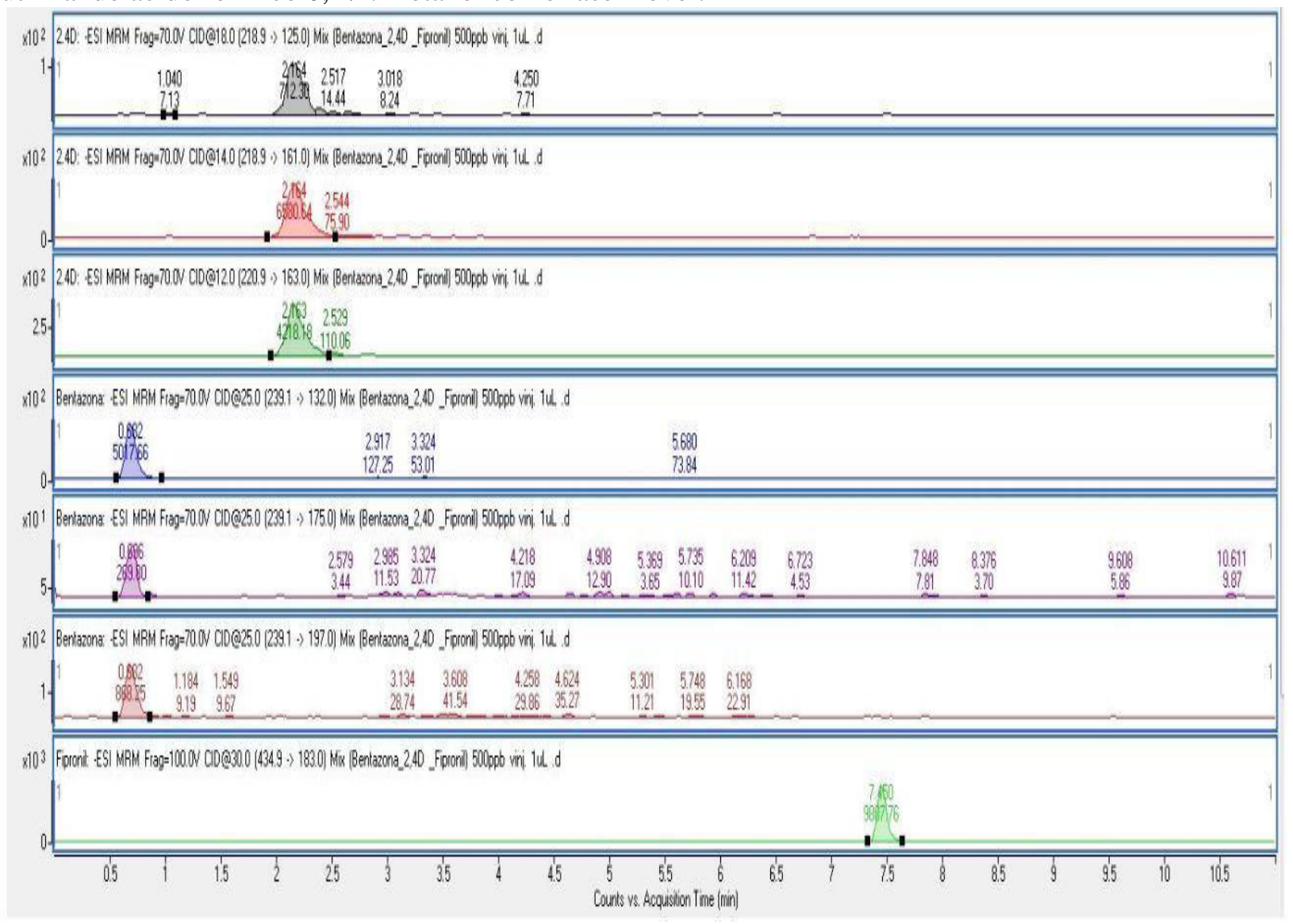

Fonte: Arquivo Pessoal.

O 2,4D (fragmentos de transição 218,1 para 125,0, 161,0 e 163,0) apresentou tempo de retenção de 2,1 minutos, a bentazona (fragmentos de transição 239,1 para 132,0, 175,0 e 197,0) apresentou tempo de retenção 0,7 minutos e o fipronil (fragmentos de transição 434,9 para 330,0, 250,0 e 183,0) teve tempo de retenção de 7,5 minutos.

- Otimização dos parâmetros da fonte de ionização para os defensivos agrícolas analisados no modo positivo.

A Tabela 20 mostra o valor das áreas de cada composto em função da condição da fonte aplicada. 
Tabela 20- Área de cada composto em função das condições da fonte de ionização.

\begin{tabular}{cccc} 
Condição & Atrazina & Imidacloprida & Simazina \\
\hline 0 & 145638 & 14786 & 45943 \\
1 & 104562 & 12345 & 41785 \\
2 & 116191 & 9164 & 56072 \\
3 & 187235 & 13851 & 34560 \\
4 & 14784 & 12456 & 41094 \\
5 & 96783 & 12345 & 36742 \\
6 & 112852 & 8245 & 46704 \\
7 & 98512 & 7127 & 41543 \\
8 & 87636 & 10987 & 32074 \\
\hline
\end{tabular}

Fonte: Arquivo pessoal

A Figura 36 representa graficamente estes valores em função da condição da fonte.

Figura 36- Representação gráfica dos valores das áreas de atrazina, imidacloprida e simazinaem função das condições da fonte.

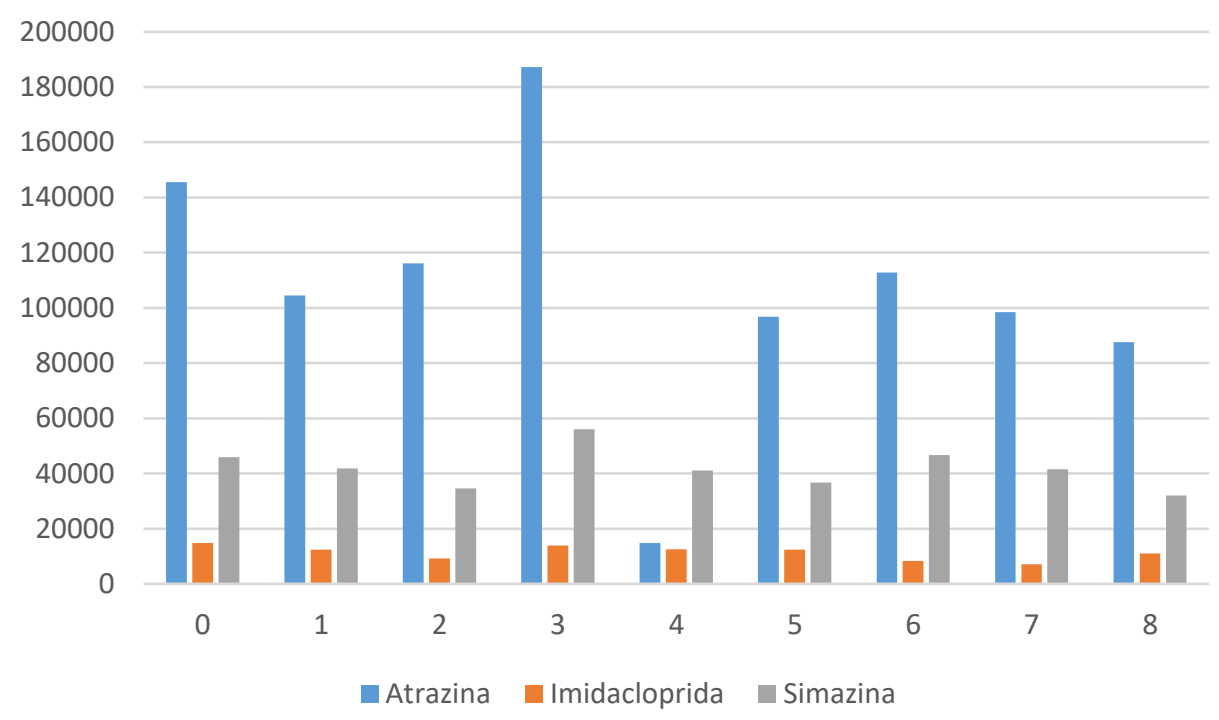

Fonte: Arquivo pessoal

A condição 3 apresentou as melhores respostas para atrazina e simazina. A imidacloprida respondeu melhor a condição 1, mas sua resposta a condição 3 foi a segunda com maior valor de área de pico. Assim, escolheu-se a condição 3 para o prosseguimento dos experimentos com atrazina, imidacloprida e simazina.

A Figura 37 (TIC) e a Figura 38(fragmentos) apresentam os cromatogramas obtidos nestas condições. 
Figura 37- Cromatogramas de corrente iônica total (TIC) da separação de atrazina, imidacloprida e simazina, eluídos na condição 3 (ver tabela 3) do teste de otimização das condições da fonte de ionização utilizando metanol: ácido fórmico $0,1 \%$ como fase móvel.

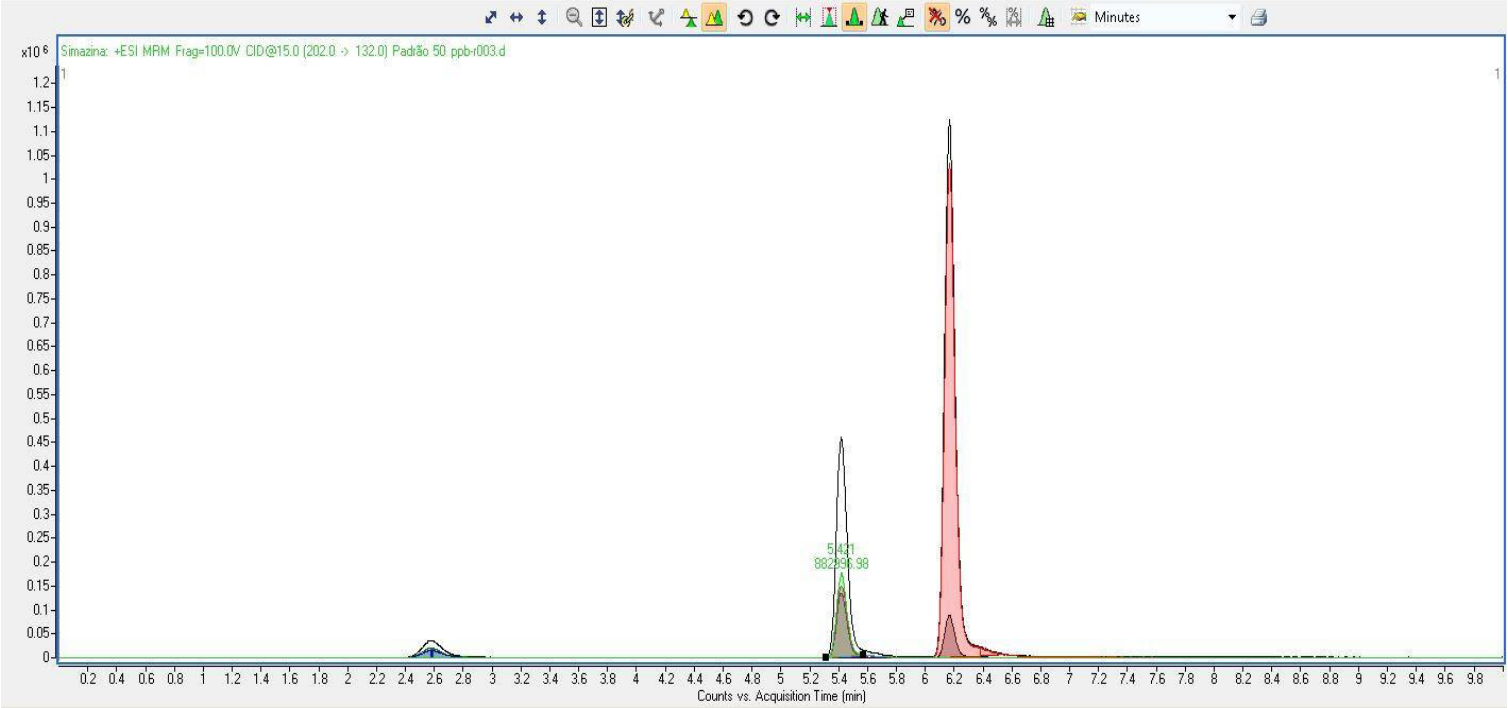

\section{Fonte: Arquivo pessoal}

Figura 38- Cromatogramas de cada fragmento (MRM) da separação de atrazina, imidacloprida e simazina eluídos na condição 3 (ver tabela 3 ) do teste de otimização das condições da fonte de ionização utilizando ácido fórmico $0,01 \%$ : metanol como fase móvel.

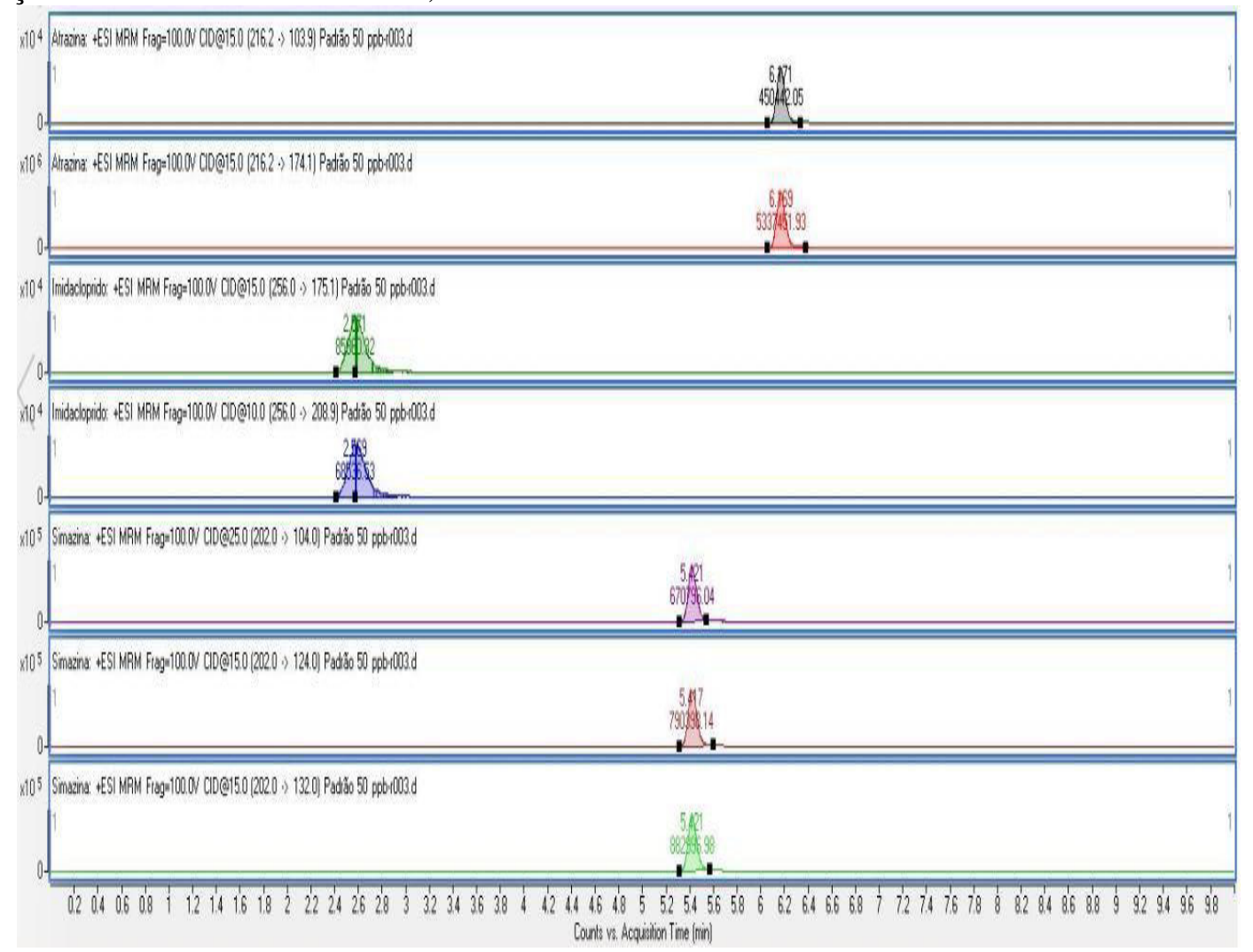

Fonte: Arquivo pessoal 
Portanto, as condições da fonte de ionização escolhidas para serem validadas no caso dos defensivos agrícolas, foram as mesmas, a condição 3 que apresenta os seguintes valores: Voltagem de $3500 \mathrm{~V}$, temperatura de $350^{\circ} \mathrm{C}$, pressão no nebulizador de 50 psi e vazão de gás igual a $13 \mathrm{~L} \cdot \mathrm{min}^{-1}$.

\subsubsection{Validação da metodologia analítica}

\subsubsection{Linearidade}

A resposta do detector mostrou-se linear para os 6 compostos. Imidacloprida e simazina mostram-se lineares no intervalo de $10-100 \mu \mathrm{g} . \mathrm{L}^{-1}$, pois não apresentaram resposta para a concentração de $1 \mu \mathrm{g} \cdot \mathrm{L}^{-1} .2,4-\mathrm{D}$, atrazina, bentazona e fipronil apresentaram linearidade de resposta de $1-100 \mu \mathrm{g} \cdot \mathrm{L}^{-1}$. O coeficiente de determinação das retas ajustadas $\left(\mathrm{R}^{2}\right)$ apresentou valores maiores que 0,990. A seguir, as figuras de 39 até 44, demostram graficamente o comportamento linear dos analitos.

Figura 39- Gráfico da variação da área em função da concentração do 2,4-D.

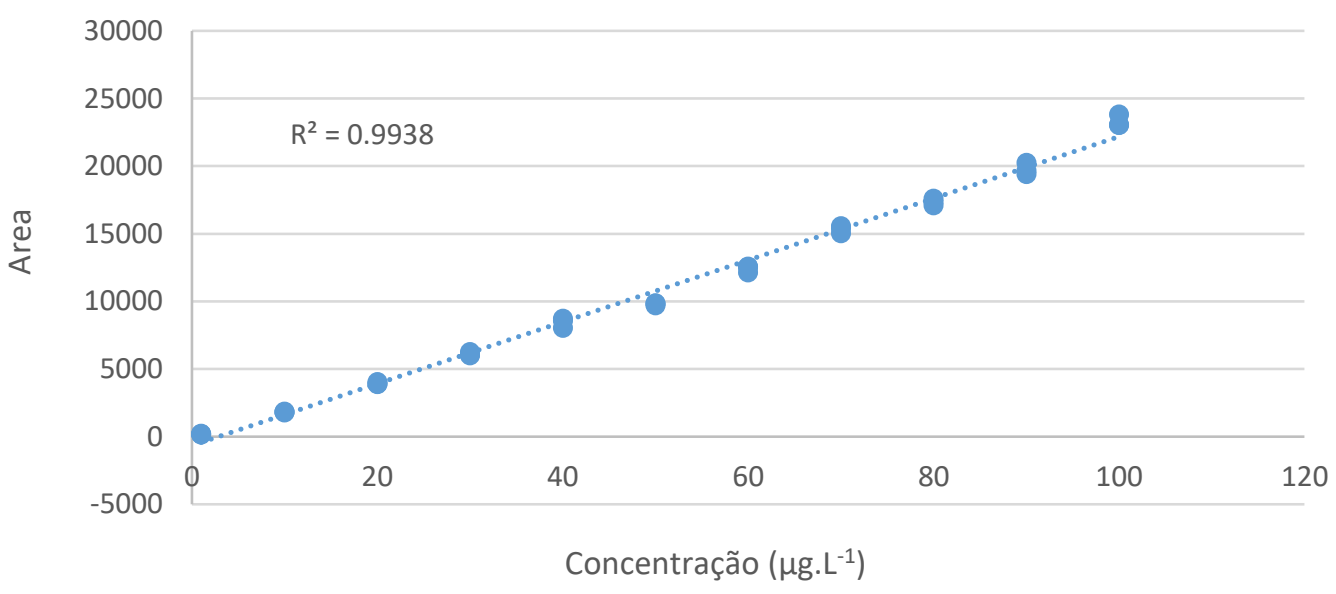

Fonte: Arquivo pessoal. 
Figura 40- Gráfico da variação da área em função da concentração de atrazina.

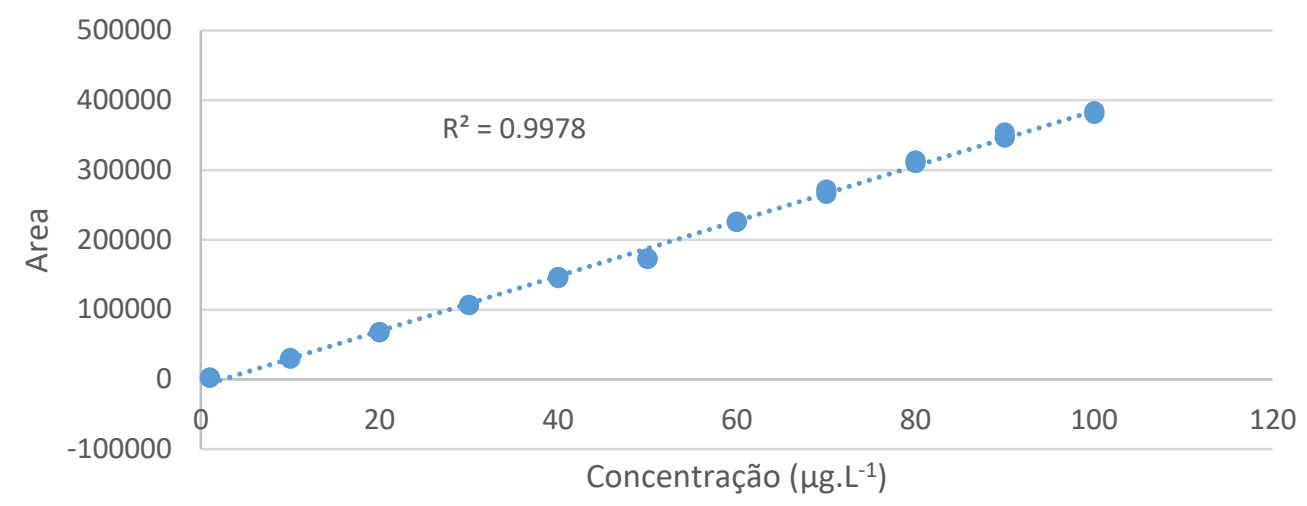

Fonte: Arquivo Pessoal.

Figura 41- Gráfico da variação da área em função concentração de Bentazona.

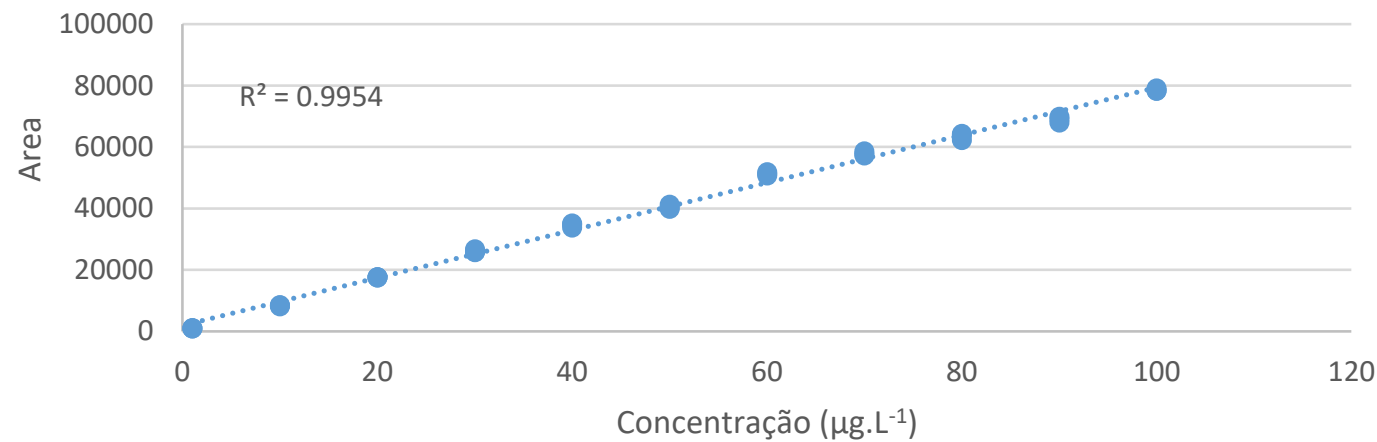

Fonte: Arquivo pessoal

Figura 42- Gráfico da variação da área em função concentração de fipronil.

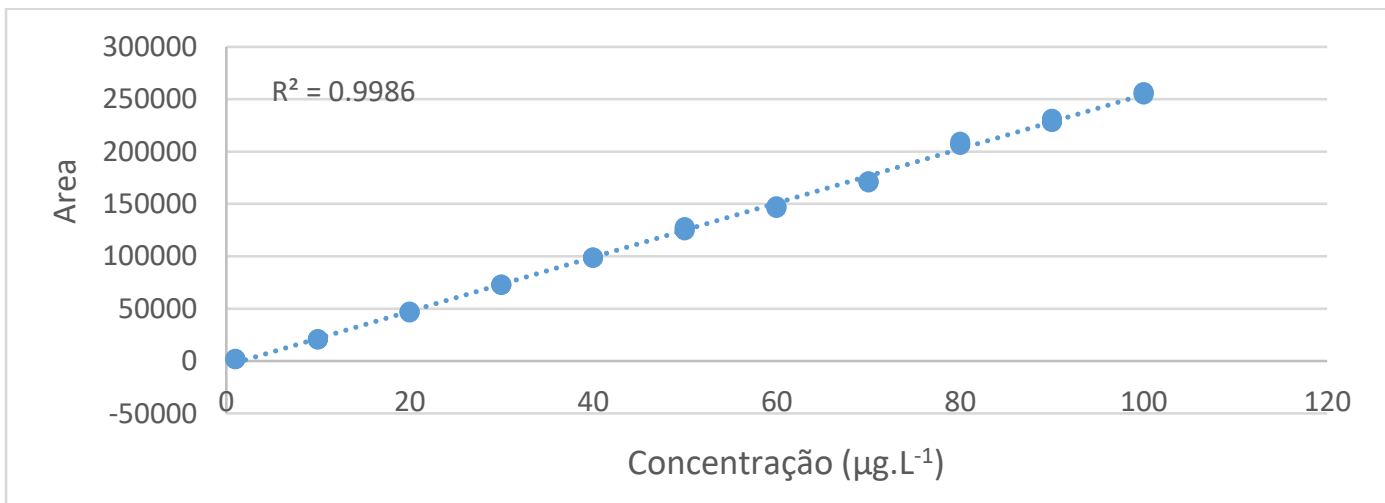

Fonte: Arquivo pessoal 
Figura 43- Gráfico da variação da área em função concentração de imidacloprida.

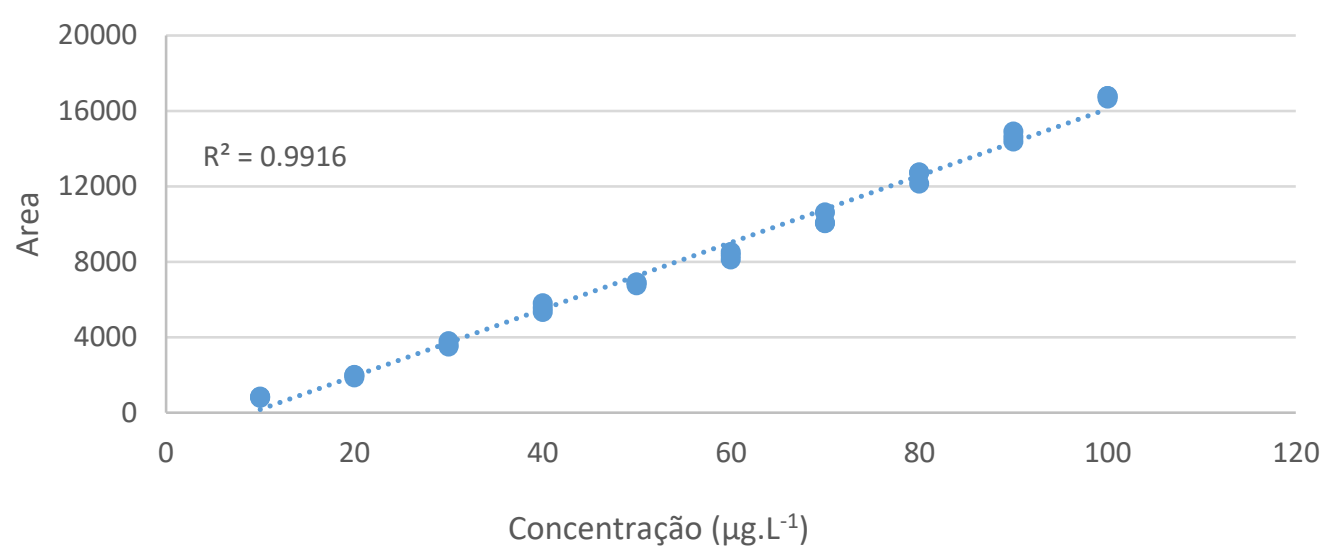

Fonte: Arquivo pessoal

Figura 44- Gráfico da variação da área em função concentração de simazina.

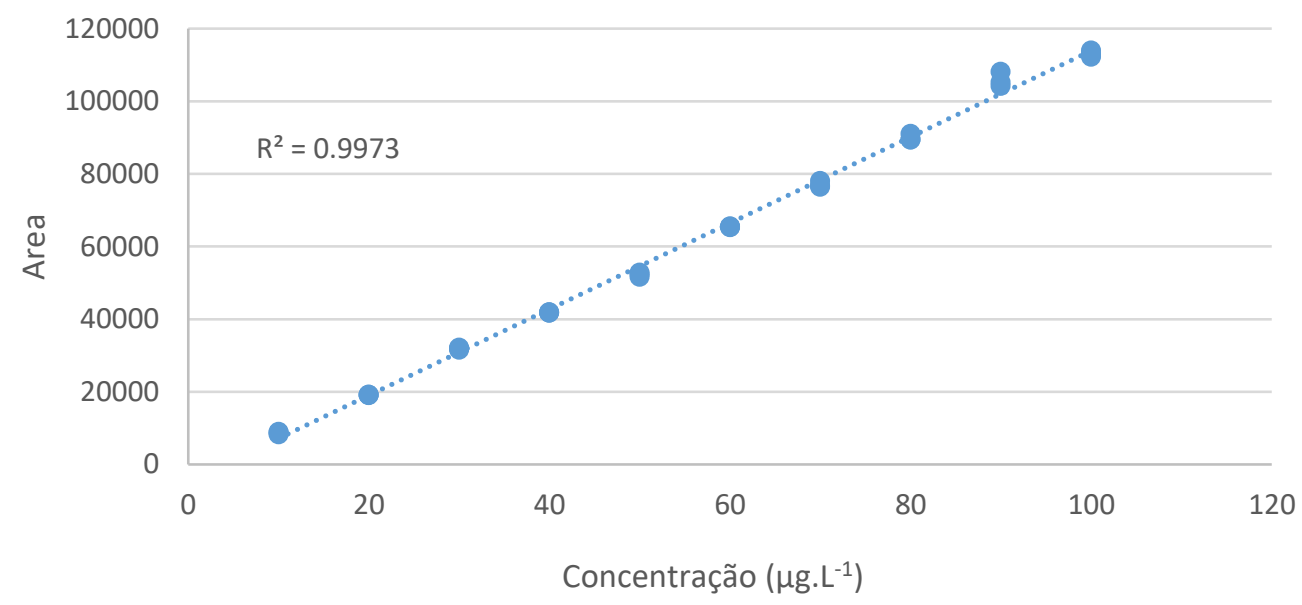

Fonte: Arquivo Pessoal

4.2.2.2 Limite de detecção (LD) e Limite de quantificação (LQ)

O limite de detecção e o limite de quantificação foram calculados de acordo com as expressões: $L Q=10 \times S a \div b$ e $L D=3 \times S a \div b$, descritas no item 4.5.2. A Tabela 21mostra os valores utilizados para o cálculo e os respectivos valores de LQ e LD para os analitos. 
Tabela 21- Erro padrão da intersecção da reta, coeficiente angular da reta, limites de quantificação e detecção instrumentais e limites de quantificação e detecção do método.

$\begin{array}{lcccccc}\text { Analito } & \text { Sa } & \text { b } & \begin{array}{c}\text { LQ }\left(\mu g . L^{-1}\right) \\ \text { Instrumenta }\end{array} & \begin{array}{c}\text { LD }\left(\mu g . L^{-1}\right) \\ \text { Instrumental }\end{array} & \begin{array}{c}\text { LQ } \\ \text { Método } \\ (\text { ng.L-1) }\end{array} & \begin{array}{c}\text { LD } \\ \text { Método } \\ \text { (ng.L } \text { (1) }^{-1}\end{array}\end{array}$

\begin{tabular}{ccccccc}
\hline 2,4-D & 192,1 & 228,4 & 8,4 & 2,5 & 8,4 & 2,5 \\
Atrazina & 3942,2 & 1971,5 & 5,0 & 1,5 & 5,0 & 1,5 \\
Bentazona & 560,4 & 774,5 & 7,2 & 2,1 & 7,2 & 2,1 \\
Fipronil & 1016,3 & 2085,8 & 3,9 & 1,2 & 3,9 & 1,2 \\
Imidacloprida & 190,5 & 177,0 & 10.8 & 3.2 & 10.8 & 3.2 \\
Simazina & 728,6 & 1185,8 & 6,1 & 1,8 & 6,1 & 1,8 \\
\hline
\end{tabular}

Fonte: Arquivo pessoal.

Sa: erro padrão do ponto de intersecção da reta da linearidade no eixo Y. b= coeficiente angular da reta.

\subsubsection{Precisão e Exatidão}

Nesta etapa a repetitividade do método foi avaliada bem como sua capacidade de gerar resultados próximos ao real. Foram preparadas amostras dos analitos em 3 níveis de concentração. Além da recuperação, foram calculados os desvios padrões relativos das recuperações de cada nível e o desvio padrão geral entre as 9 preparações. Aqui não houve um critério para aceitação ou reprovação, mas sim uma verificação da variância do nosso sistema.

A Tabela 22 mostra o resultado médio das recuperações de cada nível. Entre parênteses o desvio padrão relativo de cada nível. A última coluna (DPR\%) representa o desvio padrão relativo entre as 9 recuperações de cada analito. 
Tabela 22- Recuperações médias (\%) para cada nível de concentração e a recuperação média (\%) e o desvio padrão relativo entre as 9 recuperações. Entre parênteses o desvio padrão relativo de cada nível.

\begin{tabular}{cccccc}
\hline Analito & Baixo & Médio & Alto & $\begin{array}{c}\text { Recuperação } \\
\text { média (9 } \\
\text { amostras) }\end{array}$ & $\begin{array}{c}\text { DPR\% } \\
\text { 9 amostras }\end{array}$ \\
\hline 2,4-D & $54,7(11,8)$ & $50,3(14,6)$ & $50,3(12,0)$ & 51,8 & 11,9 \\
Atrazina & $52,3(6,7)$ & $63.3(9,3)$ & $54,7(11.8)$ & 56,8 & 12,1 \\
Bentazona & $55,0(13,7)$ & $55,3(14,6)$ & $62,3(8,1)$ & 57,6 & 12,3 \\
Fipronil & $50,7(6,9)$ & $51,3(8,8)$ & $59,7(11,2)$ & 53,9 & 11,5 \\
Imidacloprida & $67,7(6,2)$ & $70,7(6,7)$ & $77,0(6,0)$ & 71,1 & 8,8 \\
Simazina & $65,7(6,2)$ & $65,0(12,2)$ & $63,7(10,5)$ & 64,8 & 8,7 \\
\hline
\end{tabular}

Fonte: Arquivo pessoal.

A recuperação média para os defensivos agrícolas ficou próxima a faixa 50-70\%, A imidacloprida foi o analito para o qual o método se apresentou mais exato, com recuperação média de $71,1 \%$, enquanto o 2,4-D foi o que teve a menor recuperação, com 51,8\%. A simazina foi o analito com desempenho mais preciso, com um desvio padrão relativo entre as 9 determinações de $8,7 \%$, enquanto a bentazona se apresentou os resultados com maior variação, com $12,3 \%$.

\subsubsection{Efeito Matriz}

O efeito matriz foi calculado em termos da sensibilidade da curva com adição de padrão na amostra e uma curva no solvente. O resultado foi indicado em porcentagem da alteração da sensibilidade da curva no solvente em relação à curva na matriz com a adição de padrão. O valor negativo indica que a matriz causa supressão de sinal. Se valores positivos são obtidos, há indicação de que a matriz induz ao enriquecimento do sinal analítico. Se nenhum valor é obtido, a matriz não causa efeito (MONTAGNER et al., 2014a).

Segundo Trufelli e colaboradores (TRUFELLI et al., 2010) o efeito de matriz pode ser identificado ao se comparar a sensibilidade da curva analítica entre um padrão externo ( $\alpha$ s) e por adição de padrão no extrato $(\alpha \mathrm{m})$, de acordo com a equação:

$$
\text { Efeito de matriz }(\%)=[(\alpha m / \alpha s)-1)] * 100
$$

Onde $\alpha$ é o coeficiente angular da reta ajustada. 
As figuras 45, 46, 47, 48, 49 e 50 mostram a representação gráfica das curvas feitas no solvente e as curvas feitas na matriz para os 6 analitos.

Figura 45- Curvas analíticas obtidas no solvente e na matriz para 2,4-D.

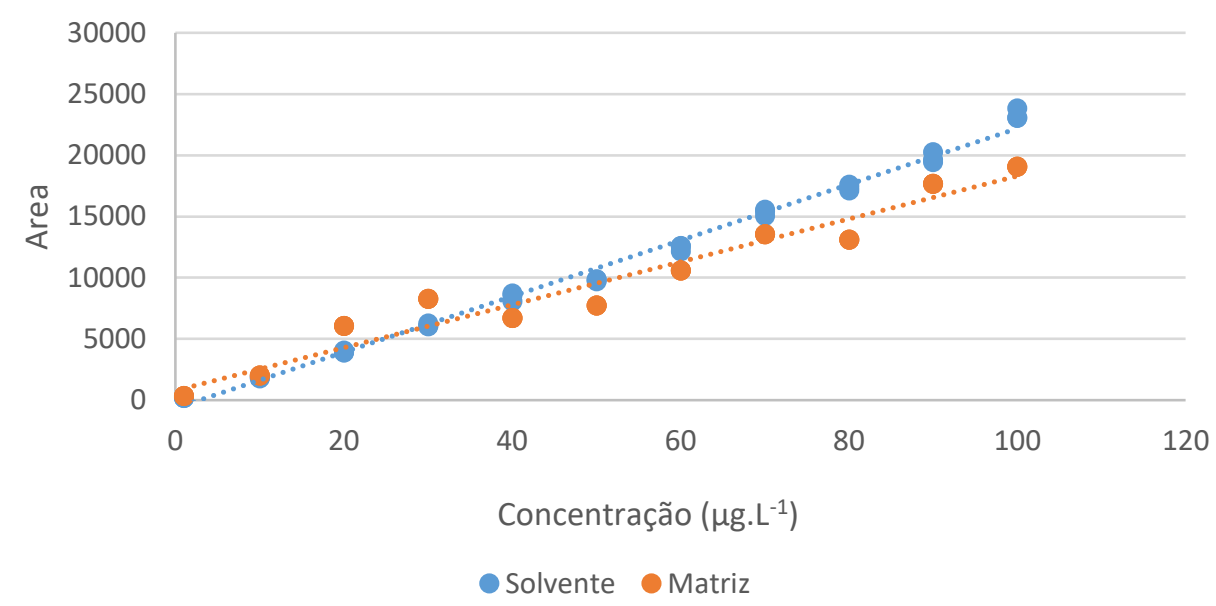

Fonte: Arquivo Pessoal

Figura 46 - Curvas analíticas obtidas no solvente e na matriz para atrazina.

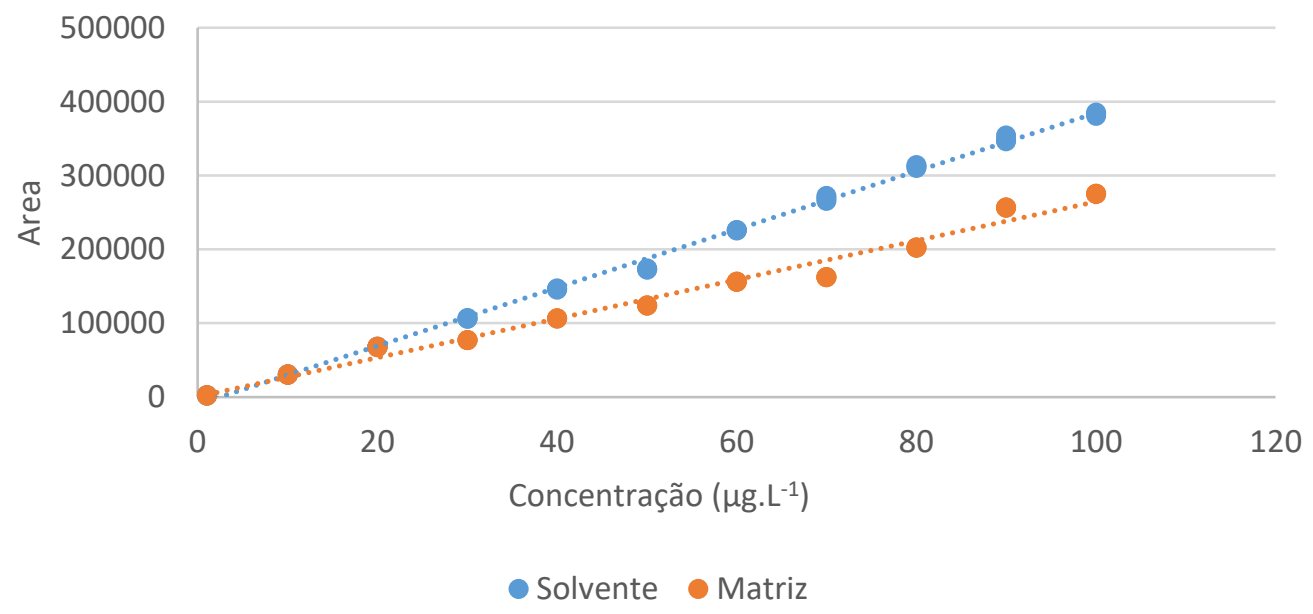

Fonte: Arquivo Pessoal 
Figura 47 - Curvas analíticas obtidas no solvente e na matriz para Bentazona.

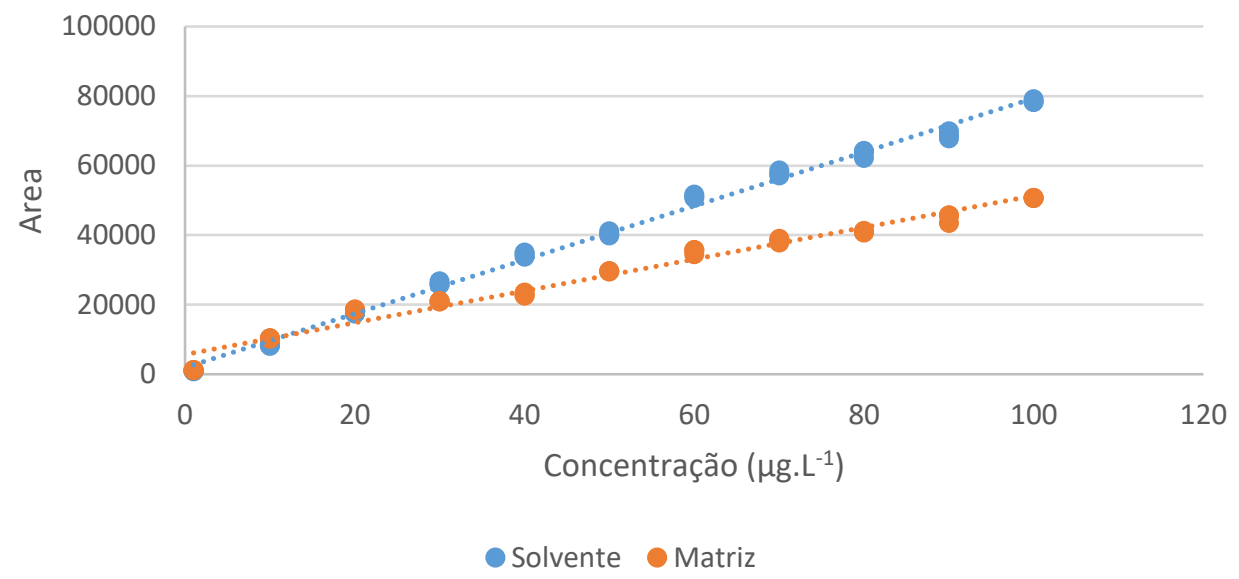

Fonte: Arquivo Pessoal

Figura 48 - Curvas analíticas obtidas no solvente e na matriz para Fipronil.

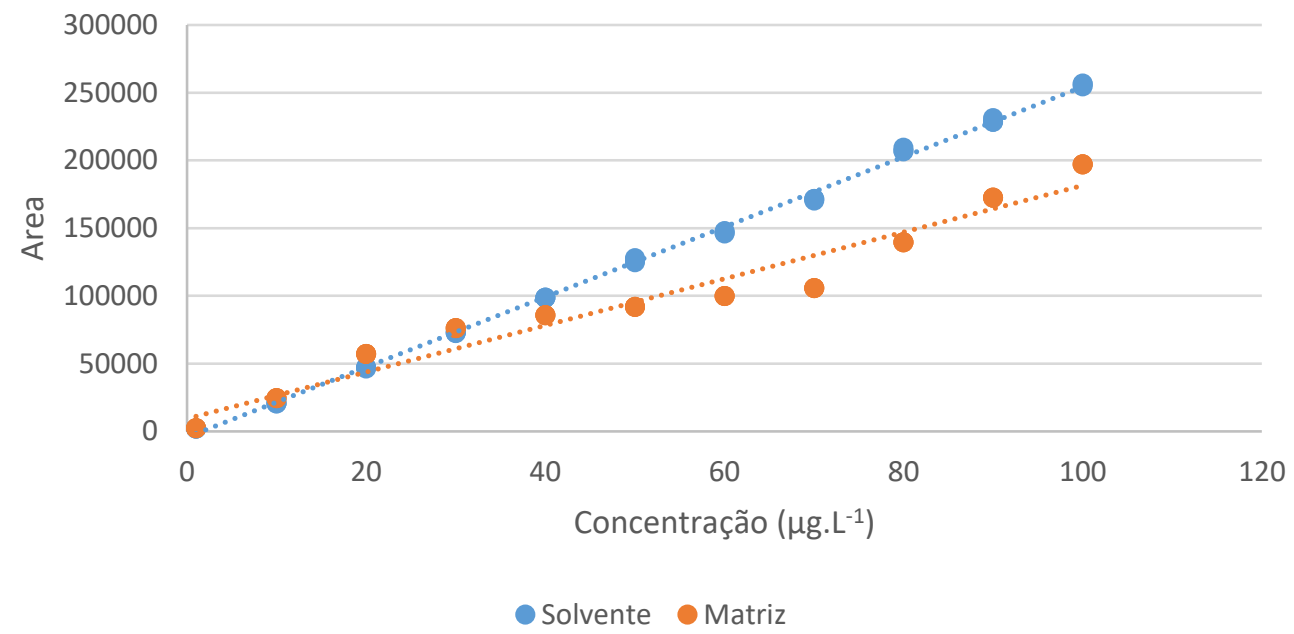

Fonte: Arquivo Pessoal

Figura 49- Curvas analíticas obtidas no solvente e na matriz para imidacloprida.

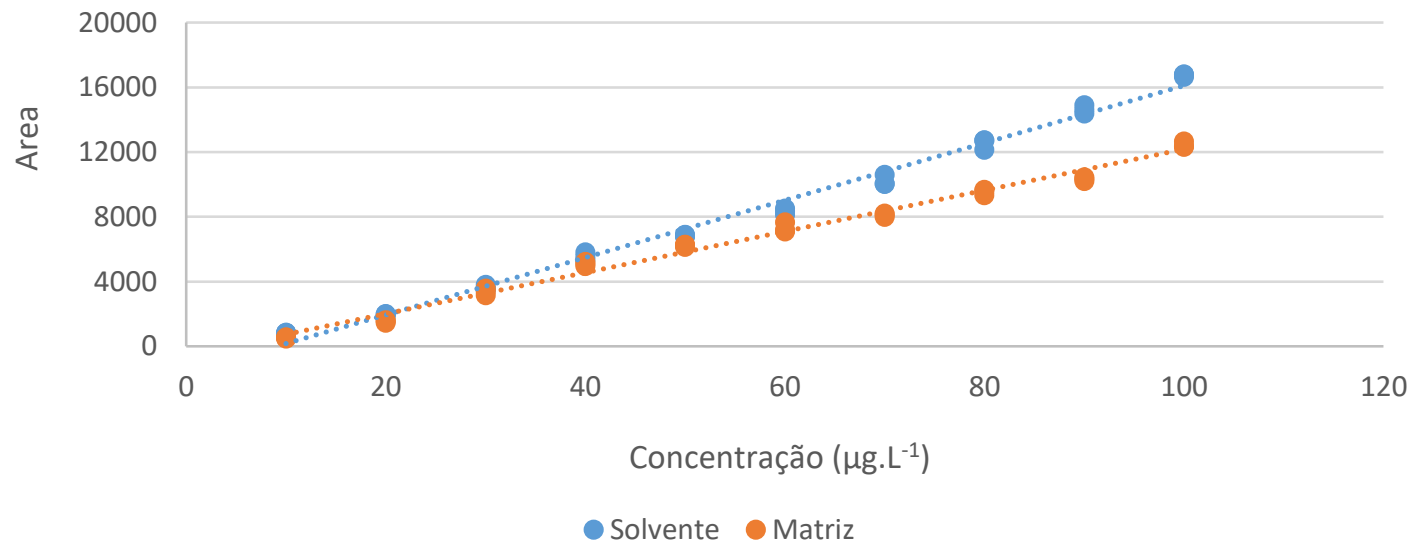

Fonte: Arquivo Pessoal 
Figura 50 - Curvas analíticas obtidas no solvente e na matriz para simazina.

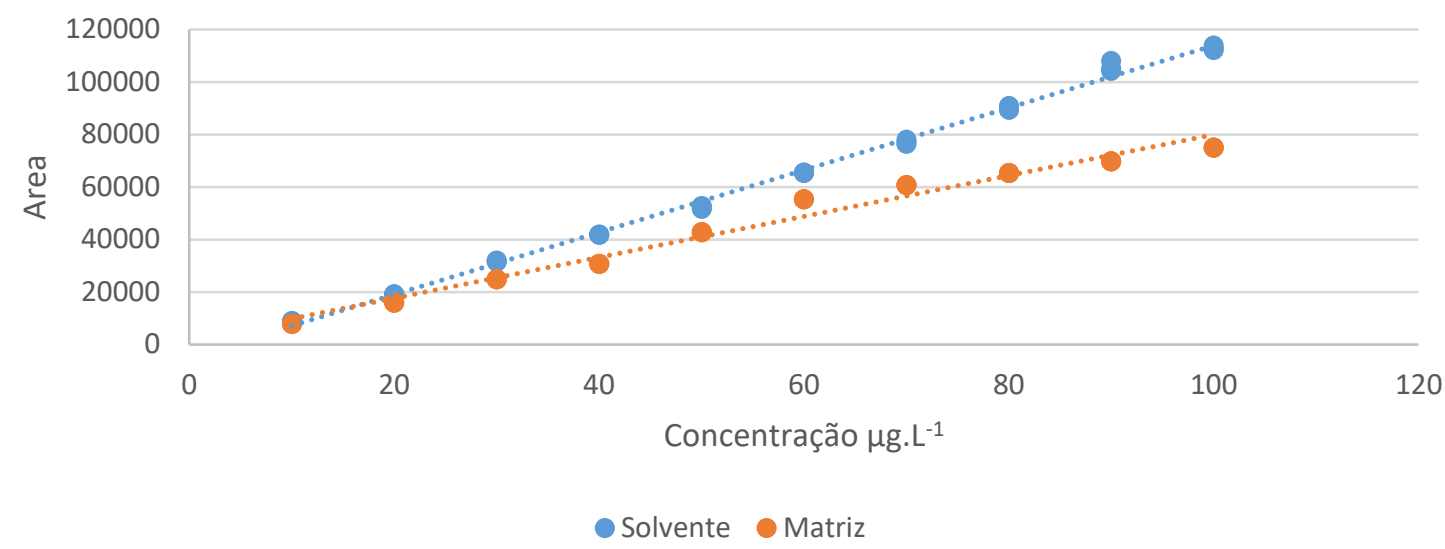

Fonte: Arquivo Pessoal

A Tabela 23 mostra os resultados do efeito matriz obtido para cada um dos 6 analitos

Tabela 23- Valores de $\alpha$ s, $\alpha$ m e do efeito matriz calculado para cada analito.

\begin{tabular}{cccc} 
Analito & $\boldsymbol{\alpha s}$ & $\boldsymbol{\alpha m}$ & Efeito matriz (\%) \\
\hline 2,4-D & 228.38 & 175.2 & -23.3 \\
Atrazina & 3942.2 & 2639 & -33.1 \\
Bentazona & 774.51 & 456.7 & $-41,0$ \\
Fipronil & 2585.8 & 1721.1 & -33.4 \\
Imidacloprida & 177.03 & 127.1 & -28.2 \\
Simazina & 1185.8 & 779 & -34.3 \\
\hline
\end{tabular}

Fonte: Arquivo Pessoal

Todos os analitos apresentaram efeito matriz negativo, demostrando que amostra de águas superficiais do rio Paraíba do Sul causam supressão de sinal nos analitos estudados neste trabalho,

4.2.5 Ocorrência de defensivos agrícolas em amostras de água superficial do Rio Paraíba do Sul.

A Tabela 24 apresenta o resultado obtido para os defensivos agrícolas para as 44 mostras de água superficial do rio Paraíba do Sul. Somente 3 dos 6 defensivos agrícolas foram identificados nas 44 amostras. Imidacloprida, fipronil e atrazina não foram identificados em nenhuma das 44 amostras.

Os defensivos agrícolas, ao contrário dos fármacos, apresentaram um comportamento sazonal. As maiores concentrações foram achadas em pontos próximos ao 
cultivo de arroz alagado. As amostras coletadas no verão apresentaram as maiores concentrações, pois o mês de outubro, período bem ativo no cultivo do arroz na região, que se passa entre agosto e dezembro (MARCHESAN et al., 2010). Importante observar que as concentrações em janeiro também tiveram um valor relativo alto, destacando-se que janeiro foi o mês com maior precipitação pluviométrica na região, com uma precipitação de $300 \mathrm{~mm}$ (INMET), significando uma maior possibilidade de transporte dos defensivos agrícolas da área de cultivo ( para o arroz irrigado usa-se uma área de várzea do rio Paraíba do Sul) até o rio Paraíba do Sul. Nas demais coletas invariavelmente houve uma diminuição da concentração, mesmo no período de maior seca, que ocorreu durante a terceira coleta (inverno), onde praticamente não choveu no mês de julho (INMET).

A 2,4-D foi identificado em 40 das 44 amostras, apresentando uma variação de concentração de 42,2 ng. $\mathrm{L}^{-1}$ (Pindamonhangaba/outono) até 14,2 ng.L $\mathrm{L}^{-1}$ (Barra Mansa/primavera). A concentração mais alta ficou cerca de 7 vezes abaixo do valor estipulado em legislação (BRASIL, 2005) para corpos d água de classe 2. O 2,4 D também foi o $3^{\circ}$ defensivo agrícola em volume de vendas no Estado de São Paulo, com cerca de 6 mil quilos vendidos (IBAMA). No Rio de Janeiro, no mesmo período, 88 quilos foram vendidos.

A atrazina, com 3 mil quilos vendidos em 2018 (IBAMA) apareceu neste estudo sendo identificada em 38 das 44 amostras. As concentrações variaram de 60,4 ng.L $\mathrm{L}^{-1}$

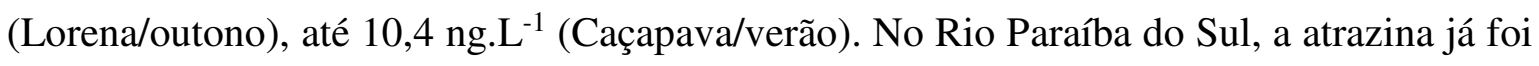
identificada na região de Campos dos Goytacazes, próxima a plantações de cana de açúcar (AZEVEDO; GERCHON; DOS REIS, 2004) na concentração de 234 ng.L ${ }^{-1}$. A técnica analítica utilizada neste estudo foi GC-MS.

A bentazona teve um volume de venda bem reduzido no Estado de São Paulo no ano de 2017. Apenas 53 quilos (IBAMA), porém ela é um herbicida muito utilizado no cultivo de arroz (MARCHESAN et al., 2010). A bentazona foi identificada em 27 amostras e as concentrações maiores foram encontradas próximas as cidades onde se realiza o cultivo de arroz irrigado. A concentração de bentazona variou de 75,8 ng. $\mathrm{L}^{-1}$ (Lorena/verão) até 12,2 ng.L ${ }^{-1}$ (Barra Mansa/outono). No Brasil, Caldas e colaboradores (CALDAS et al., 2013) determinaram bentazona em águas superficiais do Rio Grande do Sul com uma concentração média de $88 \mathrm{ng} . \mathrm{L}^{-1}$. 
Tabela 24- Concentração em ng. $\mathrm{mL}^{-1}$ dos defensivos agrícolas estudados neste trabalho para cada amostra analisada. LQ: limite de quantificação, LD: limite de detecção.

\begin{tabular}{|c|c|c|c|c|c|c|c|}
\hline & Data & $2,4-D$ & Atrazina & Bentazona & Fipronil & Imidacloprida & Simazina \\
\hline \multirow{4}{*}{ Jacareí } & 23/01/2018 & $<\mathrm{LQ}$ & 13,1 & $<L D$ & $<L D$ & $<L D$ & $<L D$ \\
\hline & $24 / 04 / 2018$ & $<\mathrm{LD}$ & $<L Q$ & $<\mathrm{LD}$ & $<\mathrm{LD}$ & $<L D$ & $<L D$ \\
\hline & $24 / 07 / 2018$ & $<\mathrm{LQ}$ & $<\mathrm{LQ}$ & $<\mathrm{LD}$ & $<L D$ & $<L D$ & $<L D$ \\
\hline & $23 / 10 / 2018$ & $<L D$ & $<L D$ & $<L D$ & $<\mathrm{LD}$ & $<\mathrm{LD}$ & $<L D$ \\
\hline \multirow{4}{*}{ São José } & $23 / 01 / 2018$ & $<L Q$ & 11,7 & $<L D$ & $<L D$ & $<L D$ & $<L D$ \\
\hline & $24 / 04 / 2018$ & $<L Q$ & $<\mathrm{LQ}$ & $<\mathrm{LD}$ & $<\mathrm{LD}$ & $<\mathrm{LD}$ & $<\mathrm{LD}$ \\
\hline & $24 / 07 / 2018$ & $<L Q$ & $<L D$ & $<L D$ & $<L D$ & $<L D$ & $<L D$ \\
\hline & $23 / 10 / 2018$ & $<\mathrm{LD}$ & $<L D$ & $<\mathrm{LD}$ & $<\mathrm{LD}$ & $<\mathrm{LD}$ & $<\mathrm{LD}$ \\
\hline \multirow{4}{*}{ Caçapava } & $23 / 01 / 2018$ & $<L Q$ & 10,4 & $<L D$ & $<\mathrm{LD}$ & $<L D$ & $<L D$ \\
\hline & $24 / 04 / 2018$ & $<L Q$ & $<L Q$ & $<L D$ & $<\mathrm{LQ}$ & $<L D$ & $<L D$ \\
\hline & $24 / 07 / 2018$ & $<L Q$ & $<L Q$ & $<L D$ & $<L D$ & $<L D$ & $<L D$ \\
\hline & $23 / 10 / 2018$ & $<L Q$ & $<L Q$ & $<L D$ & $<L D$ & $<L D$ & $<L D$ \\
\hline \multirow{4}{*}{ Taubaté } & $23 / 01 / 2018$ & $<L Q$ & 25,5 & $<L Q$ & $<L D$ & $<L D$ & $<L D$ \\
\hline & $24 / 04 / 2018$ & $<\mathrm{LQ}$ & 22,3 & $<\mathrm{LQ}$ & $<\mathrm{LD}$ & $<\mathrm{LD}$ & $<\mathrm{LD}$ \\
\hline & $24 / 07 / 2018$ & $<L Q$ & 19,1 & $<L Q$ & $<L D$ & $<L D$ & $<L D$ \\
\hline & $23 / 10 / 2018$ & $<\mathrm{LQ}$ & 38,4 & $<\mathrm{LQ}$ & $<\mathrm{LD}$ & $<\mathrm{LD}$ & $<\mathrm{LD}$ \\
\hline \multirow{4}{*}{ Pindamonhangaba } & $23 / 01 / 2018$ & 35,2 & 35,1 & 47,6 & $<L D$ & $<L D$ & $<L D$ \\
\hline & $24 / 04 / 2018$ & 31,4 & 32,4 & 41,1 & $<\mathrm{LD}$ & $<\mathrm{LD}$ & $<\mathrm{LD}$ \\
\hline & $24 / 07 / 2018$ & 20,3 & $<\mathrm{LQ}$ & 25,3 & $<\mathrm{LD}$ & $<\mathrm{LD}$ & $<L D$ \\
\hline & $23 / 10 / 2018$ & 42,2 & $<46,3$ & 54,5 & $<L D$ & $<L D$ & $<L D$ \\
\hline \multirow{4}{*}{ Guaratinguetá } & $23 / 01 / 2018$ & 23,2 & 50,0 & 36,2 & $<\mathrm{LD}$ & $<\mathrm{LD}$ & $<\mathrm{LD}$ \\
\hline & $24 / 04 / 2018$ & 19,4 & 28,7 & 34,2 & $<L D$ & $<L D$ & $<L D$ \\
\hline & $24 / 07 / 2018$ & $<\mathrm{LQ}$ & 26,3 & 33,3 & $<\mathrm{LD}$ & $<\mathrm{LD}$ & $<\mathrm{LD}$ \\
\hline & $23 / 10 / 2018$ & 31,4 & 59,2 & 59,5 & $<\mathrm{LD}$ & $<\mathrm{LD}$ & $<\mathrm{LD}$ \\
\hline \multirow{4}{*}{ Lorena } & $23 / 01 / 2018$ & 24,5 & 68,4 & 69,1 & $<\mathrm{LD}$ & $<\mathrm{LD}$ & $<\mathrm{LD}$ \\
\hline & $24 / 04 / 2018$ & 31,7 & 34,4 & 67,2 & $<\mathrm{LD}$ & $<\mathrm{LD}$ & $<\mathrm{LD}$ \\
\hline & $24 / 07 / 2018$ & $<L Q$ & 31,2 & 38,3 & $<L D$ & $<L D$ & $<L D$ \\
\hline & $23 / 10 / 2018$ & 38,3 & 72,3 & 75,8 & $<\mathrm{LD}$ & $<\mathrm{LD}$ & $<\mathrm{LD}$ \\
\hline \multirow{4}{*}{ Lavrinhas } & $25 / 01 / 2018$ & $<L Q$ & 11,3 & $<L D$ & $<L D$ & $<L D$ & $<L D$ \\
\hline & $26 / 04 / 2018$ & $<L Q$ & $<L Q$ & $<\mathrm{LD}$ & $<\mathrm{LD}$ & $<L D$ & $<L D$ \\
\hline & $26 / 07 / 2018$ & $<\mathrm{LQ}$ & $<\mathrm{LQ}$ & $<\mathrm{LD}$ & $<\mathrm{LD}$ & $<\mathrm{LD}$ & $<\mathrm{LD}$ \\
\hline & $25 / 10 / 2018$ & $<L Q$ & $<L Q$ & $<L D$ & $<L D$ & $<L D$ & $<L D$ \\
\hline \multirow{4}{*}{ Resende } & $25 / 01 / 2018$ & 16,9 & 28,5 & 16,9 & $<L D$ & $<L D$ & $<L D$ \\
\hline & $26 / 04 / 2018$ & $<L Q$ & $<L Q$ & 14,7 & $<L D$ & $<L D$ & $<L D$ \\
\hline & $24 / 07 / 2018$ & $<L Q$ & $<L Q$ & 14,0 & $<L D$ & $<L D$ & $<L D$ \\
\hline & $25 / 01 / 2018$ & $<L Q$ & $<\mathrm{LD}$ & $<\mathrm{LQ}$ & $<\mathrm{LD}$ & $<\mathrm{LD}$ & $<\mathrm{LD}$ \\
\hline \multirow{4}{*}{ Barra Mansa } & $25 / 01 / 2018$ & 18,3 & 26,1 & 14,4 & $<\mathrm{LD}$ & $<\mathrm{LD}$ & $<\mathrm{LD}$ \\
\hline & $26 / 04 / 2018$ & $<\mathrm{LQ}$ & $<L D$ & $<L Q$ & $<L D$ & $<L D$ & $<L D$ \\
\hline & $26 / 07 / 2018$ & $<\mathrm{LQ}$ & $<\mathrm{LQ}$ & 12,3 & $<\mathrm{LD}$ & $<\mathrm{LD}$ & $<\mathrm{LD}$ \\
\hline & $25 / 01 / 2018$ & 14,2 & $<L D$ & $<L Q$ & $<L D$ & $<\mathrm{LD}$ & $<L D$ \\
\hline \multirow{4}{*}{ Volta Redonda } & $25 / 01 / 2018$ & 15,8 & 28,9 & 12,2 & $<\mathrm{LD}$ & $<\mathrm{LD}$ & $<\mathrm{LD}$ \\
\hline & $26 / 04 / 2018$ & $<\mathrm{LQ}$ & $<L Q$ & $<L Q$ & $<L D$ & $<L D$ & $<L D$ \\
\hline & $26 / 07 / 2018$ & $<L Q$ & $<L Q$ & $<L Q$ & $<L D$ & $<L D$ & $<L D$ \\
\hline & $25 / 01 / 2018$ & $<\mathrm{LQ}$ & $<\mathrm{LQ}$ & $<L Q$ & $<L D$ & $<L D$ & $<L D$ \\
\hline
\end{tabular}

Fonte: Arquivo Pessoal. 


\section{CONCLUSÕES}

Para avaliar a presença dos analitos propostos em amostras de água do rio Paraíba do Sul, quatro métodos analíticos, utilizando cromatografia líquida acoplada à espectrometria de massas sequencial, para a determinação, e extração em fase sólida, como preparo de amostra, foram desenvolvidos. Os limites de detecção obtidos variaram entre 1,2 a 3,8 ng L-

${ }^{1}$, e os limites de quantificação variaram entre 3,9 a 11,2 ng L ${ }^{-1}$. Os cartuchos utilizados para o preparo de amostras foram o OASIS HLB (Waters), condicionado com metanol e água e o Strata XA (Phenomenex), também condicionado com metanol e água. As recuperações do método ficaram entre 37 e $84 \%$. Para faixas lineares de 1 a $100 \mu \mathrm{g} \mathrm{L}^{-1}, 10$ a $100 \mu \mathrm{g} \mathrm{L}^{-1}$ e 1 a $500 \mu \mathrm{g} \mathrm{L}^{-1}$ a linearidade foi superior a 0,99 para todos os analitos. Com base nos resultados obtidos, foram identificados 7 analitos dos 11 propostos

Os fármacos estudados não obedeceram a uma sazonalidade. Esperava-se valores de concentração mais elevados no inverno. O consumo de analgésicos/anti-inflamatórios tende a ser maior nesta época do ano e foi o período de 2018 que menos choveu, portanto, um efeito "concentrador" era esperado.

A cafeína mostrou-se presente em todas as 44 amostras analisadas e foi o analito entre os 11 estudados que apresentou maior valor de concentração (385 ng. $\left.\mathrm{L}^{-1}\right)$. Os valores de concentração mais alta ocorreram nos pontos com cidades mais populosas e com maior porcentagem de esgoto tratado. Sendo a cafeína um indicador de esgoto não tratado em corpos aquáticos, existe a necessidade de se apurar a eficiência dos sistemas de tratamento da região

Os defensivos agrícolas foram identificados nos pontos próximos a cultura de arroz, a mais importante da região estudada, e se aproximaram de um padrão sazonal, com concentrações maiores durante a época do plantio e na temporada de chuvas.

O 2,4-D foi aquele identificado com maior frequência (90\% das amostras) e a bentazona com apresentou a maior concentração $\left(75,8 \mathrm{ng} . \mathrm{L}^{-1}\right)$. Imidacloprida, fipronil e simazina não foram identificados.

A área onde ocorreram as maiores concentrações de defensivos agrícolas (em especial a bentazona) merece um estudo mais individualizado, incluindo estudos nos afluentes do rio Paraíba do Sul na região. 


\section{Referências}

AGÊnCIA naCiOnAl DE ÁGUAS. Bacia do Rio Paraíba do Sul. Disponível em: http://gripbsul.ana.gov.br/ABacia.html. Acesso em: 3 out. 2016.

AMÉRICO, H. J. P. et al. Fármacos em uma estação de tratamento de esgoto na região Centro-Oeste do Brasil e os riscos aos recursos hídricos. Revista Brasileira de Recursos Hidricos, v. 17, n. 2010, p. 61-67, 2012.

ARMAS, E. D. DE et al. Diagnóstico espaço-temporal da ocorrência de herbicidas nas águas superficiais e sedimentos do rio corumbataí e principais afluentes. Química Nova, v. 30, n. 5, p. 1119-1127, 2007.

AZEVEDO, D. D. A; GERCHON, E.; DOS REIS, E. O. Monitoring of pesticides and polycyclic aromatic hydrocarbons in water from Paraíba do Sul River, Brazil. Journal of the Brazilian Chemical Society, v. 15, n. 2, p. 292-299, 2004.

BELLUTA, I. et al. Avaliação temporal e espacial no córrego do cintra (Botucatu-Sp) Frente Aos Defensivos Agrícolas E Parâmetros Físico-Químicos De Qua- Lidade Da Água - Um Estudo De Caso. Revista Energia na Agricultura, v. 25, n. 014, p. 54-73, 2010.

BILA, D. M.; DEZOTTI, M. Fármacos no meio ambiente. Quimica Nova, v. 26, n. 4, p. 523-530, 2003.

BILAL, M. et al. Hazardous contaminants in the environment and their laccase-assisted degradation - A review. Journal of Environmental Management, v. 234, p. 253-264, 2019.

BOLEDA, M. R. M. R.; GALCERAN, M. T. M. T.; VENTURA, F. Validation and uncertainty estimation of a multiresidue method for pharmaceuticals in surface and treated waters by liquid chromatography-tandem mass spectrometry. Journal of Chromatography A, v. 1286, p. 146-158, 19 abr. 2013.

BORECKA, M. et al. Contamination of the southern Baltic Sea waters by the residues of selected pharmaceuticals: Method development and field studies. Marine Pollution Bulletin, v. 94, n. 1-2, p. 62-71, 2015a.

BORECKA, M. et al. Contamination of the southern Baltic Sea waters by the residues of selected pharmaceuticals: Method development and field studies. Marine Pollution 
Bulletin, v. 94, n. 1-2, p. 62-71, 15 maio 2015b.

BORTOLUZZI, E. C.; ZANELLA, R. Contaminação de águas superficiais por agrotóxicos em função do uso do solo numa microbacia hidrográfica de Agudo, RS Contamination of surface water by pesticides as a function of soil use in the Agudo watershed, RS. Revista Brasileira de Engenharia Agrícola e Ambiental, v. 10, n. 4, p. 881-887, 2006.

BRASIL. RESOLUÇÃO CONAMA No 357, DE 17 DE MARÇO DE 2005, 2005.

BRASIL. PORTARIA No- 2.914, DE 12 DE DEZEMBRO DE 2011, 2011.

CALDAS, S. S. et al. Determination of pharmaceuticals, personal care products, and pesticides in surface and treated waters : method development and survey. Environmental Science and Pollution Research, v. 20, p. 5855-5863, 2013.

CAMPANHA, M. B. et al. A 3-year study on occurrence of emerging contaminants in an urban stream of São Paulo State of Southeast Brazil. Environmental Science and Pollution Research International, p. 7936-7947, 2014.

CANELA, M. C. et al. Cafeína em águas de abastecimento público no Brasil. $1^{\circ}$ ed. São Carlos: Editora Cubo, 2014.

CASTIGLIONI, S. et al. Methodological approaches for studying pharmaceuticals in the environment by comparing predicted and measured concentrations in River Po, Italy. Regulatory Toxicology and Pharmacology, v. 39, n. 1, p. 25-32, fev. 2004.

CBH MÉDIO PARAÍBA DO SUL. Publicação Institucional do Comitê de Bacia da Região Hidrográfica do Médio Paraíba do Sul, 2013.

CETESB. Guia Nacional de Coleta e Preservação de Amostras - Água, Sedimento, Comunidades Aquáticas e Efluentes Líquidos. [s.l: s.n.].

CORTEZ, F. S. et al. Ecotoxicological effects of losartan on the brown mussel Perna perna and its occurrence in seawater from Santos Bay (Brazil). Science of The Total Environment, v. 637-638, p. 1363-1371, 1 out. 2018.

DAFOUZ, R. et al. Does the presence of caffeine in the marine environment represent an environmental risk? A regional and global study. Science of The Total Environment, v. 615, p. 632-642, 15 fev. 2018.

DEEPASK. Deepask. Disponível em: <www.deepask.com>. Acesso em: 6 jun. 2018. 
DELLAMATRICE, P. M.; MONTEIRO, R. T. R. Principais aspectos da poluição de rios brasileiros por pesticidas Main aspects of the pollution in Brazilian rivers by pesticides. Revista Brasileira de Engenharia Agrícola e Ambiental, v. 18, n. 12, p. 1296-1301, 2014. DORES, E. F. G. D. C.; DE-LAMONICA-FREIRE, E. M. Contaminação do ambiente aquático por pesticidas. estudo de caso: águas usadas para consumo humano em primavera Do Leste, Mato Grosso - Análise Preliminar. Quimica Nova, v. 24, n. 1, p. 27-36, 2001.

FARRÉ, M. LA et al. Fate and toxicity of emerging pollutants, their metabolites and transformation products in the aquatic environment. TrAC Trends in Analytical Chemistry, v. 27, n. 11, p. 991-1007, 2008.

FEHIDRO. FEHIDRO. Disponível em: <http://www.sigrh.sp.gov.br/cbhps/apresentacao>. Acesso em: 16 nov. 2018.

GAFFNEY, V. DE J. et al. Occurrence of pharmaceuticals in a water supply system and related human health risk assessment. Water Research, v. 72, p. 199-208, 2014.

GONZALEZ-REY, M. et al. Occurrence of pharmaceutical compounds and pesticides in aquatic systems. Marine Pollution Bulletin, v. 96, n. 1-2, p. 384-400, 15 jul. 2015.

GRACIA-LOR, E.; SANCHO, J. V; HERNÁNDEZ, F. Multi-class determination of around 50 pharmaceuticals, including 26 antibiotics, in environmental and wastewater samples by ultra-high performance liquid chromatography-tandem mass spectrometry. Journal of Chromatography. A, v. 1218, n. 16, p. 2264-75, 22 abr. 2011.

GRUNG, M. et al. Pesticide levels and environmental risk in aquatic environments in China — A review. Environment International, v. 81, p. 87-97, 2015.

HERNÁNDEZ, F. et al. Antibiotic residue determination in environmental waters by LCMS. TrAC Trends in Analytical Chemistry, v. 26, n. 6, p. 466-485, jun. 2007.

HILLEBRAND, O. et al. Caffeine as an indicator for the quantification of untreated wastewater in karst systems. Water Research, v. 46, n. 2, p. 395-402, 1 fev. 2012.

IBAMA. Relatórios de Comercialização de Agrotóxicos - Áreas Temáticas QA IBAMA - Instituto Brasileiro do Meio Ambiente e dos Recursos Naturais Renovaveis. Disponível em: http://www.ibama.gov.br/areas-tematicas-qa/relatorios-de-comercializacaode-agrotoxicos/tudo. Acesso em: 23 set. 2016. 
IBGE. IBGE - Cidades - Rio de Janeiro. Disponível em: http://cidades.ibge.gov.br/xtras/uf.php?lang=\&coduf=33\&search=rio-de-janeiro. Acesso em: 20 set. 2016.

INMET. INMET. Disponível em: http://www.inmet.gov.b. Acesso em: 22 dez. 2018.

IPEA. Ipeadata. Disponível em: http://www.ipeadata.gov.br. Acesso em: 09 jun. 2017

JACOMINI, A. E. et al. Assessment of Ametryn Contamination in River Water, River Sediment, and Mollusk Bivalves in São Paulo State, Brazil. Archives of Environmental Contamination and Toxicology, v. 60, n. 3, p. 452-461, 2011.

K'OREJE, K. O. et al. Occurrence patterns of pharmaceutical residues in wastewater, surface water and groundwater of Nairobi and Kisumu city, Kenya. Chemosphere, v. 149, p. 238-244, abr. 2016.

KUIVILA, K., HLADIK, M. Understanding the occurrence and transport of current-use pesticides in the San Francisco Estuary Watershed. Berkeley Planning Journal, v. 26, n. 1, p. 217-220, 2013.

KÜMMERER, K. Erratum to "Drugs in the environment: emission of drugs, diagnostic aids and disinfectants into wastewater by hospitals in relation to other sources-a review" [Chemosphere 45 (2001) 957-969]. Chemosphere, v. 48, n. 3, p. 383, jul. 2002.

LESSER, L. E. et al. Survey of 218 organic contaminants in groundwater derived from the world's largest untreated wastewater irrigation system: Mezquital Valley, Mexico. Chemosphere, v. 198, p. 510-521, 1 maio 2018.

LOPES, V. S. A. et al. Development of a solid-phase extraction system modified for preconcentration of emerging contaminants in large sample volumes from rivers of the lagoon system in the city of Rio de Janeiro, Brazil. Marine Pollution Bulletin, v. 110, n. 1, p. $572-577,15$ set. 2016 .

LOURENÇATO, L. F. Potencial de contaminação de águas superficiais por agrotóxicos na microbacia hidrográfica do campestre. 2011. 51f. Dissertação (Mestrado em Ciências Ambientais) - Faculdadde de Tecnologia - Universidade Federal do Paraná, Colombo, 2011. LUMBAQUE, E. C. et al. Degradation of pharmaceuticals in different water matrices by a solar homo / heterogeneous photo-Fenton process over modified alginate spheres. Environmental Science and Pollution Research, v.40, p.1-13, 2019. 
MAPA. Agrofit - MAPA. Disponível em: http://www.agricultura.gov.br/servicos-esistemas/sistemas/agrofit. Acesso em: 20 set. 2016.

MARCHESAN, E. et al. Rice herbicide monitoring in two Brazilian rivers during the rice growing season. Scientia Agricola, v. 64, n. 2, p. 131-137, 2007.

MARCHESAN, E. et al. Resíduos de agrotóxicos na água de rios da Depressão Central do Estado do Rio Grande do Sul, Brasil. Ciência Rural, v. 40, n. 5, p. 1053-1059, 2010.

MIKLOS, D. B. et al. Comparison of UV-AOPs (UV/H2O2, UV/PDS and UV/Chlorine) for TOrC removal from municipal wastewater effluent and optical surrogate model evaluation. Chemical Engineering Journal, v. 362, p. 537-547, 15 abr. 2019.

MIRANDA, K. et al. Pesticide residues in river sediments from the Pantanal Wetland, Brazil. Journal of Environmental Science and Health, Part B, v. 43, n. 8, p. 717-722, 2008.

MOKH, S. et al. Innovative SPE-LC-MS/MS technique for the assessment of 63 pharmaceuticals and the detection of antibiotic-resistant-bacteria: A case study natural water sources in Lebanon. Science of The Total Environment, v. 609, p. 830-841, 2017.

MONTAGNER, C. C. et al. Trace analysis of pesticides and an assessment of their occurrence in surface and drinking waters from the State of São Paulo (Brazil). Analytical Methods, v. 6, n. 17, 2014a.

MONTAGNER, C. C. et al. Occurrence and potential risk of triclosan in freshwaters of São Paulo, Brazil-the need for regulatory actions. Environmental Science and Pollution Research, v. 21, n. 3, p. 1850-1858, 2014b.

MOREIRA, J. C. et al. Contaminação de águas superficiais e de chuva por agrotóxicos em uma região do estado do Mato Grosso. Ciência \& Saúde Coletiva, v. 17, n. 6, p. 1557$1568,2012$.

PAPADAKIS, E.-N. et al. Pesticides in the surface waters of Lake Vistonis Basin, Greece: Occurrence and environmental risk assessment. Science of The Total Environment, v. 536, p. 793-802, 2015.

PETROVIĆ, M. et al. Determination of 81 pharmaceutical drugs by high performance liquid chromatography coupled to mass spectrometry with hybrid triple quadrupole-linear ion trap in different types of water in Serbia. Science of The Total Environment, v. 468-469, p. 
415-428, 2014.

PRIMEL, E. E. G. et al. Central do estado do Rio Grande do Sul, Brasil: predição teórica e monitoramento. Quim. Nova, v. 28, n. 4, p. 605-609, 2005.

REICHERT, J. F.; SOUZA, D. M.; MARTINS, A. F. Antipsychotic drugs in hospital wastewater and a preliminary risk assessment. Ecotoxicology and Environmental Safety, v. 170, p. $559-567,15$ abr. 2019.

RISSATO, S. R. et al. Determinação de pesticidas organoclorados em água de manancial, água potável e solo na região de Bauru (SP). Quimica Nova, v. 27, n. 5, p. 739-743, 2004.

RODRIGUES, K. L. T. et al. Chemometric approach to optimize the operational parameters of ESI for the determination of contaminants of emerging concern in aqueous matrices by LC-IT-TOF-HRMS. Microchemical Journal, v. 117, p. 242-249, 1 nov. 2014.

SANTOS, M. L. V.; SANTOS, E. DO N. DOS; FILHO, J. T. DE S. O Rio Paraíba do Sul e o abastecimento no Estado do Rio de Janeiro. Semioses, v. 9, n. 1, p. 36-42, 2015.

SAUVÉ, S.; DESROSIERS, M. A review of what is an emerging contaminant. Chemistry Central Journal, v. 8, n. 15, p. 1-7, 2014.

SILVA, E.; DAAM, M. A.; CEREJEIRA, M. J. Predicting the aquatic risk of realistic pesticide mixtures to species assemblages in Portuguese river basins. Journal of Environmental Sciences, v. 31, p. 12-20, 2015.

SODRÉ;, F. F.; ANTONIO, L. M.; FIGUEIREDO, J. Sistema limpo em linha para extração em fase sólida de contaminantes emergentes em águas naturais. Quim. Nova, v. 33, n. 1, p. 216-219, 2010.

SOUZA, V. G. DE; BULHÕES, E. M. R. Protocolo de avaliação rápida no baixo leito do rio paraíba do sul, no município de Campos dos Goytacazes / RJ. Caderno de Estudos Geoambientais, v. 6, n. 1, p. 32-50, 2015.

STARLING, M. C. V. M.; AMORIM, C. C.; LEÃO, M. M. D. Occurrence, control and fate of contaminants of emerging concern in environmental compartments in Brazil. Journal of Hazardous Materials, 22 abr. 2018.

STUMPF, M. et al. Polar drug residues in sewage and natural waters in the state of Rio de Janeiro, Brazil. Science of The Total Environment, v. 225, n. 1-2, p. 135-141, jan. 1999. 
TERNES, T. . et al. Behavior and occurrence of estrogens in municipal sewage treatment plants - I. Investigations in Germany, Canada and Brazil. Science of The Total Environment, v. 225, n. 1-2, p. 81-90, jan. 1999.

TERNES, T. A. Occurrence of drugs in German sewage treatment plants and rivers1Dedicated to Professor Dr. Klaus Haberer on the occasion of his 70th birthday.1. Water Research, v. 32, n. 11, p. 3245-3260, nov. 1998.

TERNES, T. A. Analytical methods for the determination of pharmaceuticals in aqueous environmental samples. TrAC Trends in Analytical Chemistry, v. 20, n. 8, p. 419-434, ago. 2001.

THOMAS, K. V. et al. Screening for selected human pharmaceuticals and cocaine in the urban streams of Manaus, Amazonas, Brazil. Journal of the American Water Resources Association, v. 50, n. 2, p. 302-308, 2014.

TLILI, I. et al. Simultaneous detection of antibiotics and other drug residues in the dissolved and particulate phases of water by an off-line SPE combined with on-line SPE-LC-MS/MS: Method development and application. Science of The Total Environment, v. 563-564, p. 424-433, set. 2016.

TRUFELLI, H. et al. AN OVERVIEW OF MATRIX EFFECTS IN LIQUID CHROMATOGRAPHY-MASS SPECTROMETRY. Mass Spectrometry Reviews, v. 30, p. 491-509, 2010.

TUNDISI, J. G. Novas Perspectivas para a Gestao de Recursos Hídricos. Revista USP, v. 70, p. 24-35, 2006.

VALENZUELA, E. F.; MENEZES, H. C.; CARDEAL, Z. L. New passive sampling device for effective monitoring of pesticides in water. Analytica Chimica Acta, 2018.

VANDERFORD, B. J. et al. Analysis of endocrine disruptors, pharmaceuticals, and personal care products in water using liquid chromatography/tandem mass spectrometry. Analytical Chemistry, v. 75, n. 22, p. 6265-6274, 2003.

VEIGA, M. M. et al. Análise da contaminação dos sistemas hídricos por agrotóxicos numa pequena comunidade rural do Sudeste do Brasil. Cadernos de Saúde Pública, v. 22, n. 11, p. 2391-2399, 2006.

YANG, Y.-Y. et al. Suitability of pharmaceuticals and personal care products (PPCPs) and 
artificial sweeteners (ASs) as wastewater indicators in the Pearl River Delta, South China. Science of The Total Environment, v. 590-591, p. 611-619, 15 jul. 2017. ZENOBIO, J. E. et al. Presence and effects of pharmaceutical and personal care products on the Baca National Wildlife Refuge, Colorado. Chemosphere, v. 120, p. 750-755, 1 fev. 2015 . 